UNIVERSIDADE DE SÃO PAULO

FACULDADE DE MEDICINA DE RIBEIRÃO PRETO

GUILHERME CONSTANTE PREIS SELLA

\begin{abstract}
A importância da atopia, asma, doença
respiratória exacerbada à aspirina e eosinofilia para a recorrência da rinossinusite crônica
\end{abstract}




\title{
A importância da atopia, asma, doença respiratória exacerbada à aspirina e eosinofilia para a recorrência da rinossinusite crônica
}

\author{
Versão Corrigida \\ Versão original encontra-se na unidade que aloja o Programa de Pós- \\ Graduação \\ Tese apresentada à Faculdade de Medicina de \\ Ribeirão Preto da Universidade de São Paulo \\ para obtenção do Título de Doutor em Ciências. \\ Área de Concentração: Morfofisiologia de \\ Estruturas Faciais. \\ Orientadora: Profa. Dra. Fabiana \\ Cardoso Pereira Valera
}


AUTORIZO A REPRODUÇÃO E DIVULGAÇÃO TOTAL OU PARCIAL DESTE TRABALHO, POR QUALQUER MEIO CONVENCIONAL OU ELETRÔNICO, PARA FINS DE ESTUDO E PESQUISA, DESDE QUE CITADA A FONTE.

FICHA CATALOGRÁFICA

Sella, Guilherme Constante Preis

A importância da atopia, asma, doença respiratória exacerbada à aspirina e eosinofilia para a recorrência da rinossinusite crônica. / Guilherme Constante Preis Sella; Orientadora, Fabiana Cardoso Pereira Valera. Ribeirão Preto. - 2019.

119p.: 22il.; $30 \mathrm{~cm}$

Tese (Doutorado) - Programa de Oftalmologia, Otorrinolaringologia e Cirurgia de Cabeça e Pescoço. Área de Concentração: Morfofisiologia de Estruturas Faciais. Faculdade de Medicina de Ribeirão Preto da Universidade de São Paulo, Ribeirão Preto, 2019.

1. Rinossinusite crônica. 2. Polipose Nasossinusal. 3. Asma. 4. Atopia. 5. Intolerância ao AAS. 6. Doença respiratória exacerbada pela aspirina. 7. Eosinofilia. 8. Recorrência cirúrgica. 9. Cirurgia endoscópica nasal. 10. Sinusectomia. 
Aluno: Sella, Guilherme Constante Preis

Título: A importância da atopia, asma, doença respiratória exacerbada à aspirina e eosinofilia para a recorrência da rinossinusite crônica.

Tese apresentada à Faculdade de Medicina de Ribeirão Preto da Universidade de São Paulo para obtenção do Título de Doutor em Ciências.

Área de Concentração: Morfofisiologia de Estruturas Faciais.

Aprovado em:

Prof. Dr.

Instituição:

Assinatura:

Prof. Dr.

Instituição:

Assinatura:

Prof. Dr.

Instituição:

Assinatura:

Prof. Dr.

Instituição:

Assinatura:

Prof. Dr.

Instituição:

Assinatura: 


\section{Dedícatóría}

Aos meus pais, Valentim e Jane, que tanto amo. Por serem eternos exemplos de bondade, humildade e sabedoría. Por dedicarem suas vidas quase que exclusivamente para minha formação profíssional e humana, me dando muito apoio, e, principalmente, carinho e companheirismo para os momentos de dificuldade.

À minha irmã Juliana, pelo amor e carinho incondicional que me acompanha por toda minha vida. Além disso, foi parte fundamental do meu projeto, me ajudando em muitos pontos; sem ela esta tese não tería acontecido.

ม̀ minha amiga e namorada Núbia, pela aceitação e pelo incentivo. Faz da minha vida uma jornada mais leve e feliz. Me dá paz e carinho. Me faz querer vencer e ser uma pessoa methor. 


\section{Agradecimentos}

$\mathcal{A}$ Deus agradeço por esta oportunidade concedida e pelas condições físicas e intelectuais que me permitiram realizar este projeto.

À minha querida orientadora, profa. Dra. Fabiana Cardoso Pereira Valera. Por todo seu conhecimento e pela paciência para me ensinar e dar apoio. Por ter acreditado em mim, e por todo suporte que me deu durante este periodo para realização deste meu sonho.

Ao Departamento de Oftalmología, Otorrinolaringologia e Cirurgía de Cabeça e Pescoço da Faculdade de Medicina de Ribeirão Preto da Universidade de São Paulo, agradeço pela oportunidade de realização do Doutorado.

À Profa. Dra. Wíma T. Anselmo-Lima, por sua notável capacidade de liderança e raciocínio, além de todo apoio demandado.

Ao Prof. Dr. Edwin Tamashiro, por sua amizade e ajuda na concepção deste projeto.

Às médicas alergologistas Thais Nociti e (minha irmã) Juliana Sella, que tanto me ajudaram.

À María Rossato, por ajudar tanto nesta obra, sempre sorrindo e otimista. 
Aos médicos assistentes da Otorrinolaringologia, que tanto me ensinaram durante o periodo da residêncía médíca.

Aos queridos funcionários do Departamento de Oftalmologia, Otorrinolaringología e Círurgía de Cabeça e Pescoço da Faculdade de Medicina de Ríbeirão Preto da Universidade de São Paulo, em especial a María Cecília Onofre, por toda compreensão e ajuda para resolver os problemas durante a pós-graduac,ão.

Aos funcionários do Ambulatório de Otorrinolaringología, pela presteza e pelo indispensável apoío no exercício da profíssão. 
Sella GCP. A importância da atopia, asma, doença respiratória exacerbada à aspirina e eosinofilia para a recorrência da rinossinusite crônica. Tese (Doutorado) - Faculdade de Medicina de Ribeirão Preto, Universidade de São Paulo. Ribeirão Preto. 2019.

Introdução: $O$ estudo dos fatores clínicos associados ao prognóstico da rinossinusite crônica (rSc), seja associada à polipose nasossinusal (RSCcPN) ou não (RSCsPN), ainda é pouco abordado a longo prazo. Objetivo: Avaliar pacientes submetidos à ESS (cirurgia endoscópica nasal, do inglês endoscopic sinus surgery) para o tratamento de RSC no Hospital das Clínicas da Faculdade de Medicina de Ribeirão Preto da Universidade de São Paulo, entre 1996 e 2006, e correlacionar a recidiva em longo prazo com parâmetros como a extensão da doença, atopia, tabagismo, asma, eosinofilia e doença respiratória exacerbada pela aspirina (DREA). Métodos: Duzentos e um pacientes foram seguidos por um período médio de 12 anos. Os dados clínicos foram levantados, assim como exames de endoscopia nasal, Tomografia Computadorizada (TC), exames séricos, prick test e prova de função pulmonar. O tempo de seguimento pós-operatório foi analisado, sendo considerado fator de mau prognóstico a indicação de novo procedimento cirúrgico. Foi realizada comparação entre os fatores pela curva de Kaplan-Meyer, e pós-teste de Log-rank. Resultados e Discussão: Pacientes com RSCcPN tiveram chance de nova cirurgia três vezes maior do que aqueles sem pólipos nasais, no período seguido. Entre os pacientes com RSCsPN, apenas a asma foi um fator de pior prognóstico significativo, levando à chance de cirurgia 5,5 vezes maior do que os não-asmáticos. Já entre os pacientes com RSCcPN, aqueles com recidiva apresentaram maior extensão da doença à TC antes da primeira cirurgia. Foram ainda considerados fatores significativamente de pior prognóstico nos pacientes com RSCcPN: asma (odds ratio [OR] de 3,2); atopia a fungos (OR de 1,9); eosinofilia periférica (considerada como $>500 / \mu \mathrm{L}$, levando a $O R$ de 1,9); e intolerância ao Ácido Acetil Salicílico (AAS) (DREA, apresentando OR de 2,5). Conclusões: Concluiu-se que a presença de pólipos per se é fator de pior prognóstico, aumentando em três vezes a chance de recorrência cirúrgica. Entre os pacientes com RSCsPN, apenas a asma influenciou o prognóstico. Já naqueles com RSCcPN, a asma, eosinofilia periférica, atopia a fungos e DREA aumentaram significativamente a probabilidade de nova intervenção cirúrgica.

Palavras-chave: Rinossinusite crônica. Polipose nasossinusal. Asma. Atopia. Intolerância ao AAS. Doença respiratória exacerbada pela aspirina. Eosinofilia. Recorrência cirúrgica. Cirurgia endoscópica nasal. Sinusectomia. 
Abstract 
Sella GCCP. The importance of atopy, asthma, aspirin-exacerbated respiratory disease and eosinofilia to chronic rhinosinusitis recurrence. Tese (Doutorado) Faculdade de Medicina de Ribeirão Preto, Universidade de São Paulo. Ribeirão Preto. 2019.

Introduction: The analysis of prognostic factors associated with the recurrence of chronic rhinosinusitis (CRS), either with nasal polyps (CRSwNP) or without (CRSsNP), is still poorly discussed in the literature. Objective: To evaluate the patients that underwent endoscopic sinus surgery (ESS) due to CRS in Clinics Hospital of Ribeirão Preto Medical School, University of São Paulo, between 1996 and 2006, and to correlate the long-term recurrence to clinical factors, such as extensiveness of the disease, atopy, smoking habits, eosinophilia, and Aspirinexacerbated respiratory disease (AERD). Methods: We collected data of 201 patients, who were followed during an average period of 12 years. Clinical data collected were: extensiveness of the disease at endoscopy and at CT scans, prick test, blood exams, and pulmonary function. The follow-up period after surgery was assessed, and the indication of a new surgical procedure was considered as a poor prognostic factor. Comparison between factors was performed by Kaplan-Meyer curve, with Log-rank post-test. Results and discussion: CRSwNP patients were 3 times more likely to need a revisional surgery than CRSsNP during the follow-up period. Only asthma was a significant prognostic factor in patients with CRSsNP, leading to 5.5 times higher chance of recurrence than non-asthmatic patients. Among patients with CRSwNP, patients with recurrence presented, prior to surgery, higher CT scan extension of the disease. Other factors that influenced the prognosis on CRSwNP were: asthma (odds ratio [OR]: 3.2); atopy for fungi (OR: 1.9); peripheral eosinophilia (considered as $>500 / \mu \mathrm{L}$, leading to an OR: 1.9); and ASA intolerance (AERD; OR: 2.5). Conclusions: The presence of polyps were related to poor prognosis per se, leading to a higher chance of surgical recurrence. Among patients with CRSsNP, only asthma influenced the prognosis. Among the patients with CRSwNP, asthma, peripheral eosinophilia, fungi atopy, and AERD significantly increased the likelihood of further surgical intervention.

Key words: Chronic rhinosinusitis. Nasal polyps. Asthma. Atopy. ASA intolerance. Aspirin-exacerbated respiratory disease. Eosinophilia. Surgical recurrence. Endoscopic sinus surgery. 
Lista de Figuras 
Figura 1 - Fluxograma dos critérios de inclusão e exclusão adotados na presente pesquisa

Figura 2 - $\quad$ Prick test realizado em paciente da pesquisa no HCFMRP-USP, demonstrando positividade para $D$ pterynyssimus, $D$ farinae e pêlo de gato, com pápulas representativas, maiores do que as observadas no controle positivo

Figura 3 - Dados coletados e divisão dos pacientes em grupos.

Figura 4 - Protocolo de seguimento no Ambulatório de Rinossinusologia do HCFMRP-USP, e critérios para avaliação, considerando-se o evento negativo

Figura 5 - Distribuição dos pacientes em cada grupo, de acordo com 0 número de cirurgias realizado, para cada um dos grupos RSC

Figura 6 - Diferença no número de cirurgias entre os grupos RSCsPN, RSCcPNsA e RSCcPNcA. Comparação entre os grupos pelo teste não paramétrico de Kruskal-Wallis ....

Figura 7 - Diferença de tempo (em anos) entre as cirurgias, entre os diferentes grupos

Figura 8 - Recidiva cirúrgica entre os RSCsPN x RSCcPN. Análise por meio da curva de Kaplan Meyer, com pós-teste de Log-rank.

Figura 9 - Diferença entre pacientes RSCsPN com e sem recidiva, de acordo com o número de seios acometidos à TC. Comparação entre os grupos pelo teste não paramétrico de Kruskal-Wallis.

Figura 10 - Diferença da extensão dos pólipos nos pacientes sem e com recidiva cirúrgica, por meio de endoscopia ou tomografia computadorizada .....

Figura 11 - Distribuição das porcentagens de positividade a um alérgeno ou múltiplos alérgenos, de acordo com o grupo

Figura 12 - Percentagem de positividade de alérgenos, em cada grupo 73

Figura 13 - Pacientes com RSCsPN: diferença da recidiva cirúrgica entre alérgicos e não alérgicos a: (A) inalantes; $(B)$ fungos, por meio da curva de Kaplan-Meyer com pós-teste de Log-rank.

Figura 14 - Pacientes com RSCcPN: diferença da recidiva cirúrgica entre alérgicos e não alérgicos a: (A) inalantes; (B) fungos, por meio da curva de Kaplan-Meyer com pós-teste de Log-rank. 
Figura 15 - Pacientes com RSCsPN: diferença da recidiva cirúrgica entre tabagistas e não tabagistas, por meio da curva de Kaplan-Meyer com pós-teste de Log-rank

Figura 16 - Pacientes com RSCcPN: diferença da recidiva cirúrgica entre tabagistas e não tabagistas, por meio da curva de Kaplan-Meyer com pós-teste de Log-rank.

Figura 17 - Pacientes com RSCsPN: diferença da recidiva cirúrgica entre aqueles sem e com asma por meio da curva de Kaplan-Meyer com pós-teste de Log-rank

Figura 18 - Pacientes com RSCcPN: diferença da recidiva cirúrgica entre os sem e com asma. Comparação entre os grupos por meio da curva de Kaplan-Meyer com pós-teste de Log-rank

Figura 19 - Diferença do nível de eosinofilia sérica entre os fatores de risco: (A) tabagismo; (B) atopia a todos os inalantes; (C) atopia a fungos; (D) presença de PN; (E) asma

Figura 20 - Pacientes com RSCsPN: diferença da recidiva cirúrgica entre os sem e com eosinofilia sérica por meio da curva de Kaplan-Meyer com pós-teste de Log-rank

Figura 21 - Pacientes com RSCcPN: diferença da recidiva cirúrgica entre aqueles sem e com eosinofilia por meio da curva de KaplanMeyer com pós-teste de Log-rank

Figura 22 - Pacientes com RSCcPN: diferença da recidiva cirúrgica entre os sem e com DREA, por meio da curva de Kaplan-Meyer com pós-teste de Log-rank. 
Tabela 1 - Comparação das modalidades para confirmação objetiva da inflamação nasossinusal................................................................... 43

Tabela 2 - Dados demográficos dos pacientes analisados no presente estudo ......65

Tabela 3 - Diferença dos dados demográficos entre pacientes asmáticos com RSCsPN e RSCcPN 
Lista de Siglas e Abreviaturas 
AAS- $\quad$ Ácido Acetil Salicílico

AINE- $\quad$ Anti-inflamatórios não-esteroidais

BF- $\quad$ Bola fúngica

CDC- $\quad$ Centers for Disease Control and Prevention

CFTR- Cystic Fribrosis Transmembrane Conductance Regulator

CJA- Complexo juncional apical

COM- Complexo osteo-meatal

coX-1- Ciclooxigenase-1

CVF- $\quad$ Capacidade vital forçada

DCP- Discinesia ciliar primária

DPOC- Doença pulmonar obstrutiva crônica

DREA- Doença respiratória exacerbada pela aspirina

ECM- Matriz extracelular

ECP- Proteína catiônica eosinofílica

ECs- Células epiteliais

ESS- $\quad$ Cirurgia endoscópica nasosinusal (do inglês Endoscopic Sinus Surgery)

EUA- $\quad$ Estados Unidos da América

FC- $\quad$ Fibrose cística

FEV1- Volume expiratório forçado

GA2LEN- Global Allergy and Asthma Network of Excellence (

H. influenzae- Haemophilus influenzae

HCFMRP-USP- Hospital das Clínicas da Faculdade de Medicina de Ribeirão Preto da Universidade de São Paulo

IC- Intervalo de confiança 
IFN-Y- Interferon gama

IL-5- Interleucina 5

IVAS- Infecções das vias aéreas superiores

LT- Leucotrienos

LTs- Leucotrienos pró-inflamatórios

OR- Odds ratio

P. aeruginosa- Pseudomonas aeruginosa

PFP. Prova de função pulmonar

PGs- Antiprostaglandinas inflamatórias

PN- $\quad$ Polipose nasossinusal

QV- $\quad$ Qualidade de Vida

RNS- Espécies de nitrogênio reativo

ROS- Espécies reativas de oxigênio

RSA- $\quad$ Rinossinusite aguda

RSC- Rinossinusite crônica

RSCCPN- Rinossinusite crônica com polipose nasal

RSCCPNcA- Rinossinusite crônica com polipose nasossinusal com asma

RSCcPNsA- Rinossinusite cronica com polipose nasossinusal sem asma

RSCsPN- Rinossinusite crônica sem polipose nasal

RSCsPNcA- Rinossinusite crônica sem polipose nasossinusal com asma

RSCsPNsA- Rinossinusite crônica sem polipose nasossinusal sem asma

RSF- Rinossinusite fúngica

RSFA- Rinossinusite fúngica alérgica

RSME- $\quad$ Rinossinusite mucínica eosinofílica 
RSTF- Rhinosinusitis Task Force

S. aureus- Staphylococcus aureus

TC- Tomografia Computadorizada

TCLE- $\quad$ Termo de Consentimento Livre e Esclarecido

Th1- $\quad$ Thelper 1

Th2- $\quad$ Thelper 2

TMA- Terapia médica apropriada

TNF- $\alpha-\quad$ Fator de necrose tumoral alfa

TPO- Teste de provocação oral

Treg- $\quad$ T reguladoras

VAS- Vias aéreas superiores 


\section{SUMÁRIO}

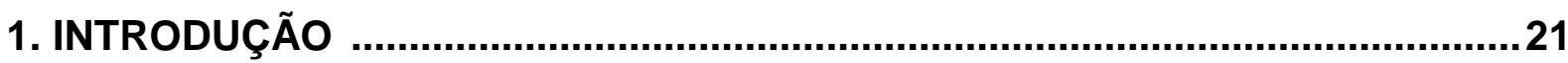

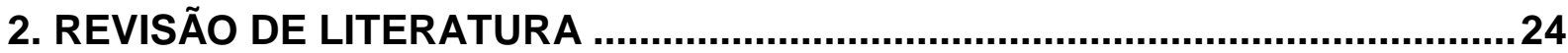

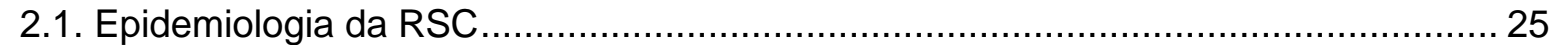

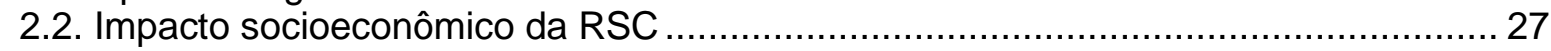

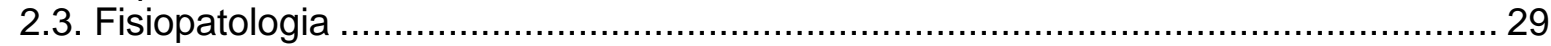

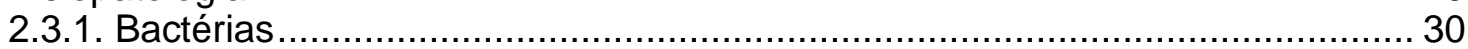

2.3.2. Fungos

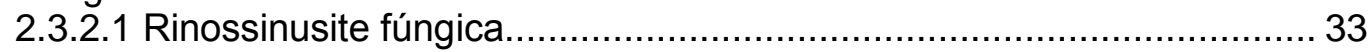

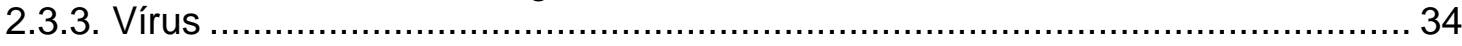

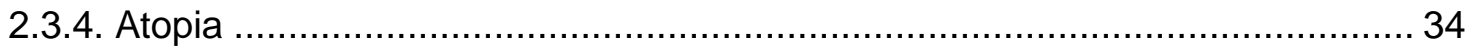

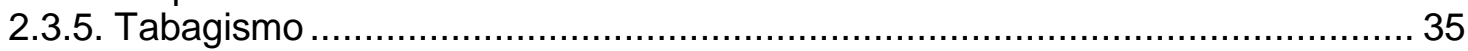

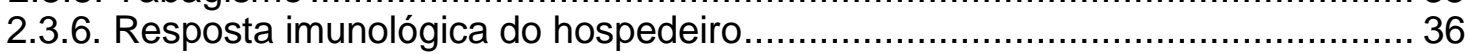

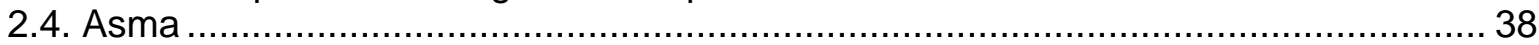

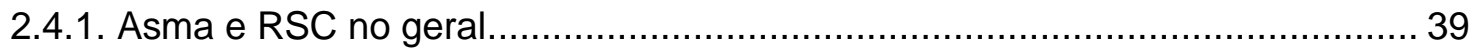

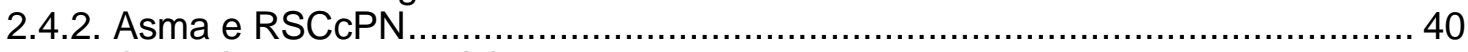

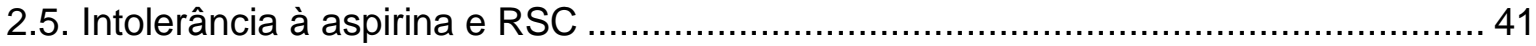

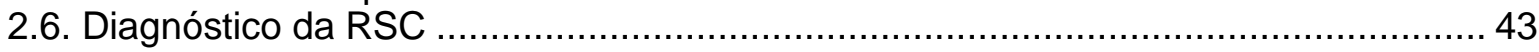

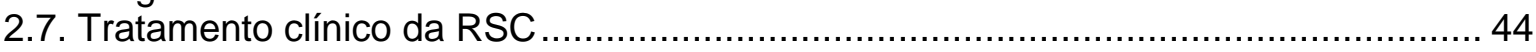

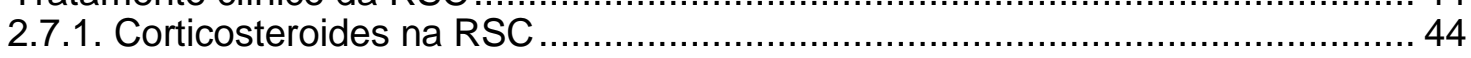

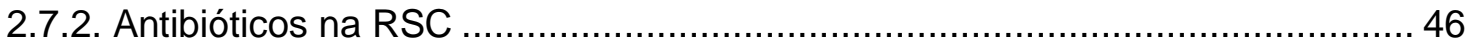

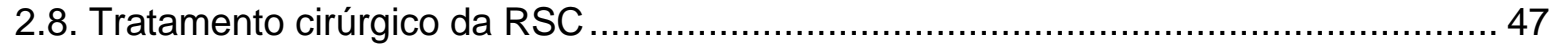

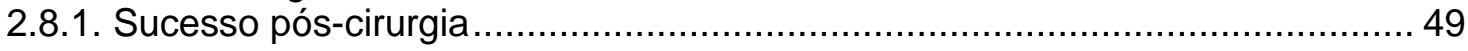

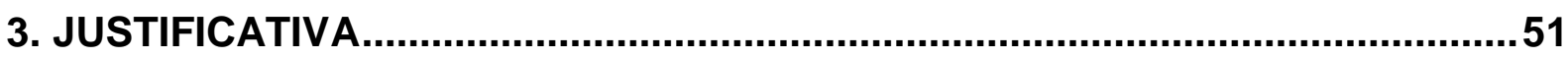

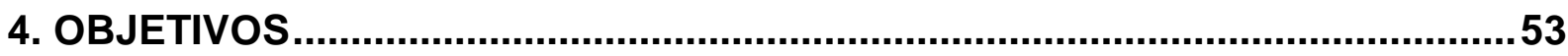

5. CASUÍSTICA E MÉTODOS .............................................................................. 55

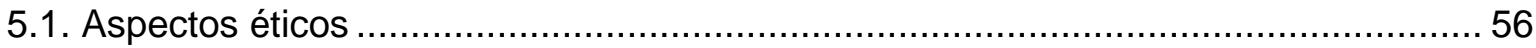

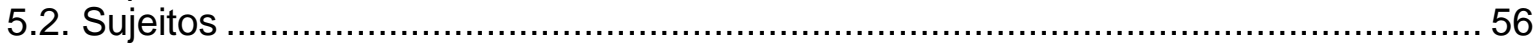

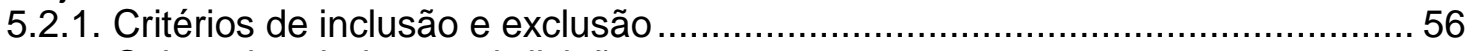

5.2.2. Coleta dos dados e subdivisão em grupos ................................................ 58

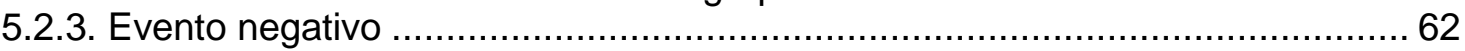

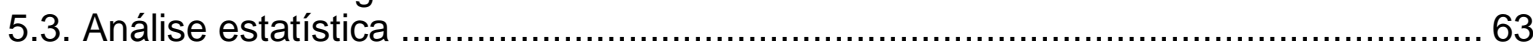

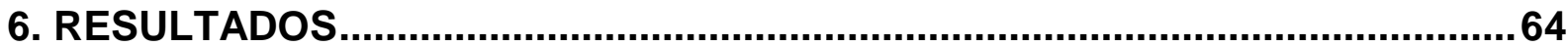

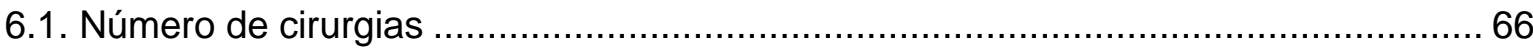

6.2. Extensão tomográfica e endoscópica da doença .................................................... 69

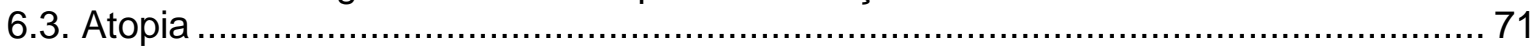

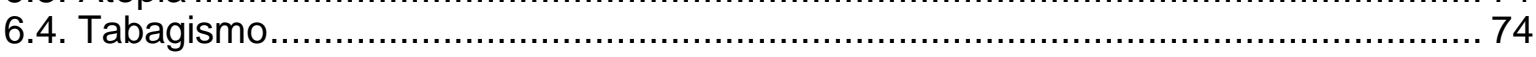

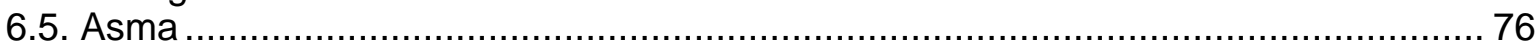

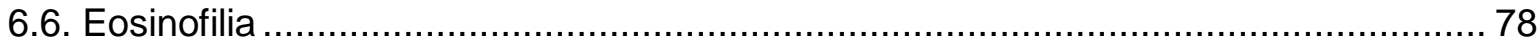

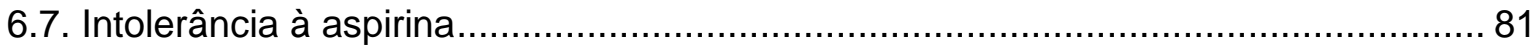

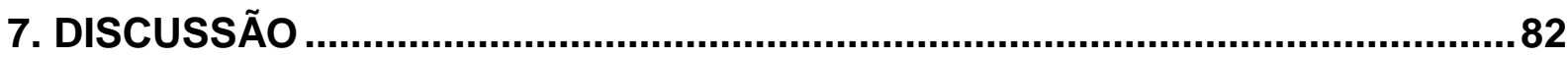

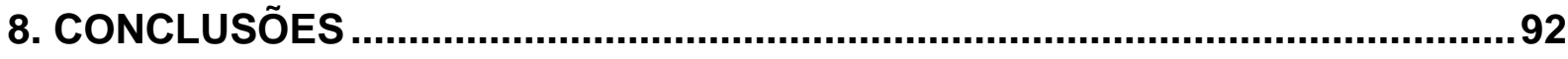

9. REFERÊNCIAS BIBLIOGRÁFICAS ..............................................................94

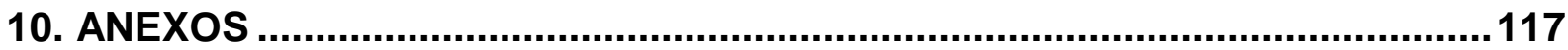


1- Introdução 
A rinossinusite crônica (RSC) é definida como inflamação sintomática dos seios paranasais e da cavidade nasal por mais que 12 semanas (Fokkens; Lund; Mullol, 2012; Anselmo-Lima et al., 2015; Orlandi et al., 2016). Esta definição é consensual e tem sido relativamente consistente nos últimos 25 anos.

A RSC constitui uma das condições mais comuns encontradas na medicina, com prevalência populacional variando entre $5 \%$ e $12 \%$, a depender do estudo e da amostragem populacional (Bachert; Zhang; Gevaert, 2015). E pode se apresentar a uma ampla gama de médicos, e num conjunto diverso de cenários, desde nos centros primários à saúde quanto nas urgências e emergências, quando ocorrem complicações graves (Bousquet et al., 2009).

É um problema de saúde pública que resulta em grande encargo financeiro para a sociedade (Fokkens et al., 2007). Acarreta alto custo direto, que engloba consultas médicas, exames complementares e radiológicos, internações hospitalares, cirurgias e tratamento medicamentoso. Mais da metade dos antibióticos prescritos nos Estados Unidos da América (EUA) são para Infecções de Vias Aéreas Superiores (IVAS), sendo que a principal delas é a rinossinusite (Fleming-Dutra et al., 2016). Além dos gastos diretos, há custos indiretos, como presenteísmo (diminuição da produtividade no trabalho) e absenteísmo (Bhattacharyya, 2010). Nos EUA, o gasto estimado com esses pacientes é de US \$8,6 bilhões por ano (Bhattacharyya, 2011a). Os questionários de QV global e doença -específica evidenciam grande impacto da RSC na QV dos pacientes (Ware; Sherbourne, 1992; Durr; Desrosiers; Dassa, 2001; DeConde; Soler, 2016).

As diretrizes mais recentes definem a RSC em adultos pelos sintomas de obstrução nasal / congestão / bloqueio, rinorreia anterior ou posterior, dor facial / pressão / plenitude e diminuição ou perda de olfato (Fokkens; Lund; Mullol, 2012; Rosenfeld et al., 2015). Apesar de darem alta sensibilidade ao diagnóstico, os sintomas sozinhos levam a uma especificidade inaceitavelmente baixa, razão pela qual eles devem ser acompanhados de achados objetivos, incluindo os de endoscopia nasal (secreção purulenta, pólipos ou edema), ou tomográficos (inflamação ou alterações da mucosa dentro dos seios da face) (Orlandi et al., 2016).

A RSC é dividida, fenotipicamente em duas entidades principais, baseadas na visualização de pólipos no nariz ou meato médio: a RSC sem polipose nasossinusal 
(RSCsPN) e a RSC com polipose nasossinusal (RSCcPN). Atualmente, evidências sugerem que essas duas entidades apresentam mecanismos fisiopatogênicos distintos.

Ampla gama de padrões inflamatórios pode atuar em conjunto com anormalidades mucociliares e/ou estruturais e está altamente relacionada ao desenvolvimento de RSC. A etiologia multifatorial da RSC, envolvendo fatores genéticos, influências ambientais, fatores ocupacionais, infecção, alergia, disfunção imunológica e doenças sistêmicas, levou à recente tentativa de definir endótipos de doenças. A RSC foi, então, classificada em diferentes grupos inflamatórios, como a inflamação de T helper 1 (Th1) ou inflamação neutrofílica; e a inflamação por T helper 2 (Th2) ou eosinofílica (Akdis et al., 2013). Ainda há pouca elucidação na literatura na relação entre RSC e alguns fatores, como atopia, asma, eosinofilia periférica, e a doença respiratória exacerbada à aspirina (DREA) ou AINE (antiinflamatórios não-esteroidais).

Em conjunto, a RSC representa uma condição com diferentes fenótipos e endótipos, que se começa a entender melhor. Em um único paciente com RSC, localizar os diferentes fatores etiológicos responsáveis pelo desenvolvimento da doença continua sendo um desafio para o futuro. Estudos anteriores avaliaram a relação entre RSC, atopia, tabagismo, asma, DREA, extensão da doença e eofinofilia, mas poucos seguiram os pacientes por longo prazo, identificando quais têm poder como fatores prognósticos. 


\subsection{Epidemiologia da RSC}

Os dados epidemiológicos da RSC são relativamente escassos e imprecisos, salientando ainda as diferentes definições e a heterogeneidade das metodologias utilizadas nas pesquisas, o que dificulta ainda mais a comparação dos dados.

Doze por cento da população dos EUA referem que algum profissional da saúde diagnosticou rinossinusite nos 12 meses anteriores em uma pesquisa com 34.525 entrevistados em 2012 (Schiller; Lucas; Pergoy, 2012; Bachert et al., 2015). Esta foi a segunda condição crônica mais prevalente nos EUA entre todas as avaliadas, perdendo apenas para deformidades ou deficiências ortopédica (Collins, 1997).

Já com base nos registros de saúde eletrônicos, a prevalência de RSC com ou sem pólipos diminui para 4,9\% \pm 0,2\% (490/10.000) (Bhattacharyya 2011a,b). Tan BK et al. (2013) revisaram os registros de saúde eletrônicos de 307.381 adultos que receberam atendimento em uma clínica americana de 2007 a 2009 e relataram que a taxa de incidência média de RSCcPN foi de $8,3( \pm 1,3)$ casos por 10.000 pessoas/ano e a de RSCsPN de $105( \pm 7,0)$ casos por 10.000 pessoas/ano.

No Canadá, a prevalência de RSC, definida como resposta afirmativa à questão "Você tem sinusite diagnosticada por um profissional de saúde?" variou de $3,4 \%$ no sexo masculino para $5,7 \%$ em mulheres, sendo $5 \%$ a média total (Chen; Dales; Lin, 2003). Além disso, houve aumento da prevalência com avanço da idade: média de $2,7 \%$ entre $20-29$ anos e $6,6 \%$ nos grupos etários de $50-59$ anos (Chen; Dales; Lin, 2003).

No estudo europeu Global Allergy and Asthma Network of Excellence (GA2LEN), adultos de 15 a 75 anos em 19 centros na Europa responderam um questionário sobre a prevalência da RSC, com base nos critérios EPOS 2007, e os autores reportaram a prevalência média de 10,9\%, variando de 6,9\% (Brandenburg, Helsinki) a 27,1\% (Hastan et al., 2011). Gordts, Clement e Buisseret (1996) relataram que $6 \%$ dos indivíduos sofriam de secreção nasal crônica na Bélgica.

Ahsan, Jumans e Nunez (2004) reportaram prevalência semelhante de RSC (9,6\% e 9,3\%) no norte da Escócia (com clima temperado) e no sul do Caribe (clima tropical). Na Coréia do Sul, a prevalência foi de 6,95\% (Kim et al., 2011); e na China 
(Shi et al., 2015), de 8\%; chegando, em algumas cidades, à prevalência de quase 10\%. Na cidade de São Paulo, Pilan et al. (2012) observaram a prevalência de RSC de 5,51\%. Foi aplicado um questionário por meio de entrevistas domiciliares a 2.006 indivíduos de 12 anos ou mais, baseado na definição preconizada pelo EP3OS 2007 (Fokkens et al., 2007).

De acordo com a definição, para diagnóstico de pólipos nasais (PN) são necessários questionários e endoscopia nasal. Assim, a endoscopia nasal é um prérequisito para a estimativa precisa da prevalência de $\mathrm{PN}$, já que o exame é essencial para confirmar o seu diagnóstico (Johansson et al., 2003).

$\mathrm{Na}$ Dinamarca, a partir de estudos de autópsia, Larsen e Tos (1991) descreveram a prevalência de $2 \%$ de PN por meio da rinoscopia anterior, enquanto que a endoscopia nasal detectou PN em 42\% das autópsias (Larsen; Tos; Baer, 1994). A partir desses estudos em cadáveres, pode-se concluir que número significativo de pacientes com PN não é corretamente diagnosticado. Por fim, o mesmo grupo de Larsen e Tos (2002) realizou um estudo prospectivo considerando os sintomas de PN, e os autores encontraram incidência estimada de 0,86 e 0,39 pacientes por mil habitantes, por ano, para homens e mulheres, respectivamente. A incidência também aumentou com a idade, atingindo picos de 1,68 e 0,82 pacientes por mil habitantes, por ano, para homens e mulheres, respectivamente, na faixa etária de 50-59 anos. A partir desses estudos, Larsen e Tos (2002) estimaram que a prevalência global de PN seria de 6,3 por 10.000 habitantes, por ano, na Dinamarca.

Johansson et al. (2003) atenderam 1900 pessoas aleatoriamente na cidade de Skovde, Suécia, aplicando questionários e realizando endoscopia nasal. Encontraram prevalência de PN de 2,7\% da população total, sendo mais frequentes nos homens (relação de 2,2 homens a cada 1 mulher), idosos (5\% aos 60 anos, ou mais) e asmáticos.

Com base em uma pesquisa que aplicou questionários enviados pelo correio a 4300 adultos na Finlândia, Hedman et al. (1999) relataram que 4,3\% da população respondeu positivamente à questão sobre saber que pólipos já foram encontrados no nariz. Em pesquisa na Coréia do Sul, a prevalência geral de pólipos diagnosticados por endoscopia nasal foi de $0,5 \%$ da população total (Min et al., 1996). 


\subsection{Impacto socioeconômico da RSC}

Por definição, os pacientes com RSC possuem alguma combinação de sintomas cardinais nasossinusais, incluindo congestão nasal, descarga nasal, pressão/dor facial e alteração do olfato. No geral, o impacto da RSC se prolonga frequentemente além da região nasossinusal, e pode ter efeitos profundos na QV (QV) do paciente.

Vários estudos utilizaram o questionário SF-36 para avaliar a QV em pacientes com RSC, revelando resultados dos domínios SF-36 nos pacientes com RSC abaixo da população normal em 5 a 7 pontos (Gliklich; Metson, 1995; Winstead; Barnett, 1998; Durr; Desrosiers; Dassa et al., 2001; DeConde; Soler, 2016). O estudo de Gliklich e Metson (1995) revelou, ainda, impacto no funcionamento social em pacientes com RSC maior do que naqueles com insuficiência cardíaca congestiva, angina, doença pulmonar obstrutiva crônica (DPOC) e dor nas costas.

O SNOT-22 é um questionário de QV mais específico para doenças Nasossinusais. Num estudo de coorte de 3.128 pacientes submetidos à cirurgia para RSC, Gillet et al. (2009) observaram um escore médio pré-operatório de 42,0 (Intervalo de confiança - IC95\% = 41,2-42,7), comparado a um SNOT-22 de 7 em voluntários saudáveis. Poetker, Mendolia-Loffredo e Smith (2007) mostraram que pacientes com RSCcPN tendem a apresentar melhor QV do que aqueles com RSCsPN, apesar de pior TC e pontuação na endoscopia, enquanto que Erskine et al. (2016) demonstraram resultado oposto.

Alt et al. (2013) observaram que um dos fatores de QV altamente influenciados pela RSC é o sono. E outro fator proeminente que impacta a QV e o bem-estar geral em pacientes com RSC é a depressão. Estudos relataram taxas de prevalência de depressão na RSC variando de 9\% a 26\% (Mace et al., 2008; Litvack; Mace; Smith, 2011; Nanayakkara et al., 2013), acima dos valores da população geral, que é entre $5 \%$ e 10\% (Centers for Disease Control and Prevention - CDC, 2010).

A RSC também tem implicações socioeconômicas significativas. Ray et al. (1999) estimaram que o custo direto total nos EUA era de 5,78 bilhões de dólares 
por ano. Murphy et al. (2002) observaram que pacientes com RSC faziam 43\% mais consultas ambulatoriais e $25 \%$ mais atendimentos urgentes do que um paciente sem RSC, e que o custo total do tratamento de um paciente com RSC era $6 \%$ mais alto do que o de adulto médio. Na Europa, apenas um estudo holandês foi encontrado: van Agthoven et al (2002) reportaram que os custos diretos de um paciente tratado em um hospital universitário para RSC grave foram de US\$1.861,00/ano.

Em 2011, os custos dos norte-americanos com RSC foram estimados em 8,6 bilhões de dólares por ano (Bhattacharyya, 2011b), gastos principalmente em medicamentos e atendimento médico. Contribuem para o alto impacto econômico desta doença: a alta prevalência da doença, o fato de ser uma condição crônica sem cura universal, as exacerbações frequentes de sintomas que provocam tratamentos agudos (além dos sintomas crônicos já existentes), o alto impacto na QV, a dificuldade de controle de sintomas, e a necessidade de procedimentos radiológicos ou endoscópicos para fazer o diagnóstico (Bhattacharyya et al., 2011).

Bhattacharyya et al. (2011) identificaram que, em pacientes submetidos à ESS (cirurgia endoscópica sinusal), os custos com cuidados de saúde para RSC no ano anterior à cirurgia foram em média de US\$2.449. A cirurgia mais os custos de curativos no pós-operatório de até 45 dias e os medicamentos obtiveram média de US\$ 7.726. No ano seguinte ao período de 45 dias após o procedimento, o custo caiu para US $\$ 885$ ( $p<0,0001$; e no segundo ano após a ESS, os custos diminuíram para US $\$ 446(p<0,0001)$.

Considerando-se que $85 \%$ dos pacientes com RSC estão em idade produtiva (entre 18 e 65 anos) (Blackwell; Collins; Coles, 2002), os custos indiretos, como dias de trabalho perdidos (absenteísmo), diminuição da produtividade no trabalho (presenteísmo) e outras formas de perda de produtividade (por exemplo, vida familiar), causam enorme impacto à população.

Goetzel et al. (2003) observaram que a rinossinusite foi uma das dez condições de saúde mais caras para os empregadores dos EUA. Os gastos totais com cuidados de saúde por trabalhador/ano para esta doença (aguda e crônica) foram de US $\$ 60,17,46 \%$, resultado do absenteísmo e da deficiência. 
Bhattacharyya (2003) estimou custos diretos e indiretos da RSC em 322 pacientes e concluiu que o custo do tratamento de RSC por paciente totalizava US\$ 1.539 por ano, sendo $40 \%$ indiretos do trabalho perdido, em média de 4,8 dias.

Seja qual for o custo preciso, fica evidente que a carga socioeconômica e em QV da doença é significativa. Como tal, é imperativo que se continue a pesquisar para se compreender melhor a fisiopatologia e fatores prognósticos da doença e a conceituar estratégias econômicas para proporcionar alívio desses sintomas aos pacientes.

\subsection{Fisiopatologia}

A inflamação da mucosa nasal em contato com o ambiente externo sugere a hipótese de que a RSC resulta de uma resposta epigenética imune inadequada ou excessiva a agentes externos, levando a inflamação mucosa persistente, influxo celular e, consequentemente, alterações clínicas (Kern et al., 2008). A RSC também pode, em raros casos, ser secundária a processos inflamatórios intrínsecos à mucosa na presumida ausência de estímulos exógenos (por exemplo, granulomatose de Wegener e sarcoidose). Por último, a RSC pode ocorrer em associação a fatores genéticos dos hospedeiros (fibrose cística), ou imunodeficiência sistêmica. Na maioria dos casos de RSC, a etiologia e a patogênese ainda não estão claras.

A RSC idiopática foi fenotipicamente dividida em RSCsPN e RSCcPN, com base em achados endoscópicos. Em termos de etiologia e patogênese, acredita-se que a RSCsPN esteja mais fortemente ligada à obstrução mecânica do complexo osteo-meatal (COM) enquanto que a RSCcPN é geralmente atribuída a uma resposta da mucosa mais difusa (Leung et al., 2011).

No entendimento atual de que a RSC idiopática resulta, principalmente, de uma disfunção entre hospedeiro e ambiente, envolvendo vários agentes exógenos e alterações na mucosa nasossinusal (Kern et al., 2008), a identificação dos agentes exógenos que conduzem ou modulam os mecanismos inflamatórios secundários tem sido o grande foco das pesquisas nos últimos anos. 
Alguns estudos sugerem o envolvimento, não apenas de loci genéticos múltiplos, mas também a importância de alterações epigenéticas ambientalmente determinadas (Vercelli, 2004; Vuillermin et al., 2009; Martino; Prescott, 2010). Em suma, a suscetibilidade do hospedeiro a doenças complexas, como a RSC, reflete os efeitos combinados de exposições ambientais passadas sobre a sequência da base de DNA, e sobre efeitos pós-transcricionais, como a metilação do DNA e os padrões de modificação das histonas. Os estresses ambientais contínuos deixam o hospedeiro susceptível, o que pode levar ao desenvolvimento do estado cronicamente inflamado, aqui representado pela RSC.

Nenhum agente microbiano, isoladamente, é capaz de justificar a diversidade e a heterogeneidade dos processos fisiopatogênicos envolvidos na RSC, de modo que a teoria microbiana nem sempre é aplicável a todos os pacientes.

Em se tratando de fisiopatologia, é possível dividir os fatores em microbiológicos, ambientais, locais e sistêmicos. A seguir será exposto o que se sabe de mais atual a respeito de cada um deles.

\subsubsection{Bactérias}

As bactérias têm papel estabelecido na rinossinusite aguda (RSA) e há muito se especulou que RSA bacteriana incompletamente tratada levava ao desenvolvimento do RSC. No entanto, embora as bactérias possam desencadear exacerbações infecciosas agudas, o papel das bactérias no processo inflamatório da RSC ainda não está claro.

Em revisão sistemática envolvendo 43 estudos e 3.528 pacientes, Thanasumpum e Batra (2015) observaram que as bactérias mais comumente encontradas nas culturas de pacientes com RSC foram os aeróbios Gram positivos (Staphylococcus coagulase negativos, 34\% e Staphylococcus aureus - S. aureus, $26 \%$ ), seguidos das bactérias aeróbias gram negativas (Haemophilus influenzae - $H$. influenzae, 27,0\% e Pseudomonas aeruginosa - $P$. aeruginosa, 21,6\%) e dos anaeróbios (Peptostreptococcus espécies, 19,6\% e Bacteroides espécies, 19,2\%).

O S. aureus tem sido encontrado principalmente em pacientes com RSC ocidentais, tanto em condições pré como pós-operatórias (Larson; Han 2011), com 
menor prevalência na população chinesa (Ba et al., 2011). Ainda, o $S$. aureus é identificado com maior frequência em pacientes com PN extensa do que em controles (Zhang et al., 2015), ou mesmo com RSCsPN (Hwang, 2013).

Uma característica peculiar do $S$. aureus é a capacidade de produzir exotoxinas com propriedades de superantígenos (Bachert et al., 2001, 2008). impacto é a distorção da resposta inflamatória, com amplificação de citocinas Th2, inibição de citocinas T reguladoras (Treg), com acentuada atividade de eosinófilos e mastócitos e aumento do dano e remodelação dos tecidos. Acredita-se que a ação primordial dos superantígenos seja a de modular a inflamação nas vias aéreas superiores (VAS), dependendo das reações particulares de cada indivíduo (Corriveau; Zhang; Bachert, 2009; van Crombruggen et al., 2011). No entanto, a simples presença de $S$. aureus produtor de enterotoxina na cavidade nasal não é suficiente para produzir reação inflamatória crônica e formação de pólipos (Heymans et al., 2010), e no geral há pouca ou nenhuma evidência na literatura que apoie o papel dos superantígenos na patogênese da RSCsPN. Assim, os superantígenos têm sido geralmente vistos por muitos como modificadores da doença, em vez de agentes etiológicos.

Outra forma que tem sido observada em RSC são os biofilmes, uma comunidade de bactérias que se envolvem com a matriz extracelular (ECM) protetora (Zhang et al. 2011b). Contudo, não se sabe qual o real papel dos biofilmes na fisiopatogenia da RSC, não sendo possível determinar se a colonização dos biofilmes seria a causa ou a consequência da reação inflamatória crônica. (Tamashiro et al., 2009). Nos pacientes com PN, a presença do biofilme parece ter relação relativamente insignificante. Zhang et al. (2011b) não encontraram associação, enquanto que Boase et al. (2013) mostraram tendência para maior número de espécies bacterianas em RSCcPN, porém sem significância estatística.

De acordo com Singhal et al. (2011), a presença de biofilme per se não é determinante para a evolução pós-operatória de pacientes com RSC, mas sim a bactéria presente nele. De acordo com esses autores, pacientes com $S$. aureus presentes no biofilme obtiveram pior prognóstico do que os com $H$. influenzae. Uma possível repercussão do biofilme sobre a mucosa foi mencionada por Tan et al. 
(2012b), que observaram maior presença de $S$. aureus intracelulares nos pacientes com RSC e biofilme do mesmo patógeno.

Bactérias intracelulares também têm sido identificadas, de modo viável, na mucosa respiratória de pacientes com RSC, especialmente o $S$. aureus (Tan et al., 2012a; Kim et al., 2013; Tan NC et al. 2013; Tan et al., 2014). A presença dessas bactérias poderia justificar outra forma de persistência bacteriana na mucosa respiratória, especialmente nas crônicas e recorrentes. Foi demonstrado que os nichos de microcolonização intracelular são capazes de reduzir o processo inflamatório adjacente, com redução do recrutamento de linfócitos T e eosinófilos ao redor (Wood et al., 2012; Ou et al., 2016), permitindo a permanência desse patógeno intracelularmente por tempo prolongado na mucosa nasal.

A "hipótese de barreira imune" propôs que os defeitos na barreira e/ou na resposta imune inata do epitélio nasossinusal possam ser importantes para a RSC (Kern et al., 2008), por facilitar a colonização com uma gama de agentes microbianos, dano de barreira acentuado e resposta imune adaptativa compensatória (Tieu; Kern; Schleimer, 2009). Postula-se que o dano epitelial e/ou disfunção da barreira hospedeira resultam em colonização por $S$. aureus (Fokkens; lund; Mullol, 2012); entretanto o oposto também já foi demonstrado, sendo que as exotoxinas produzidas pelo $S$. aureus podem induzir dano na barreira epitelial (Kim et al. 2000; Hermann et al. 2015; Malik et al., 2015).

A grande diversidade da microbiota nasossinusal, seja na forma de bactérias planctónicas, biofilmes ou mesmo formas intracelulares, assim como as inúmeras possibilidades de interação com mecanismos de imunidade inata e adaptativa do hospedeiro, devam ser importantes fatores da inflamação tecidual nas RSC, seja como desencadeador, modulador ou mesmo mantenedor da inflamação crônica nasossinusal (Anselmo-Lima et al., 2015).

\subsubsection{Fungos}

É incontestável que, em algumas condições crônicas nasossinusais, como na bola fúngica e nas formas crônicas invasivas , o papel do fungo é central (Gungor, 2012). Mas o papel dos fungos na RSC idiopática é ainda tema de grande 
discussão. O uso de técnicas de detecção sensíveis indicou que os fungos são uma presença intranasal ubíqua, identificada em cerca de $100 \%$ dos pacientes com RSC e controles (Ponikau et al., 1999). Aspergillus, Cladosporium, Candida, Aureobasidium e Alternaria são frequentemente recuperados de pacientes com RSC e controles normais (Kim et al. 2005; Murr; Goldberg; Vesper, 2006). No entanto, ainda há muita controvérsia sobre a presença de fungos e sua relação com a eosinofilia tecidual na RSCcPN (Ponikau et al., 1999; Braun et al., 2003; Orlandi et al., 2009).

\subsubsection{Rinossinusite fúngica}

A RSC causada por fungos é chamada Rinossinusite Fúngica (RSF), sendo que classicamente é dividida nas formas invasiva e não invasiva, com base no fato de os fungos terem ou não invadido o tecido submucoso nasossinusal. A maioria dos casos é não invasiva, classificada em bola fúngica (BF) e RSF alérgica (RSFA) (Katzenstein; Sale; Greenberger, 1983).

Em estudo nacional, a prevalência de RSFA foi de $6,7 \%$ dos pacientes submetidos à ESS por RSC, sendo o gênero Aspergillus o mais comum encontrado (Dall'igna et al., 2005). A fisiopatologia da RSFA continua controversa na literatura; a reação em cascata que leva a esta condição é multifatorial, envolvendo sensibilidade medida pela lgE (atopia), receptores específicos de células $T$, exposição aos fungos e fatores locais de defesa da mucosa.

O quadro clínico dos pacientes portadores de RSFA caracteriza-se por RSC, rinorreia escura e espessa, drenagem pós-nasal, atopia, PN e deformidade facial progressiva sem invasão fúngica da mucosa sinusal. Os critérios mais amplamente utilizados para o diagnóstico de RSFA são descritos por Bent e Kuhn (1994), e consistem em cinco elementos para o diagnóstico: 1) hipersensibilidade mediada por lgE confirmada; 2) mucina eosinofílica sem invasão fúngica; 3) PN; 4) TC característica; 5) cepas fúngicas positivas.

Fergunson (2000) propôs o termo rinossinusite mucínica eosinofílica (RSME) para pacientes com doença bilateral, histologicamente semelhante à RSFA, exceto pela ausência de hifas fúngicas. É importante o correto diagnóstico para o 
seguimento adequado desses pacientes, visto que a RSFA tem pior prognóstico e maior taxa de cirurgias de revisão que a RSC (Philpott et al., 2015; Younis; Ahmed 2017). A RSFA é, geralmente, tratada com cirurgia para remover os pólipos e a mucina eosinofílica, e criar acesso para a medicação intranasal tópica.

\subsubsection{Vírus}

Atualmente, existe pouca investigação a respeito da participação viral na fisiopatogenia das RSC. Apesar da alta frequência de infecções agudas do trato aéreo superior, ainda não está bem esclarecido se os vírus atuam como fonte de estimulação crônica ou se deflagram o processo inflamatório inicial (Fokkens, Lund; Mullol, 2012).

\subsubsection{Atopia}

Não há estudos controlados sobre o papel da alergia na fisiopatologia da RSC, tampouco ensaios controlados que mostrem que o tratamento de alergia altera o curso da doença. Poucos estudos compararam, entre pacientes com RSC, os com alergia aos sem alergia, deixando o papel da atopia na RSC controverso. Alguns autores sugerem que pacientes com RSC atópicas têm maiores alterações na TC, necessidade de maior número de intervenções cirúrgicas e pior QV (Kennedy, 1992; Gutman, et al. 2004; Tan et al., 2011). Entretanto, outros estudos não demonstram correlação entre a extensão tomográfica da doença e os testes alérgicos (Robinson; Douglas; Wormald, 2006; Pearlman et al., 2009; Tan et al., 2011). Ainda, os sintomas de RA se sobrepõem sobremaneira com os de RSC (Tomassen et al., 2011), o que dificulta ainda mais a diferenciação entre os dois diagnósticos, e o estudo de relação entre as duas doenças.

Níveis elevados de citocinas Th2, como IL-5 (interleucina 5) e IL-13, foram isolados em tecido de $\mathrm{PN}$, mesmo em pacientes não atópicos e a inflamação eosinofílica é comumente identificada, tanto na atopia como na RSCcPN. Além disso, os mastócitos e basófilos também são significativamente aumentados em PNs e suas contagens se correlacionam com o aumento dos eosinófilos no tecido do 
pólipo, confirmando que na RSCcPN a resposta inflamatória é, predominantemente, Th2, independente da atopia.

Entre 0,5 e 4,5\% dos indivíduos com RA têm PN (Caplin; Haynes; Spahn, 1971; Settipane; Chafee, 1977; Bunnag et al., 1983), níveis semelhantes aos da população sem atopia. Por outro lado, a prevalência de alergia em pacientes com PN também é controversa, com estudos mostrando altos níveis, de 54\% (English, 1986) a 64\% (Drake-Lee; McLoughlan, 1988), enquanto outros autores não observaram maior prevalência de atopia nos pacientes com PN (Pepys; Duveen, 1951; Bunnag et al., 1983; Drake-Lee; McLoughlan, 1988; Liu; Shun; Hsu, 1994; Settipane, 1996).

Em recente revisão sistemática, Wilson, McMains e Orlandi (2014) analisaram o papel da alergia especificamente na RSCcPN e RSCsPN, de modo que os estudos que examinaram "RSC" isoladamente foram excluídos. Diante da controvérsia nos resultados, seja para a associação da atopia com a RSCsPN ou com a RSCcPN, os autores concluíram que o nível de evidência não suporta uma recomendação forte sobre a realização de testes alérgicos em pacientes com RSC.

\subsubsection{Tabagismo}

Os efeitos deletérios da fumaça de cigarro relevantes para a RSC incluem alterações na secreção e frequência de batimento ciliar (Cohen et al., 2009) e a indução de biofilmes bacterianos (Goldstein-Daruech et al., 2011). Com base em dados in vitro, propôs-se que a fumaça de cigarro combinada à infecção viral contribuem para exacerbações agudas e inflamação eosinofílica em pacientes com RSC (Yamin et al., 2008). Espécies reativas de oxigênio (ROS) e espécies de nitrogênio reativo (RNS) do fumo do tabaco induzem secreção de citocinas próinflamatórias (Goldstein-Daruech et al., 2011), apoptose epitelial (Comhair et al., 2001; Misso; Thompson, 2005) e disfunção na barreira epitelial das vias aéreas (Xiao et al., 2011). Em geral, os dados sugerem que a fumaça de cigarro acentua a inflamação, mas não exerce papel significativo na etiologia da RSC. A prevalência de RSC é maior nos fumantes (Lieu; Feinstein, 2000; Houser; Keen, 2008) e os fumantes têm resposta menos favorável à cirurgia (Kennedy, 1992; Krzeski et al., 
2011). O tabagismo foi associado à maior prevalência de RSC em todas as partes da Europa (Gordts; Clement; Buisseret, 1996).

\subsubsection{Resposta imunológica do hospedeiro}

A mucosa nasossinusal serve como local de interface entre o hospedeiro e os agentes irritantes inalados, aerossóis, organismos comensais e agentes patogênicos. A depuração mucociliar, a exclusão física e as respostas imunes inatas e adaptativas protegem o hospedeiro do meio ambiente. Quando a barreira não evita a entrada do agente externo, as citocinas e quimiocinas agem para induzir a resposta imune subsequente, tentando eliminar esse agente. No paciente normal, esses fatores externos são eliminados sem danos nos tecidos ou o estabelecimento de um processo crônico. Assim, as alterações epiteliais e da resposta imune inata da mucosa do hospedeiro podem predispor ao desenvolvimento de RSC (Kern et al., 2008). Esta hipótese reforça a susceptibilidade do hospedeiro e a importância de fatores epigenéticos como principais fatores na patogênese da RSC.

O componente mecânico da barreira consiste em duas partes: muco respiratório e epitélio subjacente. O muco respiratório aprisiona material estranho e o move para a nasofaringe. As propriedades físicas e químicas do muco provavelmente desempenham papel significativo na eficiência e seletividade desse processo. Os defeitos genéticos e adquiridos no fluxo mucociliar estão associados à alta incidência de RSC, e a variações na viscosidade e atividade ciliar (Cutting, 2005; Chen et al., 2007; Antunes; Gudis; Cohen, 2009).

Sob o muco residem as células epiteliais (ECs), que são unidas entre si por junções apertadas e aderentes. As junções apertadas e aderentes compreendem o complexo juncional apical (CJA), criando uma barreira relativamente impermeável. Os agentes exógenos podem possuir atividade proteolítica, o que permite que eles degradem as proteínas juncionais, tornando a barreira permeável. (Nomura et al., 2014) A RSCcPN foi associada a níveis significativamente diminuídos de proteínas CJA (Zuckerman et al., 2008; Rogers et al., 2011; Soyka et al., 2012). Ainda, citocinas Th2 foram capazes de comprometer a permeabilidade epitelial e degradar as proteínas CJA (Wise et al., 2014). Estudos funcionais também documentaram a 
permeabilidade da barreira aumentada na RSCcPN (Soyka et al., 2012; Den Beste et al., 2013) Tomados em conjunto, esses estudos sugerem que a disfunção mucociliar pode desempenhar papel importante na patogênese da RSC, no geral, enquanto que uma barreira epitelial deficiente está mais intimamente ligada à RSCcPN.

Histologicamente, a RSCsPN é caracterizada por infiltrado neutrofílico, aumento de fibrose e de depósito de colágeno no estroma. A membrana basal apresenta-se pouco espessada e não há depósito de pseudocistos (van Bruaene; Bachert, 2011). Já a RSCcPN é caracterizada por extenso infiltrado leucocitário, sendo que nos europeus (Fokkens; Lund; Mullol, 2012) e nos brasileiros $80 \%$ dos casos são eosinofílicos (Couto et al., 2008), associado à franca presença de pseudocistos com acúmulo de albumina e edema, e diminuição de colágeno no estroma. A membrana basal encontra-se espessada e há alteração histológica significativa no epitélio (van Bruaene; Bachert, 2011).

As teorias mais recentes indicam que há distúrbio na interação entre imunidade inata e adaptativa em ambos os casos. Enquanto que a imunidade adaptativa é orquestrada essencialmente pelos linfócitos, e depende da prévia exposição do indivíduo a esse antígeno (Fokkens; Lund; Mullol, 2012), a imunidade inata reconhece imediatamente (sem exposição previa) o que não pertence ao organismo. Acreditava-se que esse sistema fosse rudimentar, mas, na atualidade, sabe-se que ele é complexo e que interage de forma dinâmica com a imunidade adaptativa.

Diversas células da mucosa nasal produzem citocinas e quimiocinas para atrair as células inflamatórias. Nos pacientes com RSCsPN, o padrão inflamatório é quase que exclusivamente neutrofílico, mediado por Th1 (Li et al., 2013), com aumento de interferon gama (IFN- $\gamma$ ), IL-12 e fator de necrose tumoral alfa (TNF- $\alpha$ ) (Huvenne et al., 2009; Calus et al., 2012).

Já na RSCcPN, há um padrão predominantemente misto inflamatório Th1/Th2 nas populações europeia, americana e brasileira (Figueiredo; Silva; Weckx, 2008; Otto; Wenzel, 2008; Håkansson et al., 2015), mas com franco predomínio de Th2, aumento expressivo de expressão de IL-5, IL-4, e IL-13 e do fator de transcrição GATA-3 (Fokkens et al., 2007; Calus et al., 2012; Chin; Harvey 2013). A IL-5 tem 
especial importância na RSCcPN, porque é francamente produzida por eosinófilos, e sua principal função é induzir eosinofilia tecidual (Voegels; de Melo Pádua, 2005; Figueiredo; Silva; Weckx, 2008; Otto; Wenzel, 2008; Calus et al., 2012). Além disso, a IL-5 está associada a maior risco de asma e pior prognóstico pós-operatório (Voegels; de Melo Pádua, 2005; Van Zele et al. 2014). Os eosinófilos induzem lesão tecidual, edema e vasodilatação intensa, por produzirem proteínas como ECP (proteína catiônica eosinofílica) (Otto; Wenzel 2008; Huvenne et al., 2009; Calus et al., 2012) e LT (leucotrienos) (Pezato et al., 2012), além da produção de colágeno e espessamento de membrana basal no tecido (Bassiouni; Chen; Wormald, 2013). Esse padrão inflamatório é especialmente encontrado em pacientes que apresentam DREA (Li et al., 2013).

Os fatores que determinam a suscetibilidade à RSC dependem, em parte, da variação genética da mucosa nasal (Kern et al., 2008). A fibrose cística (FC) é o caso prototípico da RSC "genética", em que a disfunção do gene CFTR (Cystic Fribrosis Transmembrane Conductance Regulator) desencadeia funções imunes e barreiras inatas defeituosas (Ooi et al., 2010). Ainda, grande variação da expressão da doença sinusal e de mutações idênticas no gene CFTR (Cimmino et al., 2003) são relatadas na RSC, e múltiplos genes estão envolvidos em um paciente determinando um fenótipo clínico (Hull; Thomson, 1998) Por fim, a importância dos fatores epigenéticos na RSC se salienta, mesmo nesses casos, uma vez que a $P$. aeruginosa pode alterar a expressão e a função de CFTR em ECs cultivadas de RSC, com ou sem FC (Trinh et al., 2015).

\subsection{Asma}

Asma é uma forma crônica de inflamação das vias aéreas inferiores, com prevalência de 5\% a 10\% na população geral (Bousquet, 2000). RSC e asma são manifestações comuns de um processo inflamatório no sistema das VAS e inferiores contíguas. Embora a etiologia e os mecanismos patogênicos subjacentes ao desenvolvimento e progresso dessas duas condições não sejam totalmente conhecidos, é claro que as VAS e inferiores são influenciadas por fatores de risco comuns (Fokkens; Lund; Mullol, 2012). 


\subsubsection{Asma e RSC}

A asma é considerada uma condição comórbida da RSC. Estudos epidemiológicos e clínicos mostraram, consistentemente, que a RSC e a asma coexistem frequentemente no mesmo paciente. Em um levantamento com mais de 52.000 adultos entre 18 a 75 anos em 12 países europeus, a prevalência de asma autorrelatada $(5,1-16,8 \%)$ foi fortemente associada aos sintomas da RSC (odds ratio - OR ajustado: 3,47, IC95\%: 3,20-3,76) em todas as idades, tanto em homens como em mulheres, independentemente do tabagismo (Jarvis et al., 2012). Já em outro estudo recente, Habib, Javer e Buxton (2016) estudaram 11.555 canadenses adultos durante 12 anos, e observaram que 6,0\% (IC 95\%: 5,4\% -6,7\%) dos entrevistados desenvolveram asma durante esse período. Ainda foram significativamente associados ao desenvolvimento de asma: RSC basal (OR: 2,7, IC95\%: 1,9-3,9), sexo feminino (OR: 1,4, IC95\%: 1,1-1,8) e alergia (OR: 2,6, IC95\%: 2,1-3.3). Quando não associada à alergia nasal, a RSC foi associada à asma de início mais tardio, normalmente após os 40 anos de idade (Jarvis et al., 2012). Em alguns centros, cerca de $50 \%$ dos pacientes com RSC têm asma (Ponikau et al., 2003; Matsuno et al., 2008).

Pacientes com asma apresentaram maior anormalidade na TC do que os nãoasmáticos (Kountakis; Bradley, 2003), e as alterações na TC em pacientes asmáticos graves foram correlacionadas com eosinofilia e alteração na função pulmonar (ten Brinke et al., 2002; Matsuno et al., 2008). No entanto, esses dados epidemiológicos e radiológicos devem ser interpretados com cautela, pois podem refletir grande viés de referência.

A ESS para RSC visa aliviar os sintomas nasossinusais, mas também beneficia os sintomas brônquicos e reduz o uso de medicação para asma (Nishioka et al., 1994; Dinis; Gomes, 1997; Dhong et al., 2001; Proimos et al., 2010), efeito que pode ser observado em um período médio de seguimento de até 6,5 anos (Senior et al., 1999). Em metanálise recente, Vashishta et al. (2013), analisando dados de 891 pacientes asmáticos submetidos à EES, observaram melhora clínica da asma após seguimento médio de 26,4 meses. 
A presença da doença das vias aéreas inferiores também pode ter impacto negativo no resultado após a ESS em alguns estudos. Os resultados após ESS foram significativamente piores no grupo asmático em comparação com o grupo não-asmático (Dinis; Gomes, 1997; Dejima et al., 2005). Piores resultados após ESS também foram encontrados em pacientes com asma e intolerância à aspirina (Amar, Frenkiel; Sobol, 2000; Batra et al., 2003). Por outro lado, outros autores relataram influência da asma no desfecho da ESS primária (Chambers et al., 1997; Mehanna et al., 2002) ou na ESS revisional (Kennedy, 1992; Kountakis; Bradley, 2003).

\subsubsection{Asma e RSCcPN}

A RSCcPN e asma coexistem em frequência e compartilham características semelhantes de inflamação e remodelação. Essa associação foi apoiada por numerosas observações de alterações histopatológicas semelhantes (Gaga et al., 2000), pela mesma célula efetiva primária (eosinófilos) e por mediadores inflamatórios comuns (Gaga et al., 2000).

A presença de PN é maior na população asmática (Settipane; Chafee, 1977), em especial nos asmáticos atópicos (10-15\%). Alternativamente, até $60 \%$ dos pacientes com PN apresentam comprometimento das vias aéreas inferiores, avaliado por história, e testes de função pulmonar e de provocação de histamina (Ragab; Clement; Vincken, 2004).

Os dados sobre os efeitos da cirurgia para RSCCPN na asma apontam efeito benéfico da mesma em diferentes parâmetros da asma. A ESS melhorou significativamente os sintomas da doença (Gaga et al., 2000; Ehnhage et al., 2009) e a função pulmonar (volume expiratório forçado - VEF1) (Batra et al. 2003). Ainda, reduziu significativamente o uso de corticosteroide oral em pacientes com RSCCPN e asma cortico-dependente, e a frequência de visitas à sala de urgência relacionadas à asma (Gaga et al. 2000). Outros estudos não mostraram efeito tão positivo da ESS sobre a asma (Uri et al., 2002; Ragab; Hassanin, 2010), embora tenha se observado tendência de melhora nos dois estudos. Mas, no geral, parece que a ESS tem efeito positivo na asma em pacientes com RSCcPN. 


\subsection{Intolerância à aspirina e RSC}

A PN recorrente está altamente associada à asma, sensibilidade à aspirina e a AINEs. Essa tríade é, muitas vezes, referida como a tríade de Samter (Samter; Beers, 1968) ou F. Widal. Atualmente, essa tríade foi renomeada como DREA ou AERD (Berges-Gimeno; Simon; Stevenson, 2002; Stevenson, 2009; Kowalski et al., 2011).

As taxas de prevalência de DREA na população geral foram estimadas em 0,6\% a 2,5\% (média de 1\%), e em 9,7\% dos pacientes com RSCcPN (Krouse et al., 2007; Baker; Quinn, 2011; Rajan et al., 2015) A prevalência de PN em asmáticos sensíveis à aspirina pode atingir 60-70\%, em comparação com menos de $10 \%$ na população de asmáticos tolerantes à aspirina (Settipane, 1996; Krouse et al., 2007).

Nos pacientes com sensibilidade ao AAS (Ácido Acetil Salicílico), a prevalência de PN está entre 36\% e 96\%, em especial nos pacientes a partir dos 40 anos (Settipane, 1996). Esses pacientes, geralmente, apresentam PN difusa (Kowalski, 2007), que acomete todos os seios paranasais, associada à asma de difícil controle (Kennedy, 1992). Ainda, DREA afeta negativamente os resultados de EES nos pacientes com RSCcPN (McFadden et al., 1997; Amar et al., 2000; Batra et al., 2003; Kim; Kountakis, 2007). A gravidade da doença é ainda refletida pela alta recorrência de PNs e frequente necessidade de ESS revisionais (Vento et al., 2000; Kowalski, 2007).

Acredita-se que, nessa população específica, haja inibição da enzima ciclooxigenase-1 (COX-1) por AINEs, com ativação inflamatória (Szczeklik; Gryglewski; Czerniawska-Mysik, 1975; Stevenson; Szczeklik 2006). A via da lipoxigenase é especialmente ativada, ocorrendo desequilíbrio de antiprostaglandinas inflamatórias (PGs) e leucotrienos pró-inflamatórios (LTs), com concomitante liberação de mastócitos e eosinófilos (Fischer et al., 1994; Nasser et al., 1996; Pawankar, 2003).

Os primeiros sintomas da DREA ocorrem, geralmente, na quarta década de vida, com rinite ou sintomas nasossinusais seguida por PN. A asma, normalmente, se desenvolve vários anos depois, e a sensibilidade clínica ao AAS e aos AINEs também pode ser mais tardia. 
O diagnóstico de hipersensibilidade ao AAS é baseado em história clínica de reação adversa precipitada por AAS ou outro AINE. O teste de provocação oral (TPO), ou provocação nasal/brônquica com aspirina são ferramentas confiáveis para confirmar ou excluir hipersensibilidade ao AAS/AINE (Fokkens; Lund; Mullol, 2012). Em pacientes asmáticos com história negativa e/ou aqueles que nunca foram expostos aos AINEs, mas possuem fatores de risco adicionais (RS, PN e história de reações quase fatais), o risco de reação adversa é aumentado e o teste de provocação é necessário (Nizankowska-Mogilnicka et al., 2007). O TPO é o padrão de referência para o diagnóstico de hipersensibilidade à aspirina e outros AINEs, e vários protocolos para a provocação oral com aspirina foram desenvolvidos e descritos (McDonald; Mathison; Stevenson, 1972; Stevenson, 2000). Existem outros testes para o diagnóstico de intolerância ao AAS, como: teste de provocação inalatória com aspirina-lisina (uma forma solúvel de ácido acetil salicílico); o teste de provocação nasal com aspirina-lisina; e mais recentemente, mas ainda em estudo, testes in vitro, que aferem a ativação de leucócitos de sangue periférico específicos à aspirina.

Uma vez confirmada a intolerância ao AAS e AINES, deve-se orientar ao paciente que evite esses medicamentos, uma vez que eles podem ser uma causa de crise asmática grave (Dahlén; Zetterström, 1990). O manejo da asma e da RS no paciente com DREA deve seguir as diretrizes gerais, mas várias medidas específicas podem ser consideradas, uma vez que esses pacientes demandam altas doses de esteroides tópicos e, ocasionalmente, corticosteroides sistêmicos ou antibióticos para controlar os sintomas. Em determinados estágios da doença, procedimentos cirúrgicos (polipectomia ou ESS) são necessários para aliviar os sintomas da RSC. Os efeitos benéficos da ESS podem se refletir na melhora dos sintomas da asma (Awad et al., 2008a), embora os pacientes com DREA parecem responder menos à intervenção cirúrgica do que os não DREA (Awad et al., 2008b; Katotomichelakis et al., 2009; Mendelsohn et al., 2011). Ainda, para esse grupo de pacientes, em específico, a dessensibilização ao AAS pode levar à melhora do controle da doença (Pleskow et al., 1982; Stevenson et al., 1996; Berges-Gimeno; Simon; Stevenson, 2003; Forer et al., 2011; Lee; Stevenson, 2011; Spies et al., 2016). 


\subsection{Diagnóstico da RSC}

O diagnóstico clínico da RSC baseia-se na presença de sinais e sintomas nasossinusais, com mais de 12 semanas de evolução (Fokkens; Lund; Mullol, 2012; Anselmo-Lima et al., 2015). Assim, esta doença em adultos é definida por dois ou mais sintomas:

- Sintomas maiores: bloqueio nasal, obstrução, congestionamento ou secreção nasal (gotejamento nasal anterior/posterior);

- Sintomas menores: dor, pressão facial, redução ou perda de olfato (em crianças esse sintoma é substituído pela tosse);

- Sinais endoscópicos: PNs, descarga mucopurulenta, principalmente do meato médio, edema, obstrução mucosa, principalmente no meato médio;

- Alterações em mucosa nasosinusal à TC.

Estudos utilizando critérios, tanto do EP3OS (Hastan et al., 2011) quanto da RSTF (Rhinosinusitis Task Force) (Damm et al., 2002), demonstram que os sintomas apresentados nos pacientes com RSC, em ordem decrescente de prevalência são: obstrução, secreção, dor/pressão e alteração do olfato.

Apesar de os sintomas serem essenciais para diagnóstico e caracterização da gravidade da RSC; eles, isoladamente, estão associados à baixa sensibilidade diagnóstica. Lupa e DelGaudio (2012) demonstraram que, entre 125 pacientes com sintomas de RSC, 40\% não apresentavam evidência radiológica de doença à TC. Tomassen et al. (2011) observaram que $61,7 \%$ dos pacientes com sintomas de RSC apresentaram endoscopia positiva, e os sintomas tiveram associação significativa com alterações ao exame (OR 2,62; IC95\%: 1,57;4,39, $\mathrm{p}<0,001)$ (Tabela 1).

Tabela 1 - Comparação das modalidades para confirmação objetiva da inflamação nasossinusal

\begin{tabular}{lccccc}
\hline \multicolumn{1}{c}{ Modalidade } & Método & Custo & Desconforto & Risco & Sensibilidade \\
\hline Endoscopia Nasal & Visualização direta & Moderado & Mínimo a moderado & Mínimo & Boa \\
Rinoscopia Anterior & Visualização direta & Baixo & Mínimo & Mínimo & Baixa \\
Tomografia Computadorizada & Radiográfica & Alto & Mínimo & Exposição à radiação & Excelente \\
\hline
\end{tabular}

Fonte: (Rosenfeld et al., 2015). 
A rinoscopia anterior isolada é de valor limitado; no entanto, continua a ser o primeiro passo na avaliação de um paciente com sintomas nasossinusais. Já a endoscopia nasal proporciona visualização significativamente melhor em comparação à rinoscopia anterior para o exame do meato médio e superior, bem como das vias de drenagem da nasofaringe e mucociliar. Bhattacharyya e Lee (2010) confirmaram a utilidade adicional da endoscopia nasal no diagnóstico da RSC.

A TC é a modalidade radiológica de escolha para avaliar os seios paranasais, devido a distinção ideal entre o osso, ar e tecido mole. No entanto, não deve ser considerado o primeiro passo no diagnóstico, exceto quando há sinais e sintomas unilaterais ou indicativos de complicação. No geral, a TC é indicada quando associada à história e ao exame endoscópico após falha no tratamento clínico. Muito recentemente, foi dada atenção à exposição à radiação associada à TC, cujo uso aumentou 20 vezes nos últimos 30 anos (Brenner; Hall, 2007; Brenner, 2010). Devese notar que anormalidades incidentais são encontradas na varredura em até um quinto da população "saudável" (Fokkens et al., 2007). Assim, na ausência de sintomas, o diagnóstico de RSC baseado em radiologia, por si só, é inadequado.

\subsection{Tratamento clínico da RSC}

O objetivo do tratamento da RSC é alcançar e manter o controle clínico, que é definido como um estado de doença em que os pacientes não apresentam sintomas, ou os sintomas não são incômodos, se possível combinado com uma mucosa saudável, ou quase saudável, com a menor dose possível de medicação (Fokkens; Lund; Mullol, 2012).

\subsubsection{Corticosteroides na RSC}

O que se sabe até hoje é que a RSC é uma doença inflamatória com diferentes gatilhos; sendo assim, os corticosteroides são medicamentos considerados cruciais na atualidade, e sua aplicação pode ser tópica intranasal ou sistêmica. 
A eficácia clínica dos glicocorticoides tópicos ou sistêmicos depende, em parte, da sua capacidade de reduzir a infiltração e a viabilidade de eosinófilos nas vias aéreas (Mullol et al., 1995a; 1997a,b), além da redução indireta da secreção de citocinas pró-inflamatórias (Mullol et al., 1995b, 2000; Roca-Ferrer et al., 1997; Xaubet et al., 2001).

Em dois estudos recentes, um de revisão sistemática (25 estudos analisados) (Wei; Adappa; Cohen, 2013) e outro de metanálise (12 estudos) (Rudmik et al., 2012), chegou-se à conclusão que o uso de corticosteroides tópicos apresentam resultados positivos em pacientes com RSCcPN, mas não se observou o mesmo benefício em pacientes sem polipose. Outra metanálise (Lal; Hwang, 2011) mostrou que os resultados do uso do corticosteroide tópico na RSCsPN não são tão uniformes, com efeitos sobre os sintomas comparáveis ao placebo (Parikh et al., 2001; Lavigne et al., 2002; Lund et al., 2004; Furukido et al., 2005; Jorissen; Bachert, 2009), apesar de promover efeitos positivos sobre outros desfechos, tais como escores endoscópicos e aspecto radiológico. Em outra revisão sistemática, com 48 estudos, observou-se que o tratamento cirúrgico prévio é um fator de benefício para a efetividade dos corticosteroides tópicos, principalmente por auxiliar na distribuição do medicamento na mucosa nasossinusal (Snidvongs et al., 2013). Em uma revisão da Cochrane, os corticosteroides tópicos foram eficazes na melhora dos sintomas, na redução dos pólipos e da taxa de recorrência pós -cirúrgica; e os pacientes submetidos à cirurgia nasossinusal prévia responderam melhor a essa terapêutica (Kalish et al., 2012).

Estudos utilizando corticosteroide sistêmico para RSC são mais escassos e quase que exclusivos na RSCcPN. Uma revisão sistemática indicou que o uso desse tipo de droga, por curto período de tempo, leva à melhora dos sintomas (Poetker et al., 2013). No entanto, considerando a cronicidade da RSCcPN, os benefícios de curta duração com esta terapia precisam ser equilibrados com os potenciais efeitos colaterais em longo prazo (Fokkens; Lund; Mullol, 2012; Orlandi et al., 2016). Esses mesmos autores concluíram que não existem evidências que permitam a indicação ou contraindicação do seu uso de forma sistematizada para a RSCcPN. 


\subsubsection{Antibióticos na RSC}

O papel dos micróbios na RSC como agentes causadores ou colonizadores ainda não é claro. Entretanto, na prática, esse grupo de medicamentos segue constante dentro do arsenal de drogas utilizadas para esses pacientes (Dubin et al., 2007), possivelmente pela falta de alternativas terapêuticas ou de conhecimento do impacto de bactérias na fisiopatologia da RSC (Pandak et al., 2011).

Os estudos mais recentes não suportam o uso de antibióticos para a RSC. Meltzer e Hamilos (2011), em artigo de revisão, concluíram que não há publicações capazes de definir uma antibioticoterapia efetiva para o tratamento da RSC, e destacam que, enquanto não forem bem definidas as diferentes apresentações da doença, os tratamentos seguirão com limitações de resultados.

O uso de antibiótico sistêmico na RSC pode ocorrer, tanto para o tratamento de curto (inferior a quatro semanas) como de longo prazo (utilizado para efeitos antiinflamatórios sobrepostos aos de antibacterianos).

Existe a recomendação de uso de antibióticos em curto prazo na exacerbação da RSCsPN, com cultura positiva (Fokkens; Lund; Mullol, 2012). No entanto, não há ensaios controlados com placebo suficientes. $O$ antibiótico indicado é, geralmente, de amplo espectro para controlar os organismos aeróbicos e anaeróbios.

Quanto ao tratamento antibiótico em longo prazo, numerosos estudos demonstraram a eficácia dos macrolídeos na redução dos marcadores inflamatórios e no aumento dos batimentos ciliares, reduzindo a secreção nos seios paranasais. (Scadding et al., 1995; Ichimura et al., 1996; Suzuki et al., 1997). Porém, estudos maiores e controlados por placebo em uma população com RSC definida são necessários. Sendo assim, o uso de antibiótico em longo prazo fica reservado para pacientes nos quais os corticosteroides nasais e a irrigação salina não conseguiram reduzir os sintomas a um nível aceitável (Fokkens; Lund; Mullol, 2012). Os dados atuais sugerem que a eficácia dos macrolídeos é menor em pacientes com RSCcPN, com achados graves à TC, como asma, IgE elevada e pólipos com infiltração aumentada de eosinófilos (Wallwork et al., 2006; Haruna et al., 2009).

Os ensaios controlados com placebo mostraram apenas benefício mínimo dos antibióticos tópicos, adicionais ao placebo (Ponikau et al., 1999; Lim; Citardi; Leong, 
2008). Portanto, não houve evidência quanto ao uso de antibióticos tópicos na RSCCPN.

\subsection{Tratamento cirúrgico da RSC}

Apesar de não haver ensaios que forneçam evidências de maior nível, uma série de estudos prospectivos grandes e bem organizados mostrou que a ESS é segura e eficaz no controle de pacientes com RSCsPN, quando o tratamento médico falhou. A ESS tem maior eficácia no controle da obstrução nasal e da dor facial do que no gotejamento pós-nasal ou na hiposmia, e está associado à melhora significativa na QV nesses pacientes (Fokkens; Lund; Mullol, 2012).

A intervenção cirúrgica no tratamento de PN também é considerada em pacientes que não conseguem melhorar após tratamento clínico otimizado. Os consensos internacionais referentes a indicações para ESS citam, invariavelmente, falha da "terapia médica apropriada" (TMA) como pré-requisito; cirurgia sem teste prévio de tratamento médico clínico é incomum (Orlandi et al., 2016). Existem várias diretrizes com recomendações, e estas demonstram consistência no que diz respeito à inclusão de antibióticos orais, corticosteroides tópicos e uso seletivo de corticosteroides orais (Marple et al., 2009; Fokkens; Lund; Mullol, 2012). Uma revisão sistemática recente demonstrou que corticosteroides tópicos, antibióticos orais e corticosteroides orais foram usados em $91 \%, 88 \%$ e $62 \%$ de todos os protocolos de TMA por uma média de oito semanas, 23 dias e 18 dias, respectivamente (Dautremont; Rudmik, 2015).

Na RSCcPN, os objetivos cirúrgicos primários são de se estabelecer uma via aérea nasal patente e aliviar a obstrução do fluxo de saída dos seios; diminuir a carga inflamatória global e abrir os seios para administração tópica de fármacos no pós-operatório (Scadding et al., 2011; Chin; Harvey 2013; Orlandi et al., 2016). Há também evidências crescentes sustentando que o tratamento cirúrgico agressivo da RSCcPN pode levar à melhora mais acentuada sobre a intensidade da asma (van Drunen et al., 2009; DeMarcantonio; Han, 2011).

A técnica mais amplamente utilizada para o tratamento cirúrgico da RSC é a ESS e as discussões mais importantes ocorrem em torno da extensão da dissecção 
cirúrgica. As diretrizes atuais, baseadas fundamentalmente em estudos de série de casos e opinião de experts, indicam que o manejo cirúrgico deve ser individualizado. A tendência atual para a RSCcPN e RSCsPN é a dissecção cirúrgica, de acordo com a extensão da doença (Fokkens; Lund; Mullol, 2012), não havendo diferença no seguimento pós-operatório entre realizar sinusotomia frontal mais ampla (Draf 3 versus. sinusotomia mais localizada - Draf $2 \mathrm{~B}$ ) em pacientes com RSC refratária (Patel et al., 2018).

Cuidados pós-operatórios são importantes para aumentar o sucesso da cirurgia. Os cuidados iniciais envolvem retornos com intervalos curtos para curativos nasais. Rudmik et al. (2011) encontraram evidências de grau B sobre o efeito benéfico dos curativos pós-operatórios sobre a ESS, com melhora na aparência e redução de complicações, como sinéquias.

Considera-se muito importante continuar o tratamento clínico no pósoperatório em quase todas as formas de RSC. Atualmente, recomenda-se a lavagem salina nasal e os corticoides tópicos nasais após a ESS (Wei; Adappa; Cohen, 2013), com o intuito de evitar a alta tendência de recorrência, principalmente na RSCcPN.

Rudmik et al. (2011) revisaram seis estudos sobre os cuidados após a ESS e verificaram que a maioria deles demonstrou melhora nos escores de sintomas quando soluções salinas foram usadas no pós-operatório. Devido ao perfil de segurança favorável, baixo custo, a falta de risco de absorção farmacêutica sistêmica e a aceitação do paciente, o uso de solução salina no pós-operatório torna-se uma estratégia de terapia tópica atraente em médio e longo prazo.

A eficácia dos corticoides tópicos foi investigada em diferentes pesquisas, e quase todas mostraram redução dos sintomas em pacientes com RSCsPN (Baradaranfar et al., 2014); e os pacientes com RSCcPN apresentaram melhora significativa no tamanho dos pólipos e nos sintomas; e diminuição da recorrência dos pólipos no primeiro ano pós-cirurgia (Fandiño et al., 2013).

Uma metanálise que incluiu três artigos demonstrou que o uso profilático de antibióticos no período pós-operatório não esteve associado à redução estatisticamente significativa de infecção, escores endoscópicos e sintomas (Saleh et al., 2012) Em consenso recente, Orlandi et al. (2016) sugeriram que o uso de 
macrolídeos por mais de três semanas no pós-operatório de pacientes RSCsPN causa redução nos escores de endoscopia e alguns sintomas, particularmente em pacientes sem IgE elevada.

\subsubsection{Sucesso pós-cirurgia}

Estudos que avaliam, tanto os resultados objetivos quanto os subjetivos da ESS na RSC, independentemente da graduação dos pólipos, demonstram amplamente que a cirurgia proporciona melhora na QV (geral e específico da doença) e nos escores endoscópicos nos pacientes em que falhou a TMA (Smith et al., 2005, 2010) Além disso, os sintomas cardinais (DeConde et al., 2015) e a maioria dos sintomas classicamente atribuídos à RSC (Soler; Mace; Smith, 2008) melhoram substancialmente após a ESS (Rudmik et al., 2014).

Aproximadamente $15-20 \%$ dos pacientes com RSC operados respondem, de forma insatisfatória, à cirurgia sinusal, mesmo com terapia médica concomitante, e terminam por requerer procedimento cirúrgico secundário (Hopkins et al., 2009; Georgalas et al., 2014), sendo que esta taxa pode aumentar até $50 \%$ nos casos de RSCcPN em seguimento por até cinco anos (Mendelsohn et al.; 2011; Wu et al. 2014; DeConde et al., 2017). A lateralização da concha média, as sinéquias e a formação de cicatrizes no meato médio e a ressecção incompleta do processo uncinado ou das células etmoidais são achados frequentes em pacientes submetidos à cirurgia revisional (Ramadan, 1999).

Recentes avaliações mostram que, diante de alto grau de inflamação de mucosa, os desfechos cirúrgicos são piores (Mendelsohn et al., 2011; Bassiouni; Naidoo; Wormald, 2012). Ainda, pacientes com maior processo inflamatório podem apresentar melhores resultados com cirurgia mais radical e extensa, como a megaantrostomia maxilar endoscópica e o Draf 3 (Cho; Hwang, 2008; Lee; Chiu, 2010). Felizmente, aprimoramentos tecnológicos permitem que essas técnicas mais radicais possam ser realizadas com segurança por via endonasal endoscópica, em pacientes com RSC recalcitrante a tratamento medicamentoso e à cirurgia endoscópica tradicional. 
As taxas de complicações maiores (complicações orbitárias ou intracranianas, sangramento que necessitou ligação arterial ou descompressão orbitária e retorno à sala de cirurgia) e menores (qualquer outro efeito adverso) foram descritos em alguns estudos, respectivamente, como: 0,85\% e 6,9\% (May et al., 1994); e 0,4\% e 6,6\% (Hopkins et al., 2006); 1,2 e 15,3\% (Velosoteles; Cerejeira, 2017). Os fatores descritos associados a maior risco de complicação são: idade, cirurgia de revisão, pólipos e variações anatômicas. As taxas de complicações graves na cirurgia revisional são maiores quando comparadas à cirurgia inicial, saltando de aproximadamente 1 para 7\% (Chu; Lebowitz; Jacobs, 1997; Bhattacharyya, 2004). 
3. Justificativa 
A RSC é uma doença de alta prevalência, que interfere consideravelmente na QV e tem alto custo socioeconômico. Na literatura, muito se tem publicado em relação à fisiopatologia e ao tratamento desta doença. No entanto, são poucos os estudos que realizaram seguimento clínico desses pacientes por longo período, e avaliado quais fatores poderiam influenciar no sucesso terapêutico. A justificativa para o desenvolvimento deste estudo é tentar identificar fatores preditivos ao seguimento e prognóstico dos pacientes com RSCcPN ou RSCsPN. 
4. Objetivos 
O objetivo principal deste estudo foi analisar o seguimento de pacientes submetidos à EES por RSCcPN ou RSCsPN, entre 1 de janeiro de 1996 e 31 de dezembro de 2006, no HCFMRP-USP, e relacionar o insucesso do tratamento com os critérios clínicos como extensão da doença, atopia, tabagismo, asma, eosinofilia e DREA. 
5. Casuística e Métodos 


\subsection{Aspectos éticos}

O projeto foi aprovado no Comitê de Ética e Pesquisa do Hospital das Clínicas da Faculdade de Medicina de Ribeirão Preto da Universidade de São Paulo (HCFMRP-USP) no CAAE 13091313.7.0000.5440 (Anexo).

\subsection{Sujeitos}

Foram pesquisados no sistema pacientes submetidos à ESS entre 1 de janeiro de 1996 e 31 de dezembro de 2006 no HCFRMP-USP. Esse período foi escolhido, pois a primeira ESS foi realizada nesse hospital em 1995.

\subsubsection{Critérios de inclusão e exclusão}

Foram encontrados 542 prontuários de pacientes submetidos à ESS nesse período. Aqueles submetidos à cirurgia por outras causas, que não por RSC, foram excluídos, entre elas:

- Complicações de procedimentos dentários;

- Complicações de RSA;

- Dacriocistorinostomias;

- Descompressão orbitária;

- Descompressão do nervo óptico;

- Correção de fístulas nasoliquóricas;

- Controle de epistaxe;

- Remoção de corpo estranho;

- Fibrose cística;

- Imunodeficiências;

- Doenças mucociliares congênitas (por exemplo, discinesia ciliar primária - DCP).

- RSF invasiva ou não invasiva (BF, RSFA ou RSME);

- Abuso de cocaína;

- Doenças granulomatosas e vasculites sistêmicas; 
- Disfunções tubárias;

- Mucoceles;

- Cistos de retenção;

- Pólipo antrocoanal;

- Neoplasias nasossinusais de qualquer natureza (benigna ou maligna).

Pela análise dos prontuários foram excluídos, nessa fase, 96 pacientes por terem sido operados por outras causas que não RSC, restando então 446 pacientes.

Para o paciente com RSC, a cirurgia adotada foi a ESS, e a sua extensão em relação aos seios da face foi realizada de acordo com a extensão da doença, fosse a observada em endoscopia nasal durante o procedimento, ou anteriormente, pela avaliação tomográfica. Dos 446 pacientes submetidos à ESS por RSC, foram selecionados apenas aqueles cujos prontuários possuissem os dados completos, e seguimento mínimo por cinco anos. Os pacientes foram avaliados em retornos de rotina, ou chamados por carta ou telefonema para reavaliação. Nessa fase, outros 104 pacientes não foram avaliados por não terem condições clínicas para comparecer ao ambulatório, ou por óbito; restando, então, 342 possíveis candidatos para a pesquisa (Figura 1). 
Figura 1 - Fluxograma dos critérios de inclusão e exclusão adotados na presente pesquisa

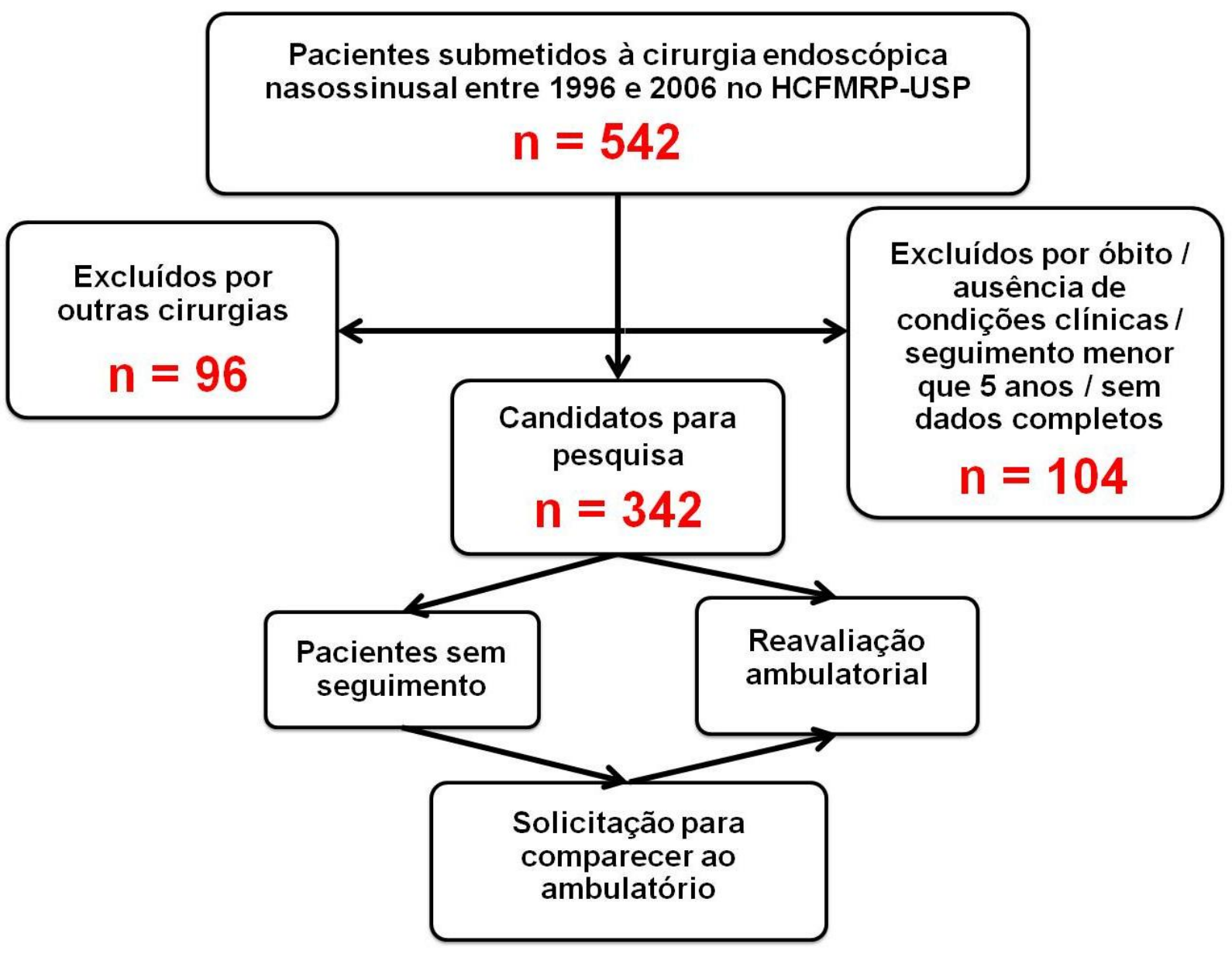

\subsubsection{Coleta dos dados e subdivisão em grupos}

Foram coletados os seguintes dados dos pacientes que compareceram para reavaliação ambulatorial:

- Queixas nasossinusais, incluindo obstrução nasal, sintomas irritativos nasais e alteração do olfato (hiposmia ou anosmia);

- Exame físico: rinoscopia anterior;

- Endoscopia nasal: presença ou não de pólipos, e sua extensão na cavidade nasal pela classificação de Lund e Kennedy (1995), sendo: grau 0 (ausência de pólipos); grau 1 (pólipos somente no meato médio); grau 2 (pólipos saindo do meato médio, mas não obstruindo 
completamente a fossa nasal); e grau 3 (pólipos obstruindo completamente a fossa nasal);

- Presença ou não de asma, e sua gravidade por critérios clínicos; dados da prova de função pulmonar (PFP) como: (volume expiratório forçado) FEV1/CVF (capacidade vital forçada), FEV1 predito e CVF predito;

- Presença ou não de tabagismo;

- Presença ou não de intolerância a medicamentos, com foco para o AAS e AINEs;

- Prick test: Foram avaliados 19 tipos de alérgenos respiratórios de sete classes diferentes, sendo: ácaros ( $D$ pterynyssimus, $D$ farinae, $B$ tropicalis), baratas ( $B$ germânica, $P$ americana), pêlos de gatos e de cachorros, fungos (Alternaria sp, Cladosporium sp, Helminthosporium sp, Aspergilus mix, Penicilium sp, fungos mix 2, Fusarium sp, Trichophyton $\mathrm{sp}$, Candida sp), gramíneas (grama batatais e mistura gramas) e pólens (mistura árvores) (Figura 2). Os extratos eram da empresa Hollister-Stier Laboratories, tendo sido testado também um controle positivo e um negativo. Os pacientes foram orientados a suspender o uso de antihistamínicos por pelo menos sete dias antes de realizar o teste. Testes em que se identificou negatividade no controle positivo não foram considerados e foram repetidos posteriormente. 
Figura 2 - Prick test realizado em paciente da pesquisa no HCFMRP-USP, demonstrando positividade para $D$ pterynyssimus, $D$ farinae e pêlo de gato, com pápulas representativas, maiores do que as observadas no controle positivo

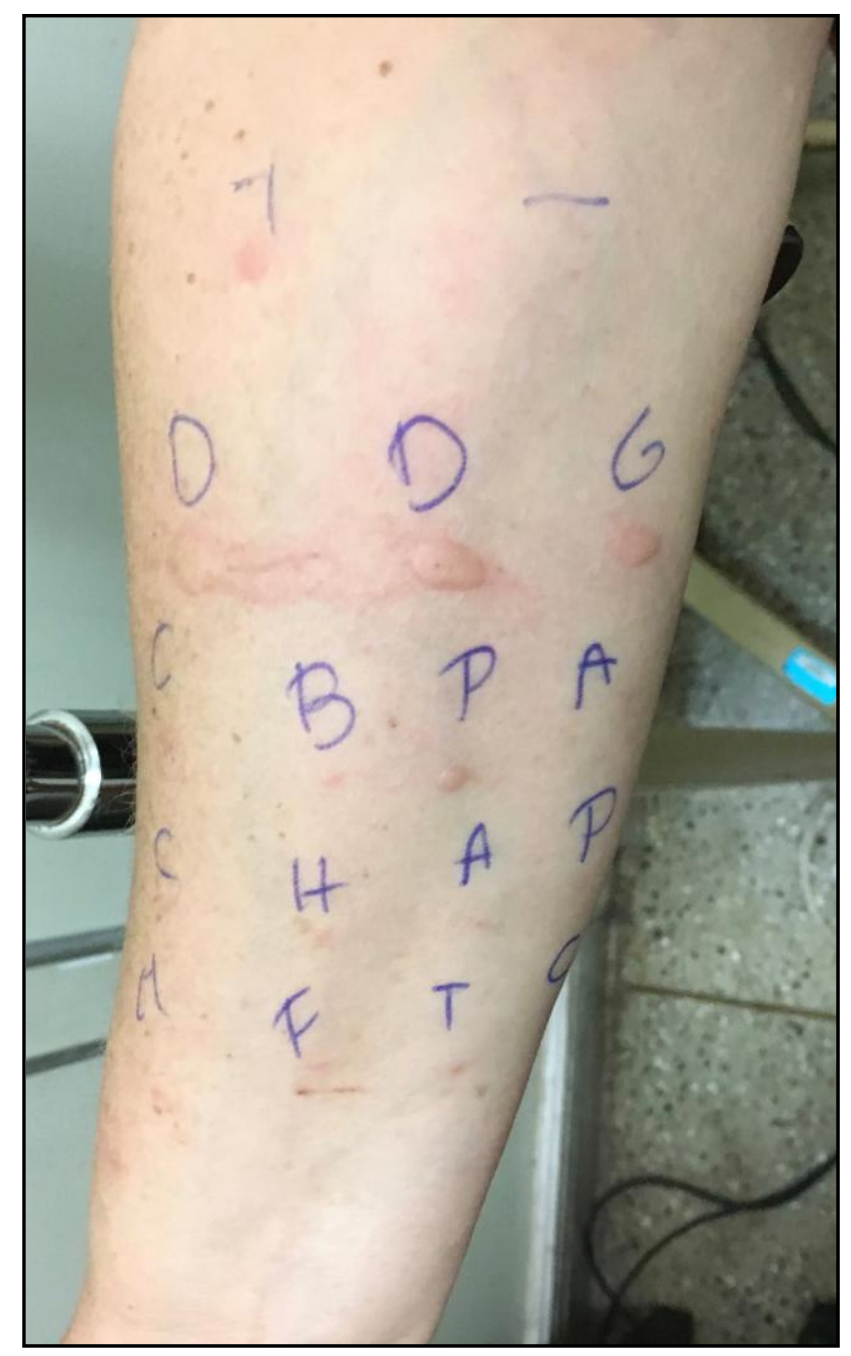

- Hemograma (incluindo contagem de glóbulos brancos e eosinófilos): Níveis de eosinófilos maiores que $500 / \mu \mathrm{L}$ de sangue foram considerados como eosinofilia periférica positiva.

- TC de seios da face: Como os pacientes foram operados num período em que não havia sistema informatizado para arquivo de imagens no HCFMRP-USP, foi encontrado um número alto TCs cujas imagens são estavam digitalizadas. Assim, a extensão da doença nos seios paranasais foi estadiada a partir do laudo do exame. A TC escolhida foi a realizada o 
mais próximo antes da primeira cirurgia. Em cada seio paranasal de cada lado foi atribuído um valor: $0=$ não acometido, ou 1= acometido; como foram avaliados cinco seios (maxilar, etmoide anterior, etmoide posterior, esfenoide e frontal), 0 valor final foi de 0 a 10 para cada paciente. Importante reforçar que os laudos de TCs no HCFMRP-USP são descritos com detalhes e que foram incluídos pacientes somente se eles tivessem realizado os exames no referido hospital, e os laudos dos seus exames estivessem anexados no prontuário.

Baseados nos dados coletados, os pacientes foram divididos em dois grupos: pacientes com RSCsPN e RSCcPN; e estes ainda foram subdivididos em com e sem asma, dependendo da análise a ser realizada (Figura 3).

Figura 3 - Dados coletados e divisão dos pacientes em grupos

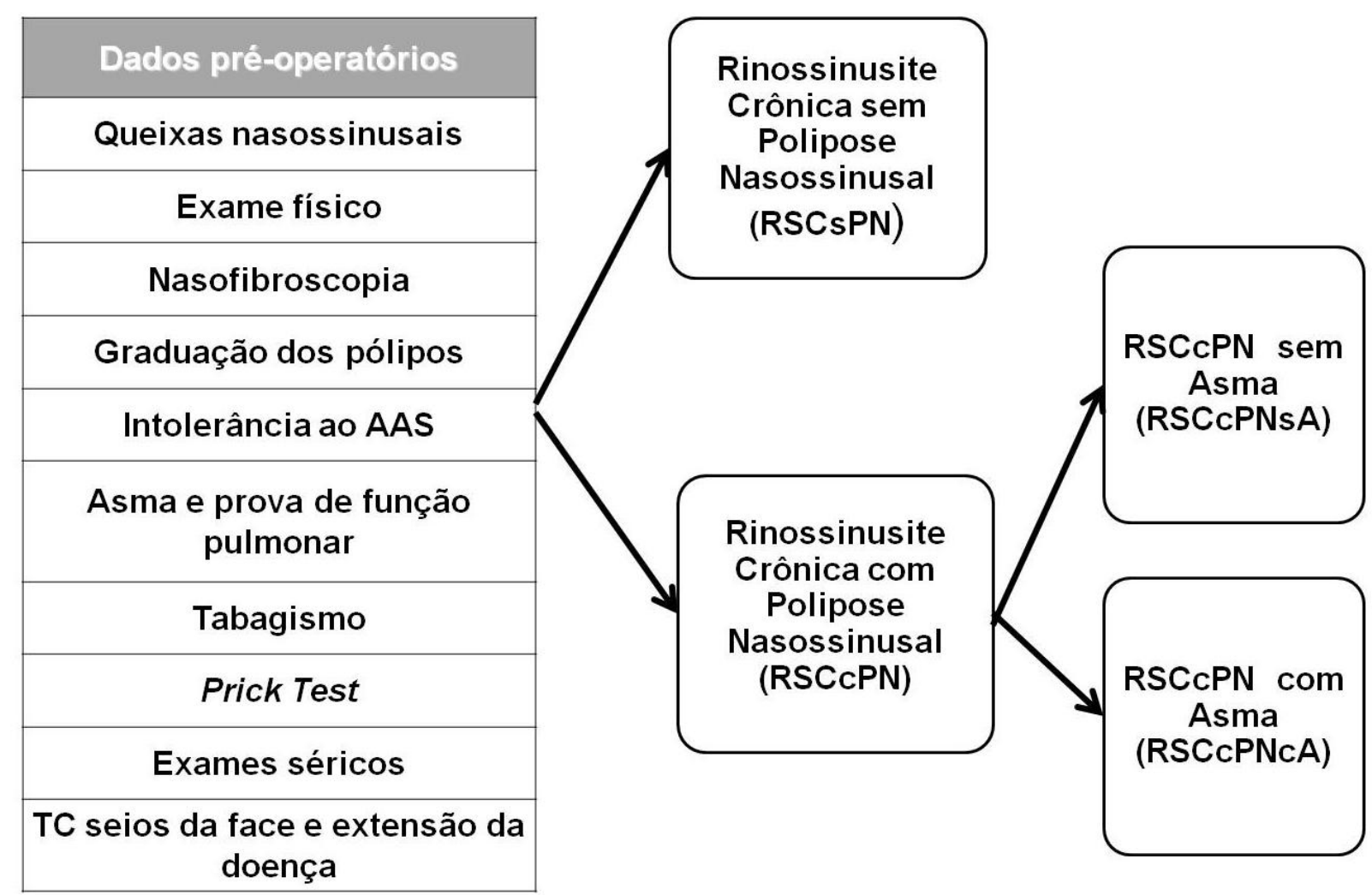


Por fim, o seguimento dos pacientes foi comparado entre: 1) pacientes com RSCsPN e RSCcPN; 2) atópicos e não atópicos; 3) tabagistas e não tabagistas; 4) asmáticos e não asmáticos; 5) pacientes com e sem eosinofilia periférica; 6) pacientes DREA ou não DREA. Como o seguimento já é sabidamente diferente entre as doenças RSCcPN e RSCsPN, essas variáveis foram também consideradas, e cada parâmetro acima avaliado foi considerado em cada um dos subgrupos: RSCsPN e RSCcPN.

\subsubsection{Evento negativo}

Os pacientes seguidos por esse período foram alocados em dois grupos distintos: grupo 1, em que houve sucesso no tratamento cirúrgico, e o paciente se apresentava assintomático e as alterações à endoscopia não justificavam novo procedimento; grupo 2, em que houve retorno dos sintomas e sinais, mesmo após tratamento clínico otimizado no pós-operatório, justificando a indicação de nova intervenção cirúrgica. Esse foi considerado o evento negativo para a análise. Caso o paciente fosse submetido a uma nova cirurgia por uma razão que não a recidiva da RSC, como as complicações inerentes ao procedimento (complicações maiores e menores), este evento não foi considerado no protocolo (Figura 4). Como exemplos:

- Fístulas liquóricas

- Fístulas oro-antrais

- Sinéquias extensas

- Sangramentos

- Complicações orbitárias

- Estenose do seio maxilar 
Figura 4 - Protocolo de seguimento no Ambulatório de Rinossinusologia do HCFMRP-USP, e critérios para avaliação, considerando-se o evento negativo

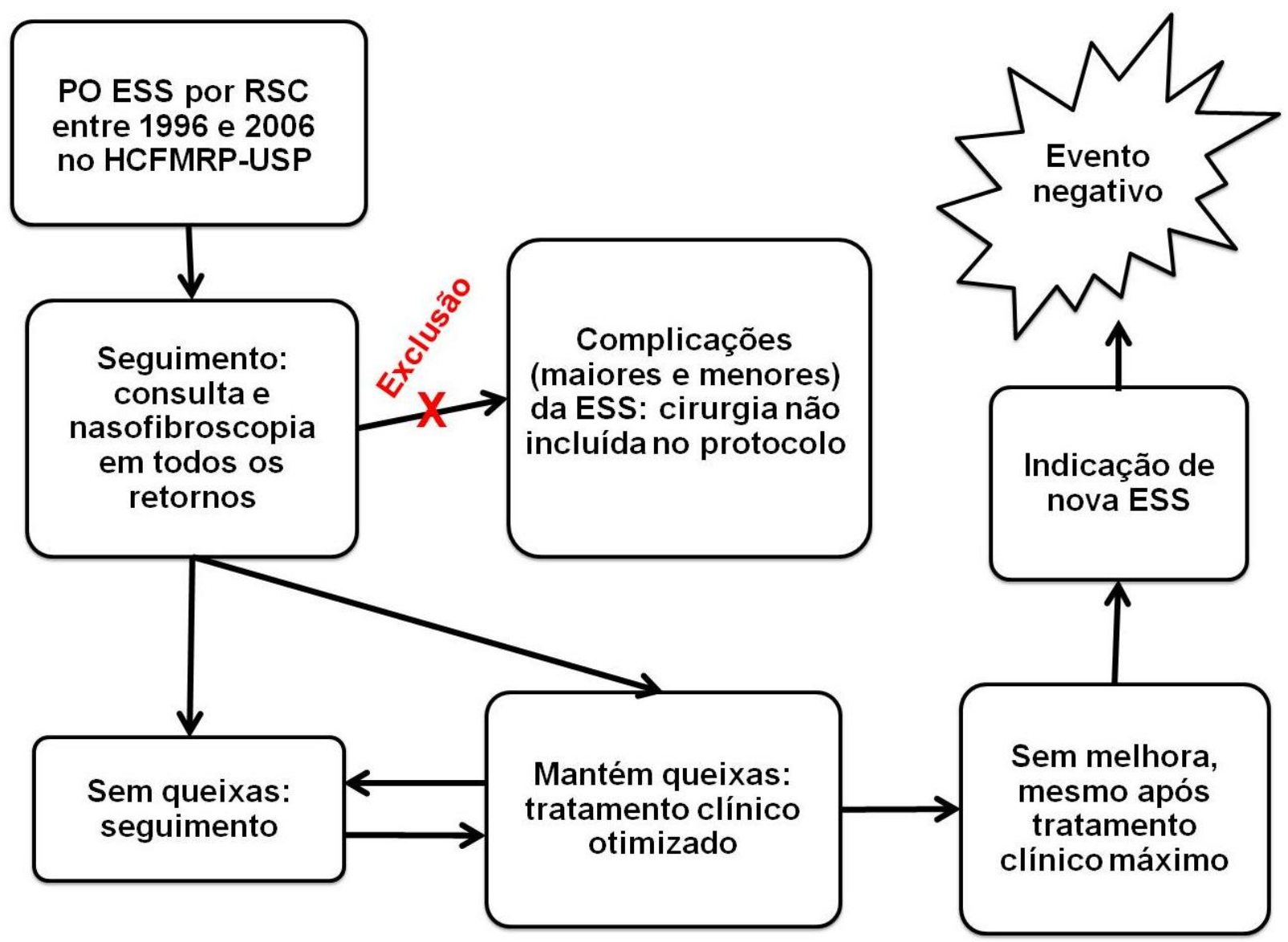

\subsection{Análise estatística}

Para a comparação entre os grupos, foram realizados testes não paramétricos de Mann-Whitney para variáveis numéricas, considerando-se os parâmetros sem distribuição normal dentro de cada subgrupo. A análise de contingência foi utilizada para o estudo de proporções entre os grupos. Curvas de Kaplan Meyer, com pós-teste de Log-Rank, foram usadas para os testes de recorrência, sendo considerado para nova indicação cirúrgica o momento em que ocorreu o evento negativo. Em todos os testes, foi considerado significativo quando $p<0,05$. 
6. Resultados 
Foram coletados dados de 201 pacientes operados por RSC, cujos prontuários continham informações completas, e que retornaram para reavaliação: 81 com RSCsPN, sendo $67 \mathrm{sem}$ asma (grupo RSCsPNsA) e 14 com asma (grupo RSCsPNcA); e 120 com RSCcPN, sendo 67 sem asma (grupo RSCcPNsA) e 53 com asma (grupo RSCcPNcA). Cada paciente foi seguido por um período médio de $12 \pm 3,5$ anos, desde quando foi submetido à primeira ESS até o último retorno, sendo que o menor seguimento foi de 5,6 anos e o maior de 21,2 anos. Os dados demográficos e sintomas predominantes estão apresentados na Tabela 2.

Tabela 2 - Dados demográficos dos pacientes analisados no presente estudo

\begin{tabular}{|c|c|c|c|c|c|}
\hline \multirow[t]{2}{*}{ Parâmetros } & $\begin{array}{l}\text { RSCsPN } \\
\text { sem asma }\end{array}$ & $\begin{array}{l}\text { RSCsPN } \\
\text { com asma }\end{array}$ & $\begin{array}{l}\text { RSCcPN } \\
\text { sem asma }\end{array}$ & $\begin{array}{l}\text { RSCcPN } \\
\text { com asma }\end{array}$ & Total \\
\hline & $(n=67)$ & $(n=14)$ & $(\mathrm{n}=67)$ & $(n=53)$ & $(n=201)$ \\
\hline$\overline{\text { Idade média }( \pm \mathrm{DP})}$ & $39 \pm 15$ anos & $30 \pm 19$ anos & $42 \pm 14$ anos & $45 \pm 15$ anos & $41 \pm 15$ anos \\
\hline Distribuição (gênero) & $23 \mathrm{M} / 44 \mathrm{~F}$ & $1 \mathrm{M} / 13 \mathrm{~F}$ & $38 \mathrm{M} / 29 \mathrm{~F}$ & $22 \mathrm{M} / 31 \mathrm{~F}$ & $84 \mathrm{M} / 117 \mathrm{~F}$ \\
\hline Seguimento (anos) & $11,3 \pm 3,5$ & $11,6 \pm 3,3$ & $12,4 \pm 3,7$ & $12,1 \pm 3,3$ & $12 \pm 3,5$ \\
\hline \multicolumn{6}{|l|}{$\begin{array}{c}\text { Queixas } \\
\text { (\% pacientes) }\end{array}$} \\
\hline Hiposmia & $30 \%$ & $30 \%$ & $32 \%$ & $70 \%$ & $41 \%$ \\
\hline anosmia & $3 \%$ & $7 \%$ & $19 \%$ & $13 \%$ & $11 \%$ \\
\hline Obstrução nasal & $97 \%$ & $92 \%$ & $100 \%$ & $92 \%$ & $98 \%$ \\
\hline Sintomas irritativos & $78 \%$ & $78 \%$ & $76 \%$ & $83 \%$ & $79 \%$ \\
\hline
\end{tabular}

M: Masculino; F: Feminino

Dos pacientes com RSCsPN, 88\% estavam assintomáticos no último retorno; dos 67 com RSCcPNsA, 54 (80\%) não relataram queixas nasossinusais e 48 (72\%) não apresentavam $P N$ à endoscopia nasal na última consulta. Dos 53 pacientes com RSCcPNcA, 36 (68\%) não referiram queixas nasossinusais e 29 (54\%) não apresentaram qualquer grau de polipose à endoscopia nasal. 


\subsection{Número de cirurgias}

A média de cirurgia dos pacientes seguidos nesse período foi de $1,09 \pm 0,28$ no

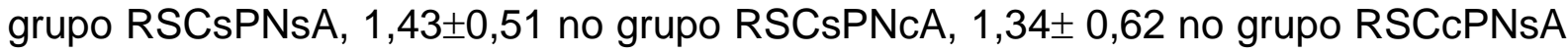
e 1,94 $\pm 0,93$ no grupo RSCcPNcA. No geral, $32 \%$ necessitaram de pelo menos mais uma intervenção cirúrgica ao longo do seguimento (Figura 5).

Figura 5 - Distribuição dos pacientes em cada grupo, de acordo com o número de cirurgias realizado, para cada um dos grupos $\mathrm{RSC}$

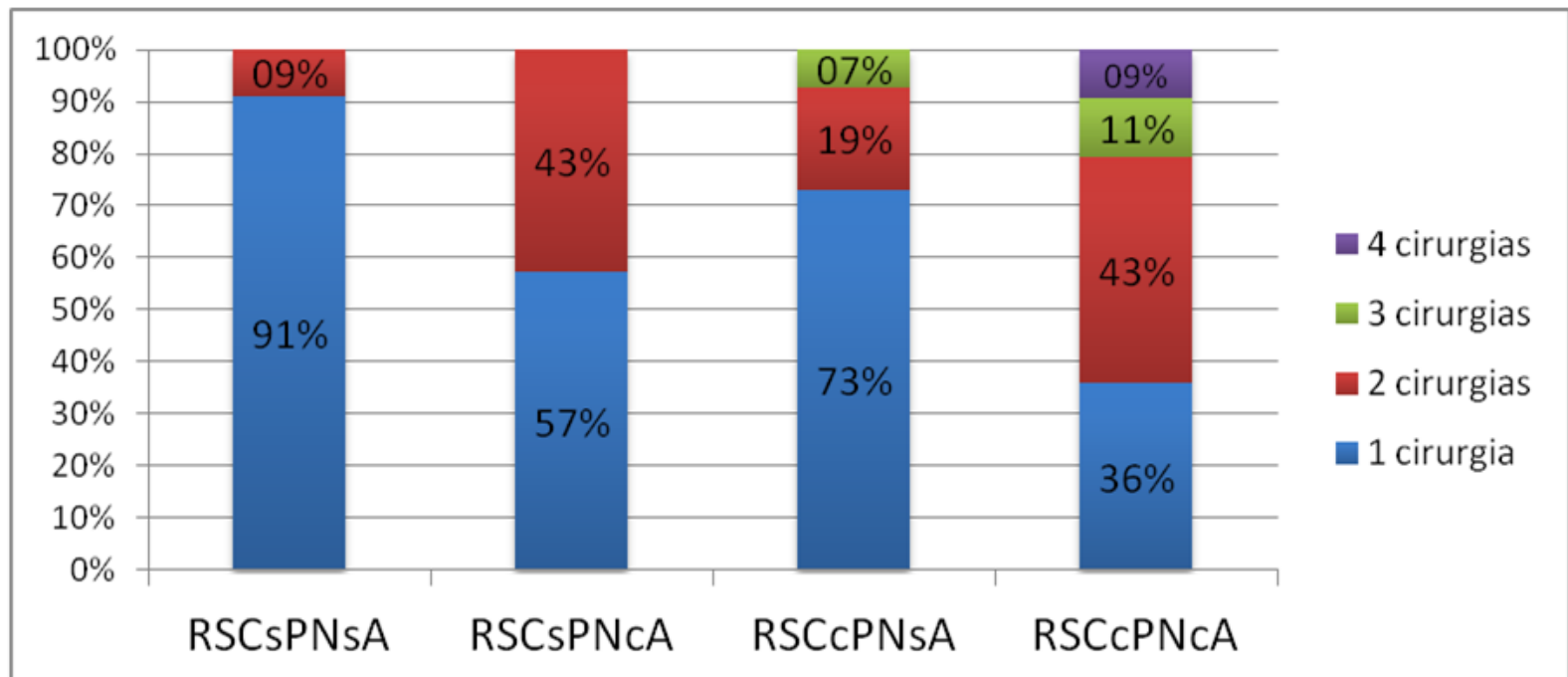

RSCsPNsA: Rinossinusite crônica sem polipose nasossinusal sem asma; RSCsPNcA: Rinossinusite crônica sem polipose nasossinusal com asma; RSCcPNsA: rinossinusite cronica com polipose nasossinusal sem asma; RSCcPNcA: rinossinusite crônica com polipose nasossinusal com asma.

Observou-se que os pacientes com RSCcPNcA foram submetidos a um número estatisticamente maior de cirurgias do que aqueles com RSCsPN (com e sem asma) ou RSCcPNsA ( $p<0,0001$ ), quando aplicado o teste ANOVA (Figura 6). 
Figura 6 - Diferença no número de cirurgias entre os grupos RSCsPN, RSCcPNsA e RSCcPNcA. Comparação entre os grupos pelo teste não paramétrico de Kruskal-Wallis

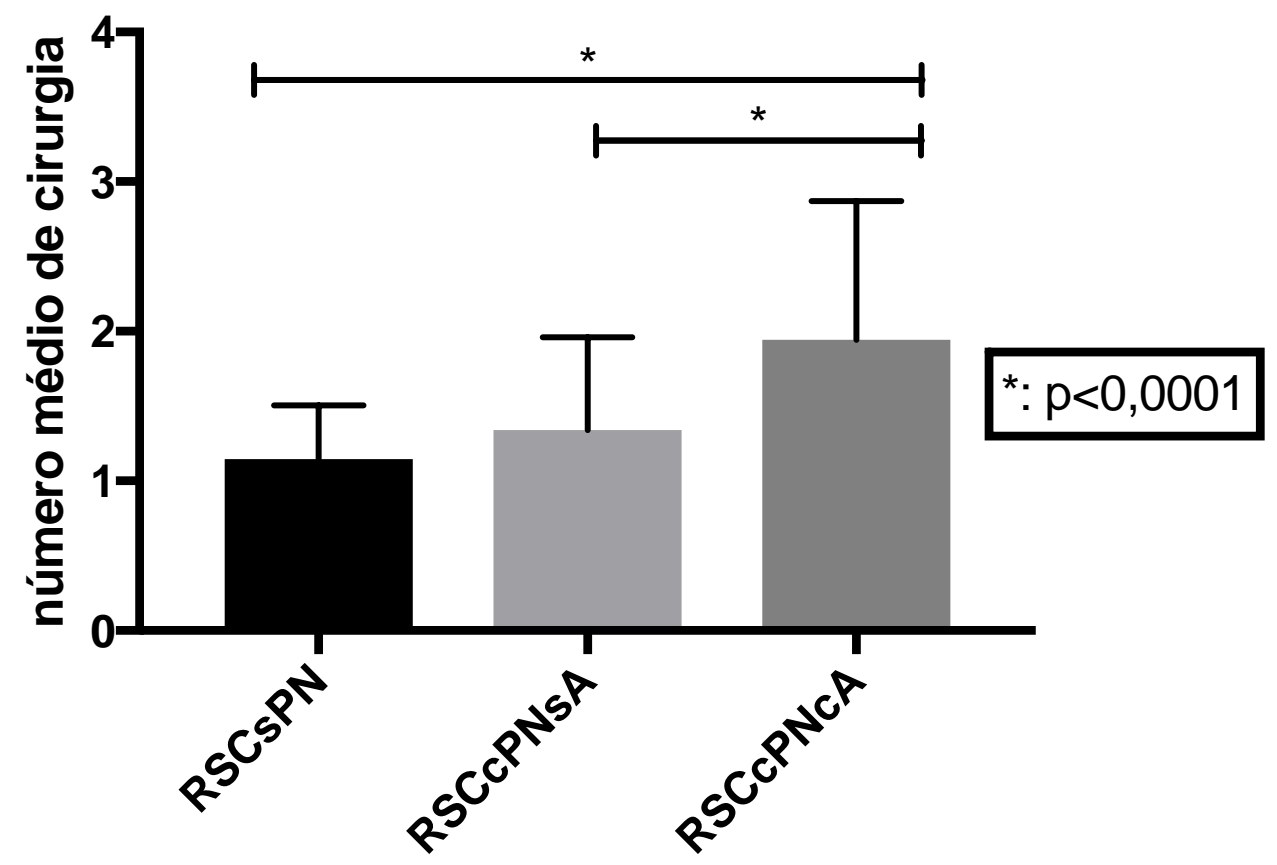

O intervalo entre a primeira e a segunda cirurgia foi semelhante no grupo de pacientes com PNs, submetidos à duas cirurgias, sendo 6,2 anos nos sem asma $(n=13)$ e 6,8 naqueles com asma $(n=23)$. O mesmo ocorreu nos pacientes RSCsPN: o tempo médio entre a primeira e a segunda cirurgia para RSCsPNsA foi de 4,7 anos $(n=6)$ e para RSCsPNcA foi de 4,6 anos $(n=6)$. O tempo entre a segunda e a terceira cirurgia no grupo RSCcPNsA foi de seis anos $(n=5)$, enquanto que no grupo RSCcPNcA foi de 4,5 anos ( $n=6)$; e apenas este último grupo necessitou de uma quarta cirurgia, sendo que o intervalo entre a terceira e quarta cirurgia foi de 4,9 anos $(n=5)$ (Figura 7). A média final de tempo entre a primeira e a segunda cirurgia nos RSCcPN foi de 6,6 anos, e nos RSCsPN foi de 4,7 anos. 
Figura 7 - Diferença de tempo (em anos) entre as cirurgias, entre os diferentes grupos

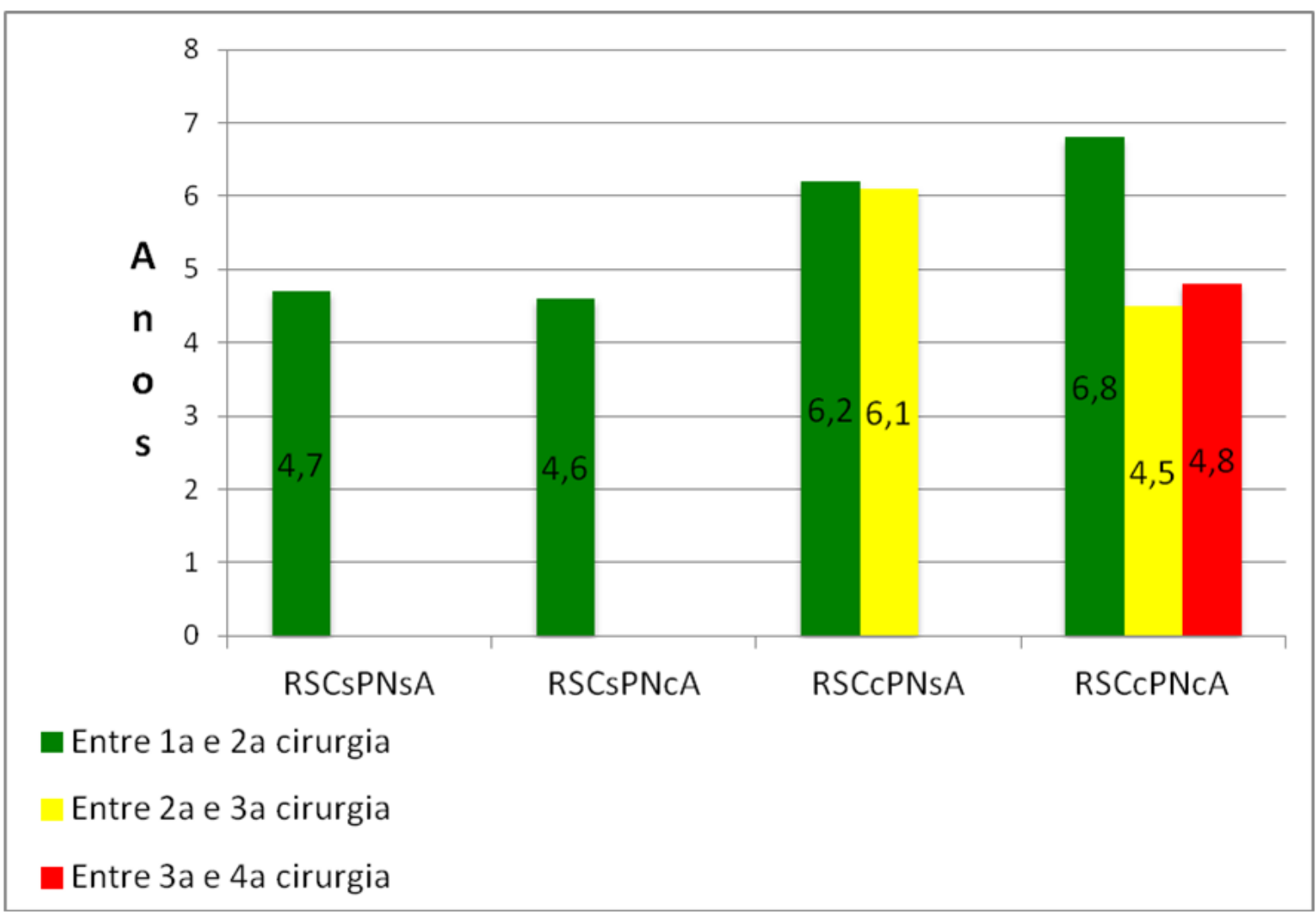

Ao se comparar a chance de recidiva cirúrgica ao longo do tempo de seguimento entre os pacientes RSCcPN versus RSCsPN, verificou-se diferença estatística entre os grupos ( $p<0,0005)$, sendo que pacientes com RSCcPN obtiveram OR de 3,03 para chance de recorrência (Figura 8). 
Figura 8 - Recidiva cirúrgica entre os RSCsPN x RSCcPN. Análise por meio da curva de Kaplan Meyer, com pós-teste de Log-rank

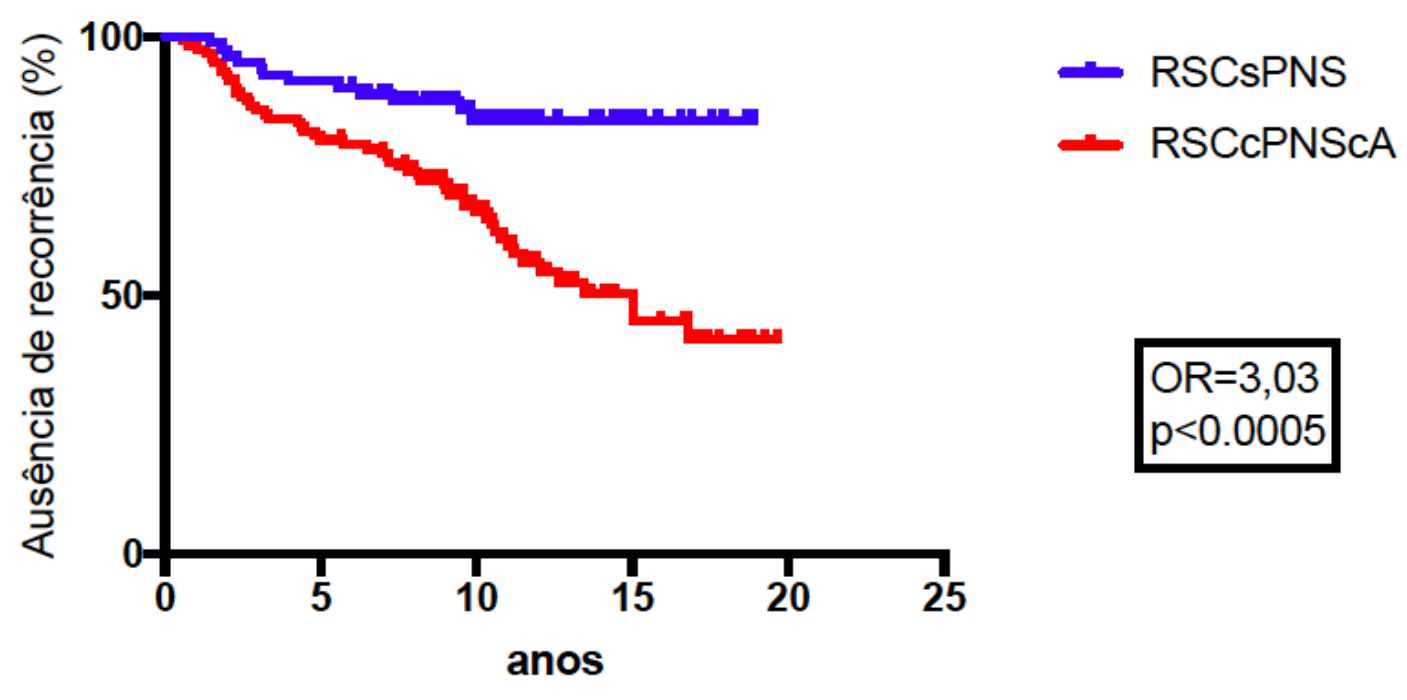

Uma vez identificada essa diferença altamente significativa, decidiu-se realizar as futuras análises considerando cada grupo em separado.

\subsection{Extensão tomográfica e endoscópica da doença}

O tempo médio entre a realização da TC e a primeira cirurgia foi seis meses e quinze dias. Em $71 \%$ dos pacientes RSCcPNcA, todos os seios da face estavam acometidos antes da primeira cirurgia; este valor foi de 50\% nos RSCcPNsA, e de apenas $4 \%$ nos RSCsPN. Em relação à extensão da doença no nariz e nos seios paranasais, o número de seios acometidos, visualizados na $\mathrm{TC}$, em pacientes com RSCsPN, não foi diferente entre aqueles sem e com recidiva (respectivamente $5,3 \pm 0,2$ versus. $4,1 \pm 1,1 ; p=0,3$; IC95\%: $-3,86 ; 1,30$ ) (Figura 9). 
Figura 9 - Diferença entre pacientes RSCsPN com e sem recidiva, de acordo com o número de seios acometidos à TC. Comparação entre os grupos pelo teste não paramétrico de Kruskal-Wallis

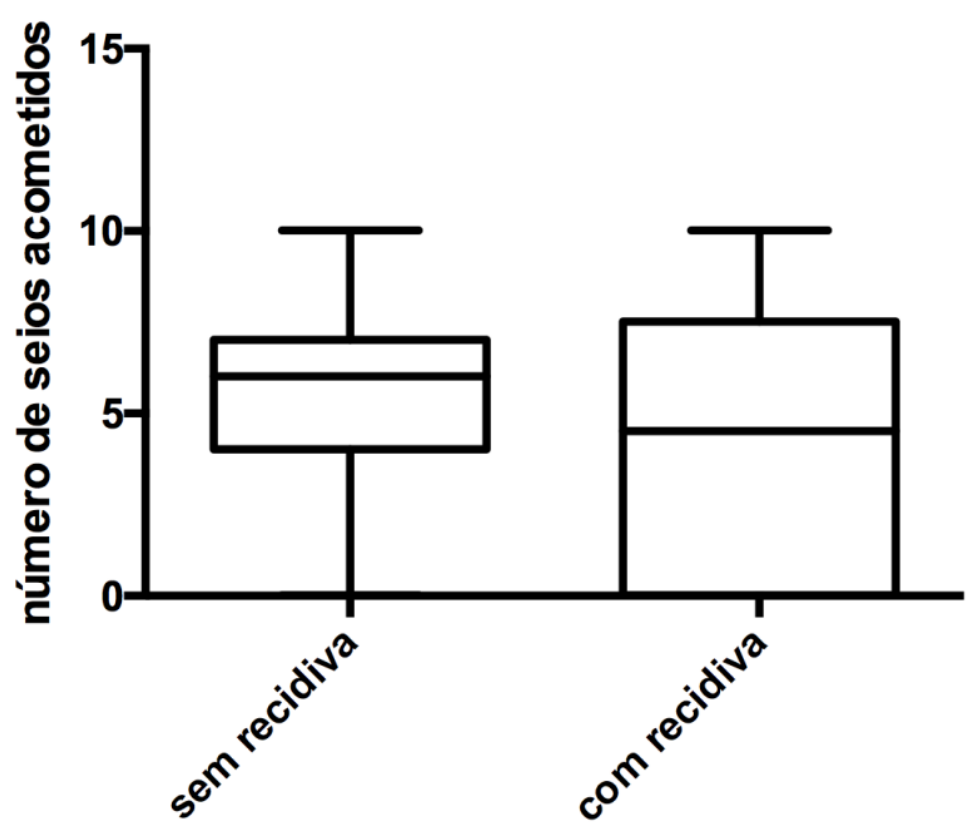

A endoscopia nasal identificou, na primeira cirurgia, distribuição semelhante de classificação dos pólipos nos pacientes RSCcPN asmáticos (28\% grau 1; 28\% grau 2 e 44\% grau 3) e os não asmáticos (22\% grau 1, 20\% grau 2 e 58\% grau 3). Entre os pacientes com RSCcPN, houve tendência à diferença de graduação dos PNs encontrados na endoscopia durante a primeira cirurgia entre os pacientes que depois apresentaram ou não recorrência (respectivamente, $2,4 \pm 0,1$ versus. $2,1 \pm 0,1$; $p=0,053 ;$ IC95\%: -0,004;0,59). Houve, ainda, diferença significativa entre os grupos quanto à extensão da doença à TC antes da primeira cirurgia (respectivamente, $6,8 \pm 0,5$ versus. $8,5 \pm 0,4 ; p=0,015 ;$ IC95\%: 0,32;3,00) (Figura 10). 
Figura 10 - Diferença da extensão dos pólipos nos pacientes sem e com recidiva cirúrgica, por meio de endoscopia ou tomografia computadorizada
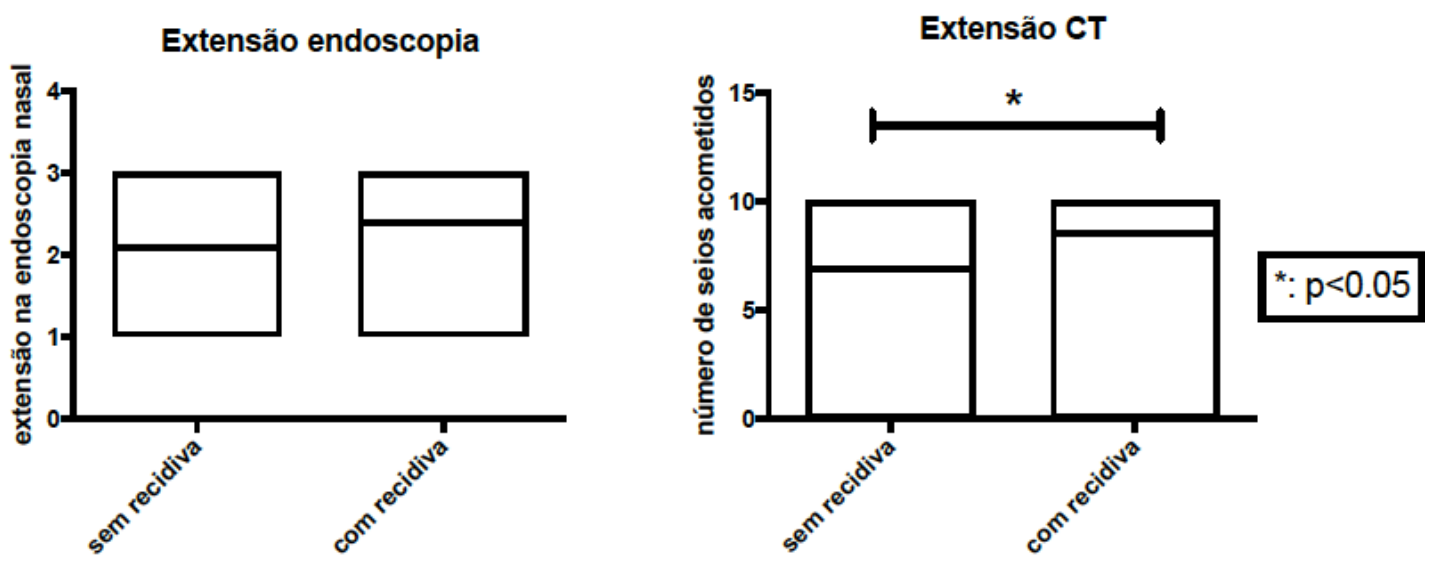

\subsection{Atopia}

Quanto ao prick test, os grupos apresentaram resultados semelhantes de prevalência, estando presente em 63\% do grupo RSCsPN (60\% sem asma e 70\% com asma) e $62,5 \%$ do grupo com RSCcPN (57\% sem asma e 70\% com asma). Nos pacientes atópicos, a sensibilidade a múltiplos alérgenos esteve presente, respectivamente, em 33\% no grupo RSCsPN, 24\% do grupo RSCcPNsA e $40 \%$ no grupo RSCcPNcA (Figura 11). 
Figura 11 - Distribuição das porcentagens de positividade a um alérgeno ou múltiplos alérgenos, de acordo com o grupo

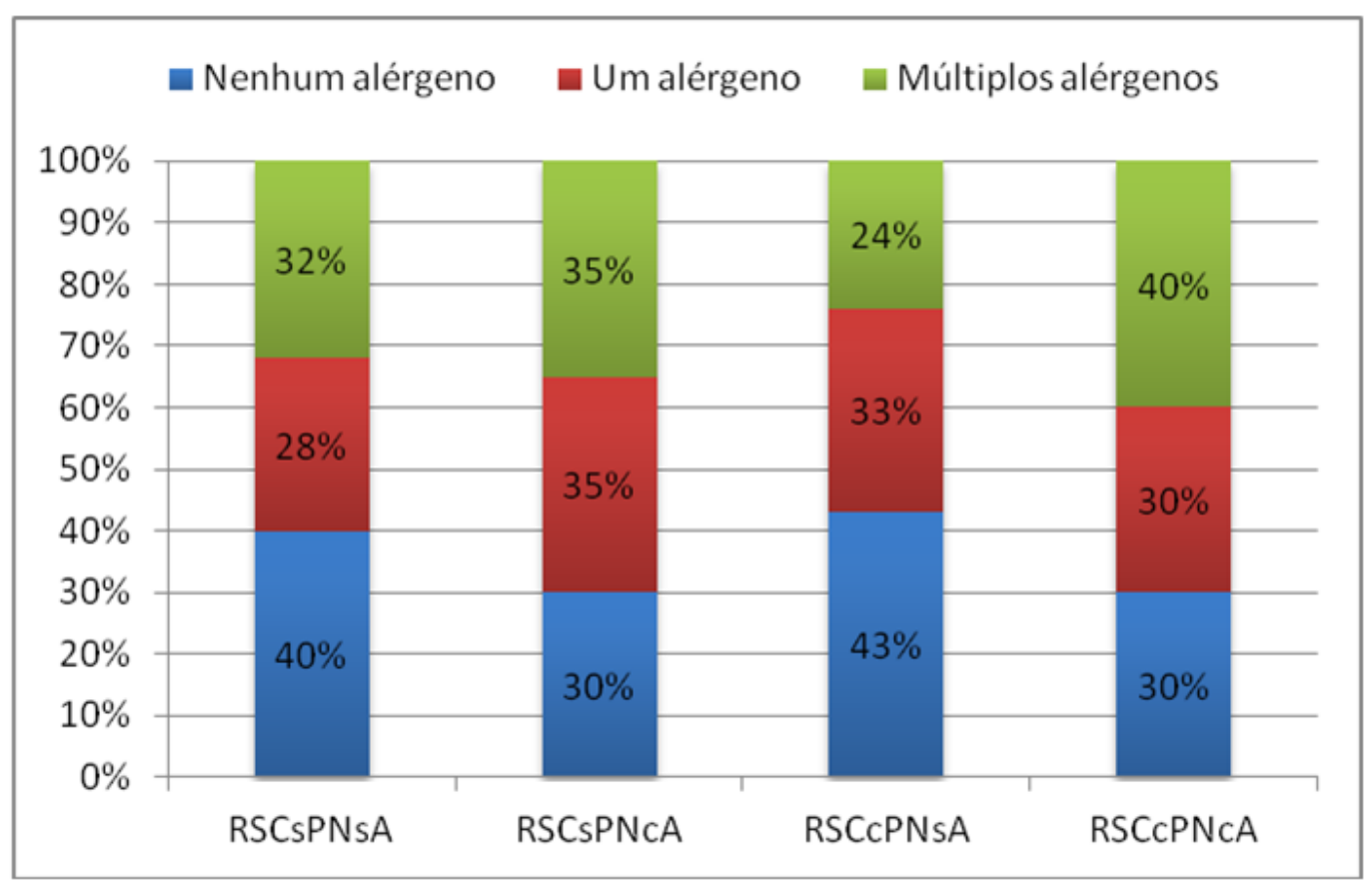

Em todos os grupos, as classes de alérgenos mais comumente detectadas foram as de ácaros (D. pteronyssimus, $D$. farinae e $B$. tropicalis), seguidos pelas baratas (B. germânica e $P$. americana) e pelos fungos. Abaixo está a distribuição de positividade do prick test por classes (Figura 12). Um dado interessante foi que o grupo de pacientes RSCcPNcA apresentou prick test positivo significativamente maior para fungos do que os outros grupos $(p<0,01)$. 
Figura 12 - Percentagem de positividade de alérgenos, em cada grupo

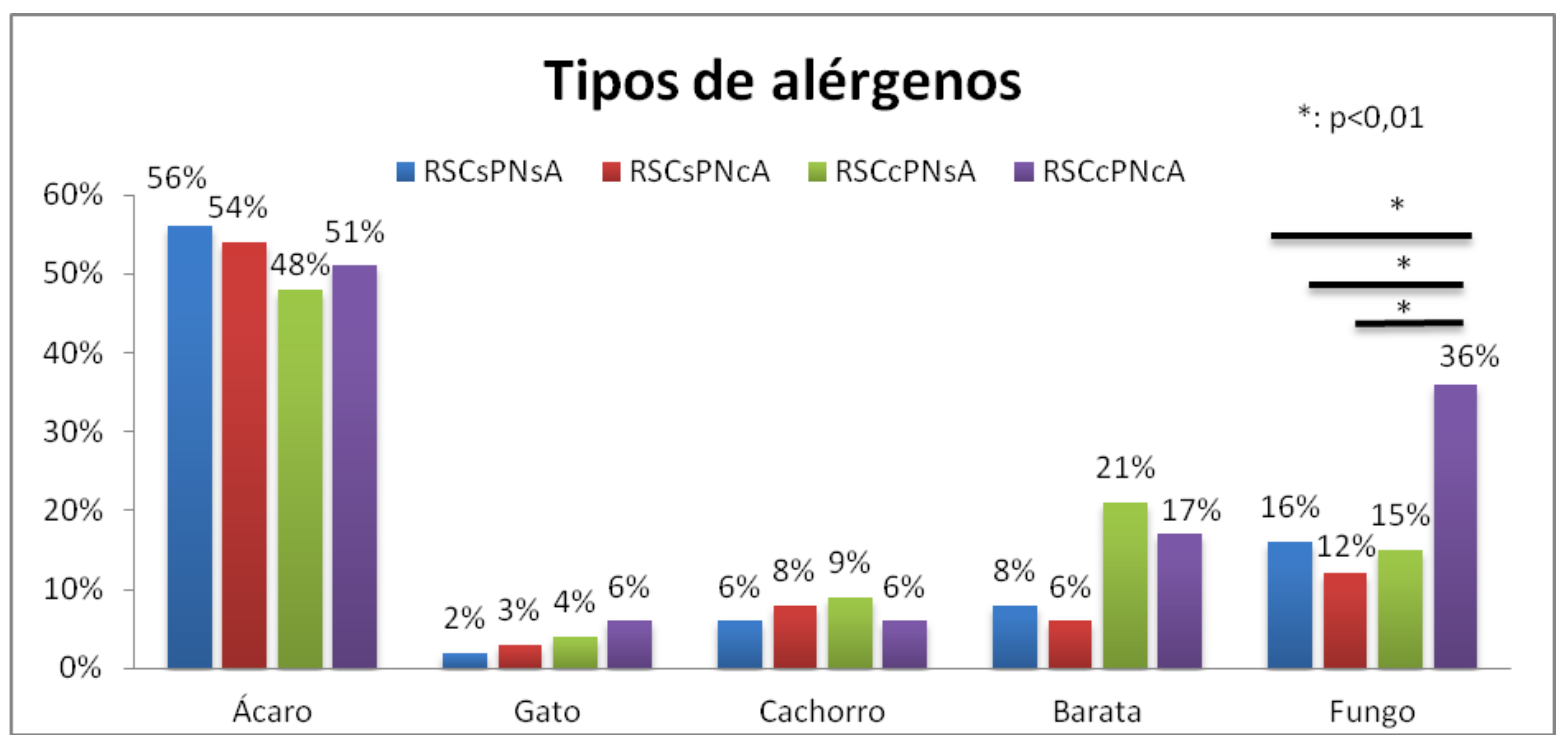

Nos pacientes com RSCsPN, a atopia, tanto para inalantes $(p=0,22)$ quanto para fungos $(p=0,43)$, não mudou o prognóstico (Figura 13).

Figura 13 - Pacientes com RSCsPN: diferença da recidiva cirúrgica entre alérgicos e não alérgicos a: (A) inalantes; (B) fungos, por meio da curva de KaplanMeyer com pós-teste de Log-rank

A

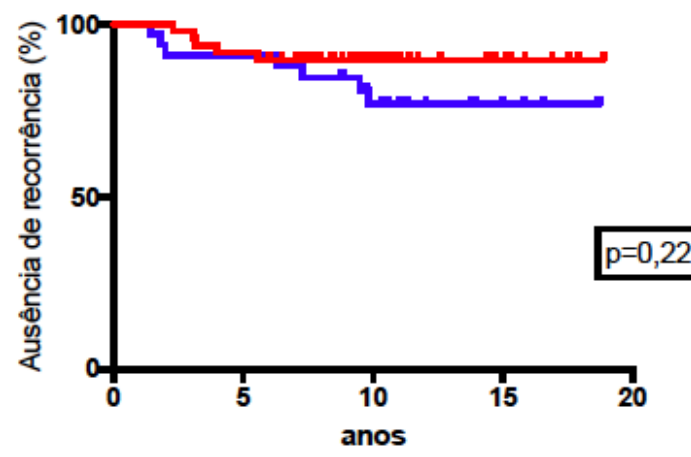

- alergia a inalantes
ـ não alérgico
B

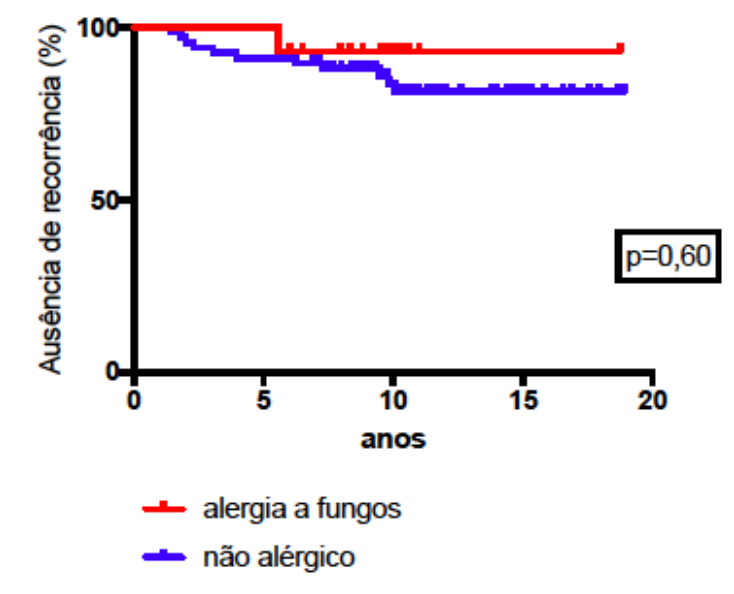


A atopia a inalantes também não alterou o prognóstico entre os pacientes RSCcPN $(p=0,55)$. No entanto, aqueles com RSCcPN e alergia a fungos apresentaram maior chance de recorrência $(O R=1,9 ; p<0,05)$ do que os $R S C c P N$ e sem atopia a fungos (Figura 14).

Figura 14 - Pacientes com RSCcPN: diferença da recidiva cirúrgica entre alérgicos e não alérgicos a: (A) inalantes; (B) fungos, por meio da curva de Kaplan-Meyer com pós-teste de Log-rank

A

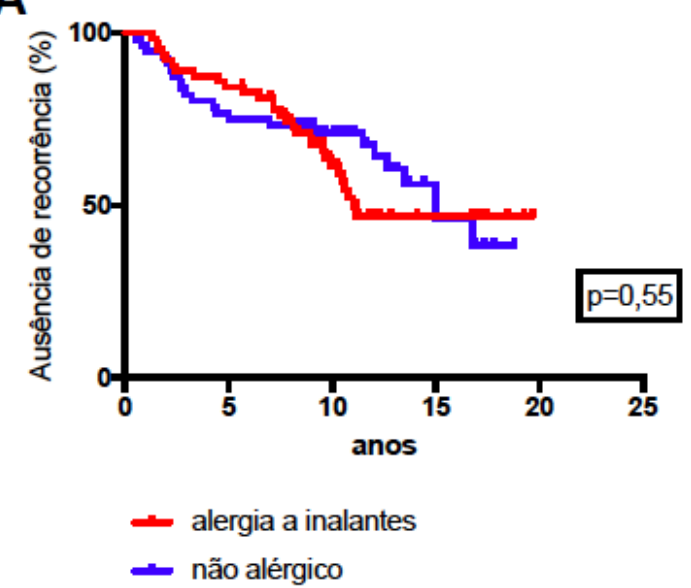

B

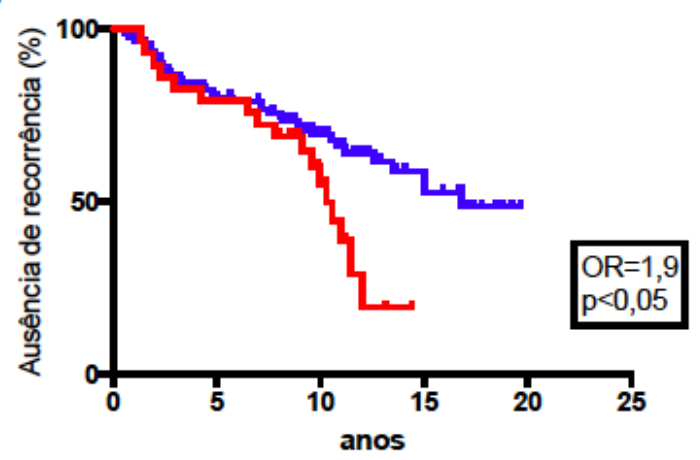

- alergia a fungos

— não alérgico

\subsection{Tabagismo}

Oito pacientes com RSCsPN $(9,8 \%)$ eram tabagistas, e não houve aumento do risco relativo para novo evento cirúrgico para eles $(p=0,24)$ (Figura 15). 
Figura 15 - Pacientes com RSCsPN: diferença da recidiva cirúrgica entre tabagistas e não tabagistas, por meio da curva de Kaplan-Meyer com pós-teste de Log-rank

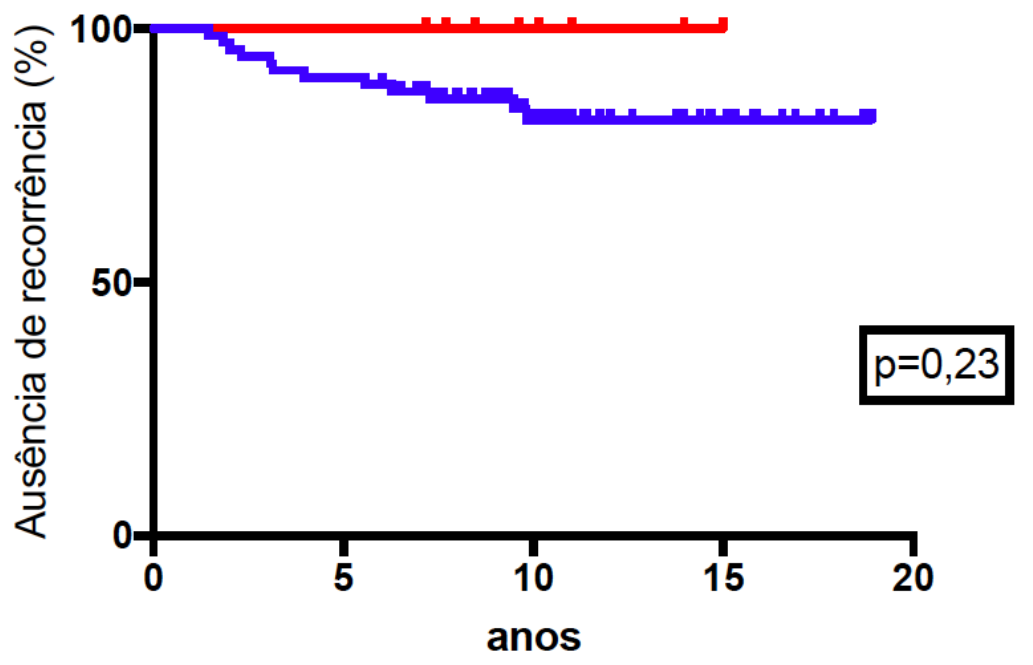

- RSCsPN não tabagista

- RSCsPN tabagista

O mesmo ocorreu no grupo RSCcPN, em que 13 pacientes eram tabagistas $(10,8 \%)$, e novamente não foi observado aumento do risco relativo para recidiva cirúrgica $(p=0,47)$ (Figura 16).

Figura 16 - Pacientes com RSCcPN: diferença da recidiva cirúrgica entre tabagistas e não tabagistas, por meio da curva de Kaplan-Meyer com pós-teste de Log-rank

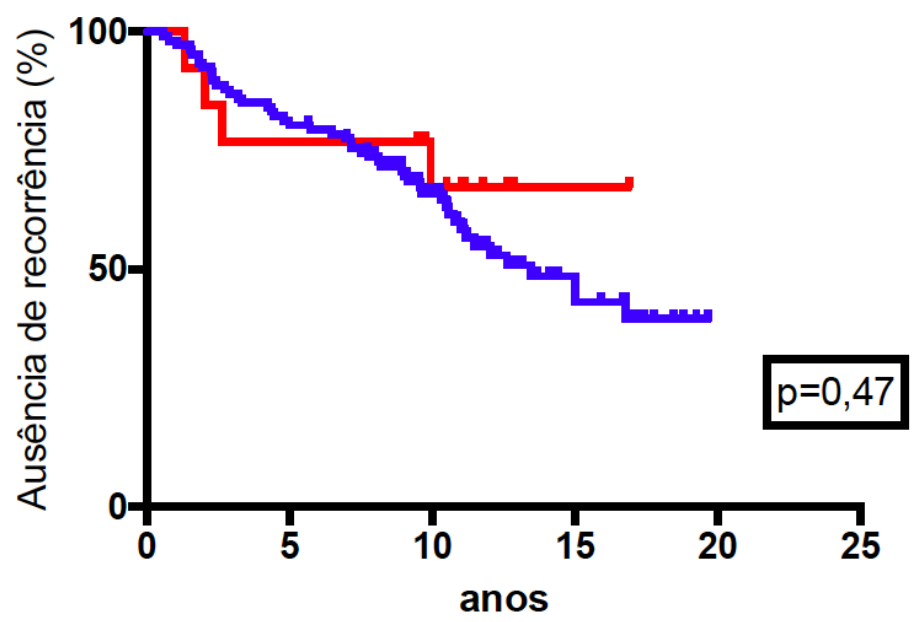

- RSCcPN não tabagista

- RSCcPN tabagista 
Cabe aqui ressaltar que o número total de pacientes tabagistas foi pequeno nesta casuística, o que pode ter influenciado nos resultados.

\subsection{Asma}

Dos 81 pacientes com RSCsPN, apenas 14 (17\%) apresentaram asma, sendo seis considerados graves, dois moderados, dois leves e quatro intermitentes. Os pacientes do grupo RSCsPN apresentaram PFP no pré-operatório com valores de FEV1/CVF $84 \pm 16 \%$, FEV1 predito $91 \pm 26 \%$ e CVF predito $101 \pm 15 \%$. E 53 dos 120 pacientes com RSCcPN (44\%) apresentaram asma, sendo 26 com asma classificada como grave, oito moderada, 11 leve e oito intermitentes. Os valores de PFP foram FEV1/CVF $74 \pm 15 \%$, FEV1 predito $80 \pm 27 \%$ e CVF predito $97 \pm 22 \%$ (Tabela 3).

Tabela 3 - Diferença dos dados demográficos entre pacientes asmáticos com RSCsPN e RSCcPN

\begin{tabular}{lcc}
\hline Pacientes com asma & RSCsPN $\mathrm{n=14(17 \% )}$ & RSCcPN $\mathrm{n}=53(44 \%)$ \\
\hline Gravidade da asma & $\mathrm{n}(\%)$ & $\mathrm{n}(\%)$ \\
- Intermitente & $4(28,5 \%)$ & $8(15 \%)$ \\
- Leve & $2(14,25 \%)$ & $11(21 \%)$ \\
- Moderada & $2(14,25 \%)$ & $8(15 \%)$ \\
- Grave & $6(43 \%)$ & $26(49 \%)$ \\
FEV1/CVF (média) & $84 \pm 16 \%$ & $74 \pm 15 \%$ \\
FEV1 predito (média) & $91 \pm 26 \%$ & $80 \pm 27 \%$ \\
CVF predito (média) & $101 \pm 15 \%$ & $97 \pm 22 \%$
\end{tabular}

FEV: Volume expiratório forçado; CVF: Capacidade vital forçada.

No grupo RSCsPN, a asma influenciou negativamente o prognóstico, sendo considerada evento significativo $(p<0,001)$ com OR=5,5 (Figura 17). 
Figura 17 - Pacientes com RSCsPN: diferença da recidiva cirúrgica entre aqueles sem e com asma por meio da curva de Kaplan-Meyer com pós-teste de Log-rank

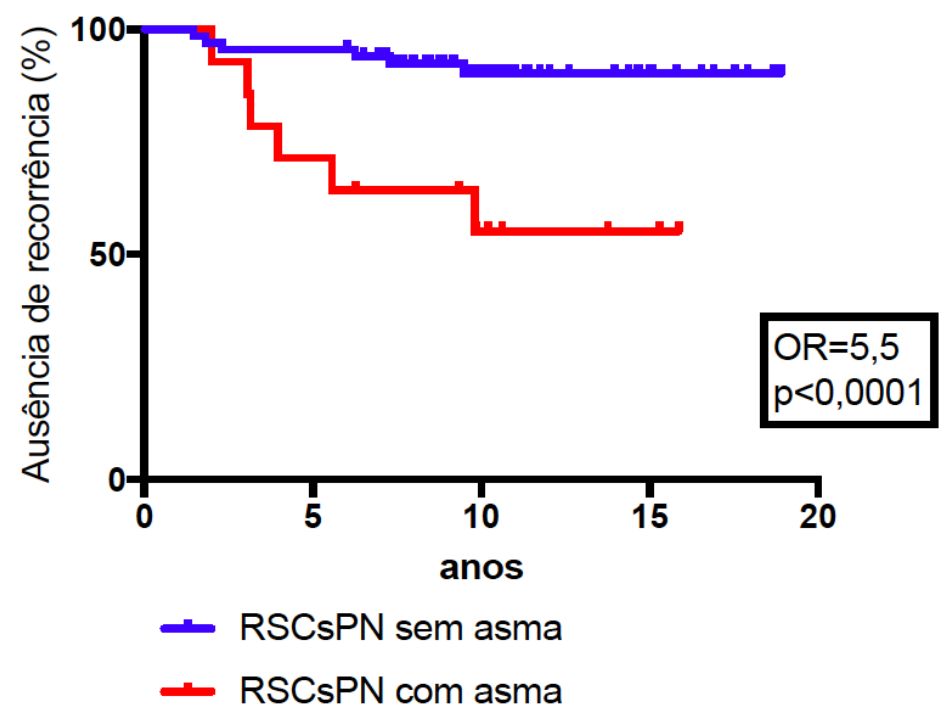

E a asma também esteve relacionada a risco significativamente maior $(p<0,0001)$ de recidiva entre os pacientes RSCCPN: os asmáticos apresentaram chance 3,2 vezes maior de nova abordagem cirúrgica quando comparados com os não asmáticos, durante o período de seguimento (Figura 18).

Figura 18 - Pacientes com RSCcPN: diferença da recidiva cirúrgica entre os sem e com asma. Comparação entre os grupos por meio da curva de Kaplan-Meyer com pós-teste de Log-rank

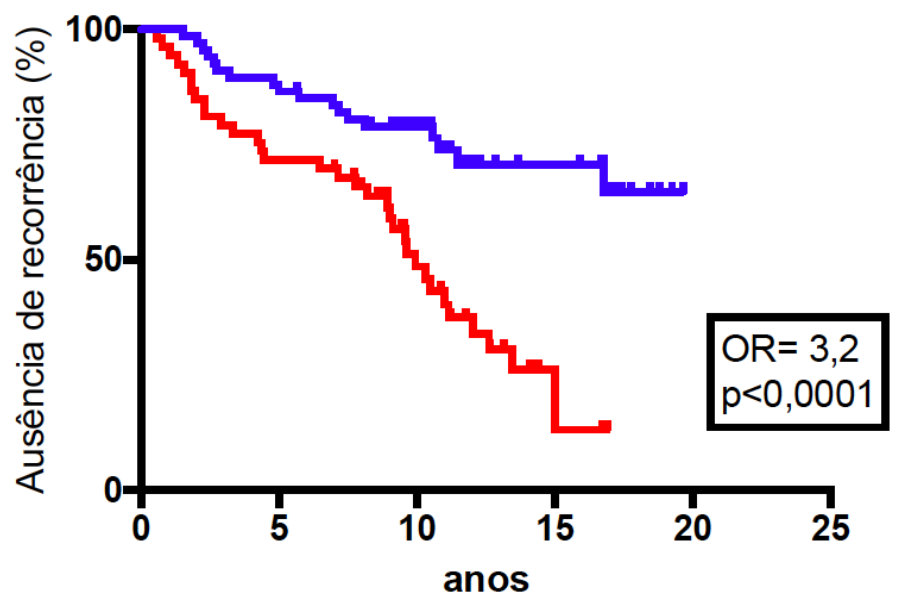

- RSCcPN sem asma

- RSCcPN com asma 


\subsection{Eosinofilia}

Em relação à eosinofilia sérica, não houve diferença estatística entre os grupos RSCcPN e RSCsPN $(444,6 \pm 32,1$ para RSCcPN versus. $377,3 \pm 40,7$ para RSCsPN, p=0,19; IC95\%: -35,2;169,9). A eosinofilia também não esteve associada à atopia $(448,1 \pm 38,4$ em atópicos versus. $379,5 \pm 30,3$ em não atópicos, $p=0,16$; IC95\%: -165,2;28,0), atopia a fungos (496 $\pm 98,7$ em atópicos a fungos versus. 429,9 $\pm 30,4$ em não atópicos a fungos; $p=0,52$; IC95\%: $-277,5 ; 145,3)$ ou ao tabagismo $(520 \pm 84,5 \mathrm{em}$ tabagistas versus. $404,8 \pm 26,4 \mathrm{em}$ não tabagistas, $p=0,20$, IC95\%: -298,4;67,9). Porém, os asmáticos apresentaram média de 564,6 $\pm 49,3$ eosinófilos $/ \mu \mathrm{L}$ e os não asmáticos 338,5 $\pm 25,9$ eosinófilos $/ \mu \mathrm{L}$, sendo significativamente diferentes entre si ( $p<0,0001$; IC95\%: -336,6;-115,5) (Figura 19). 
Figura 19 - Diferença do nível de eosinofilia sérica entre os fatores de risco: (A) tabagismo; (B) atopia a todos os inalantes; (C) atopia a fungos; (D) presença de PN; (E) asma
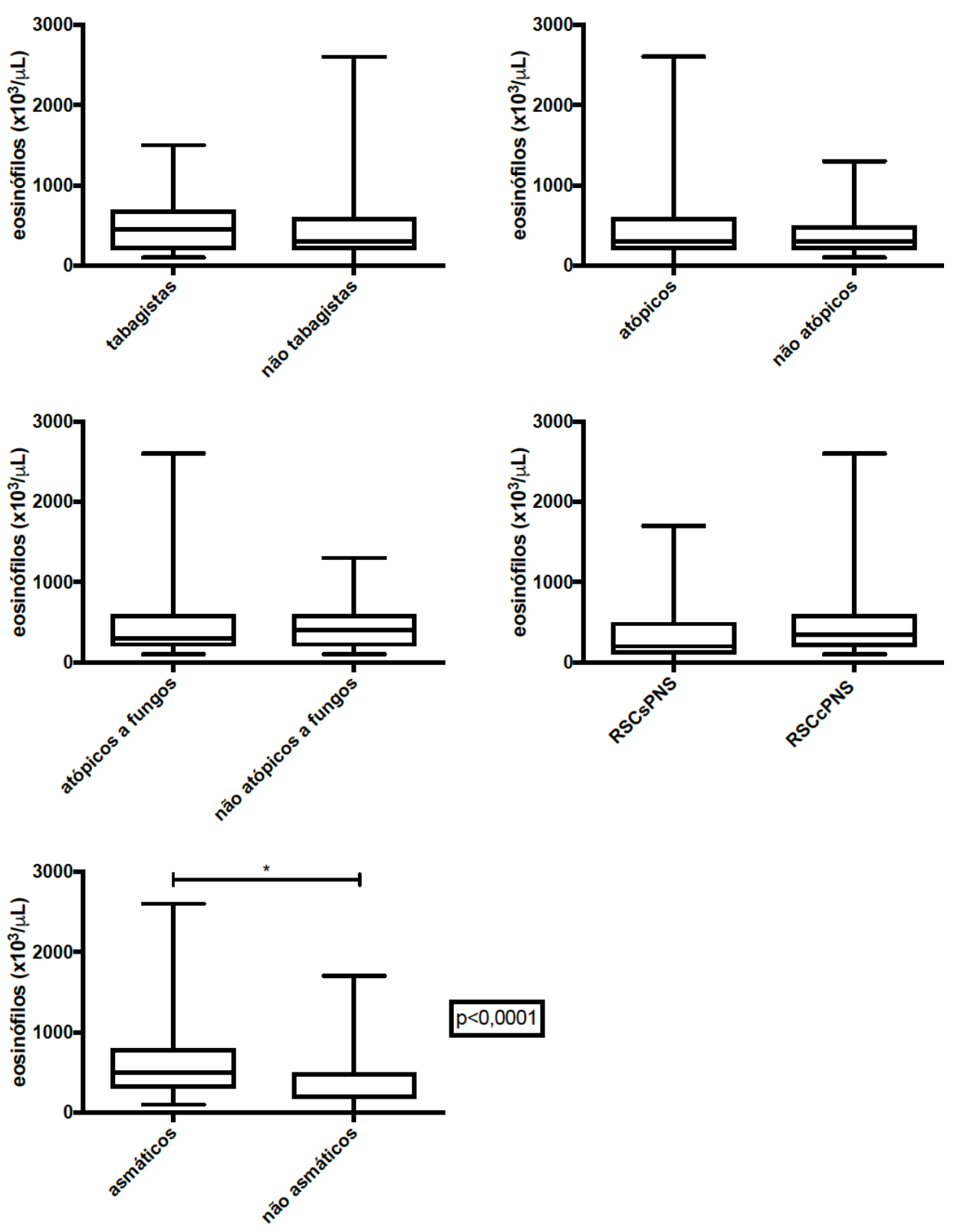

Ainda, verificou-se se a eosinofilia sérica alteraria o desfecho dos pacientes, considerando eosinofilia o número de eosinófilos maior que 500/ $\mu \mathrm{L}$. Observou-se que esta não influenciou o desfecho em pacientes com RSCsPN $(p=0,59)$ (Figura 20). 
Figura 20 - Pacientes com RSCsPN: diferença da recidiva cirúrgica entre os sem e com eosinofilia sérica por meio da curva de Kaplan-Meyer com pós-teste de Logrank

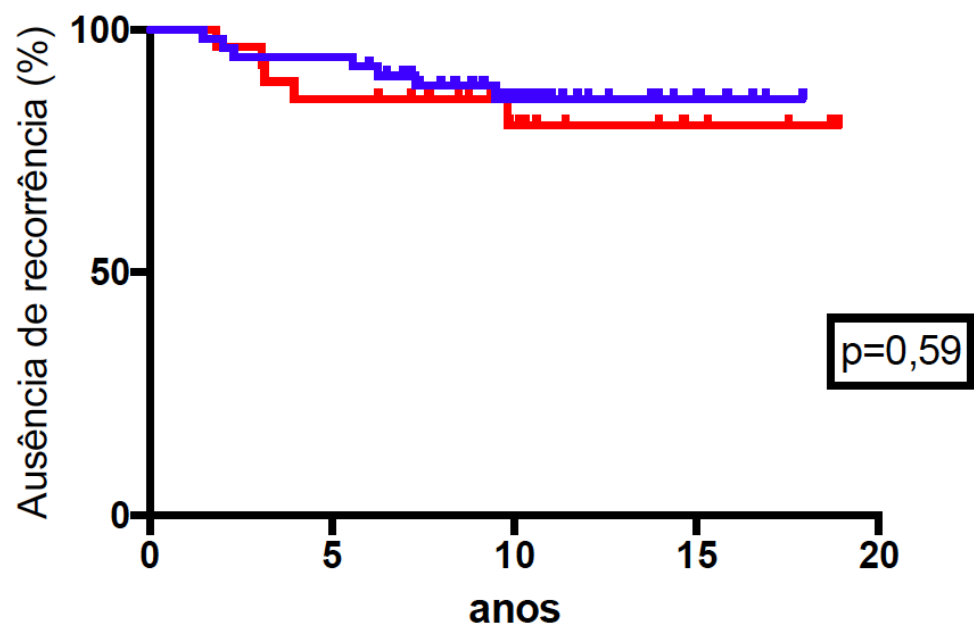

- RSCsPN sem eosinofilia

- RSCsPN com eosinofilia

Em contrapartida, a eosinofilia influenciou a evolução clínica dos pacientes com RSCcPN, levando a um OR de 1,92 ( $p<0,01)$ (Figura 21).

Figura 21 - Pacientes com RSCcPN: diferença da recidiva cirúrgica entre aqueles sem e com eosinofilia por meio da curva de Kaplan-Meyer com pós-teste de Log-rank

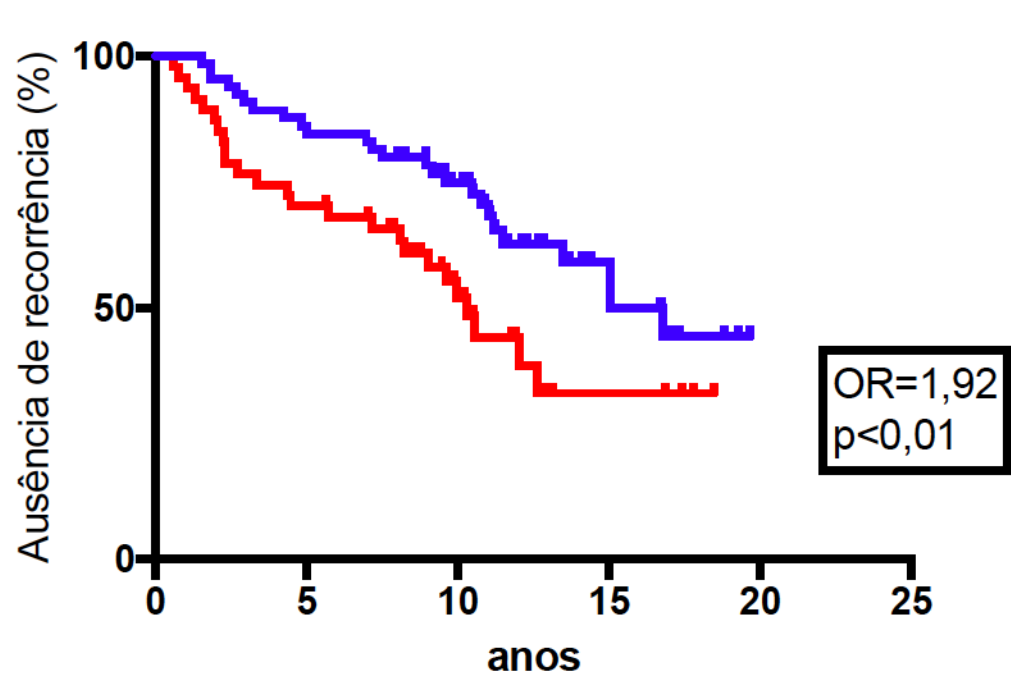

- RSCcPN sem eosinofilia

- RSCcPN com eosinofilia 


\subsection{Intolerância à aspirina}

Intolerância ao AAS foi evidenciada em 29 dos 53 (55\%) pacientes do grupo RSCcPNcA, configurando DREA. Esses pacientes apresentaram média maior de eventos cirúrgicos $(2,03)$ do que os RSCcPN sem DREA $(1,82)$, ou do que os RSCsPN $(1,12)$. E quando analisada a recorrência cirúrgica nos pacientes DREA comparando com os RSCcPN não DREA, ao longo do seguimento, constatou-se diferença significativa $(p<0,001)$, com $O R=2,46$ (Figura 22).

Figura 22 - Pacientes com RSCcPN: diferença da recidiva cirúrgica entre os sem e com DREA, por meio da curva de Kaplan-Meyer com pós-teste de Log-rank

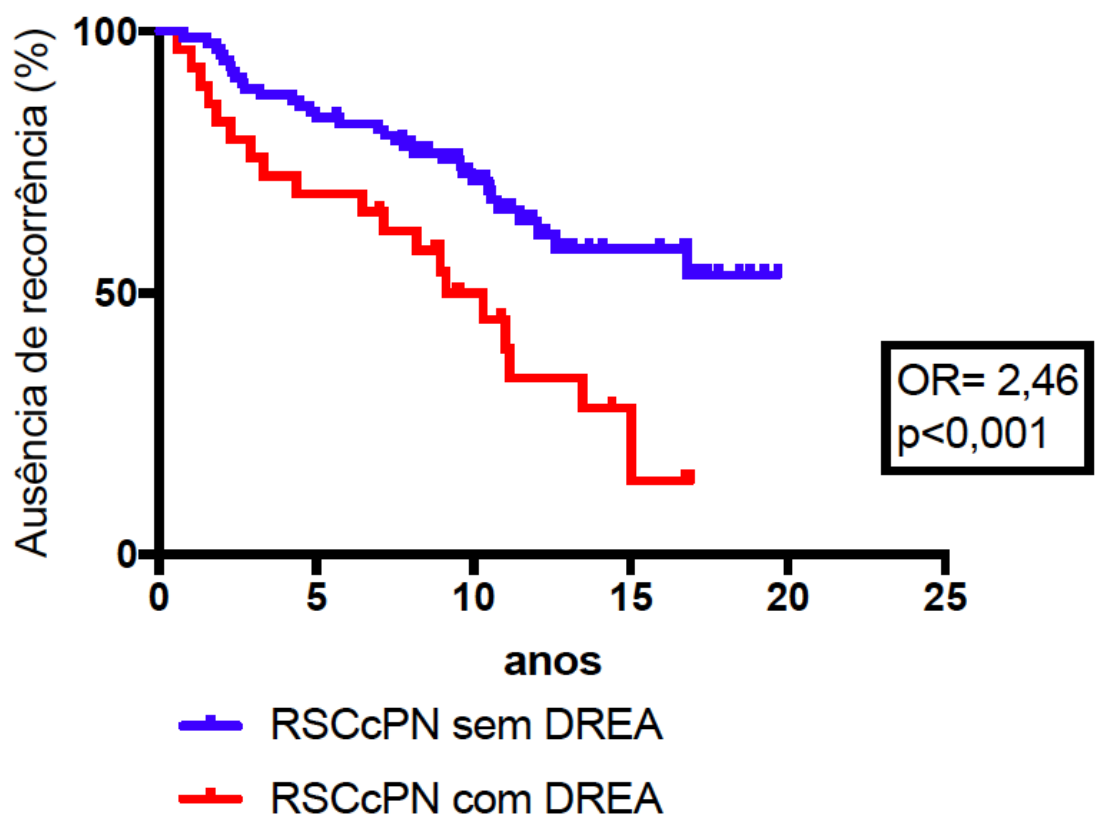


7. Discussão 
A pesquisa de fatores que possam influenciar no prognóstico para a RSC é de suma importância, ajudando no entendimento de quais são importantes para o prognóstico da doença, e na identificação de pacientes que necessitariam de cuidados e/ou tratamentos clínicos/cirúrgicos adicionais. Existem divergências na literatura sobre quais desses fatores prognósticos podem identificar os pacientes mais suscetíveis à recorrência da RSC e prever a necessidade de reintervenção. Este fato pode ser explicado por diferentes metodologias e tipos de estudos utilizados, incluindo a seleção da amostra (que geralmente mistura pacientes RSCcPN e RSCsPN, num mesmo grupo) e o tipo de análise estatística realizada. Ainda são escassos os estudos de longo prazo.

Existem poucos dados na literatura tratando especificamente a respeito da idade dos pacientes com RSCsPN. No presente estudo, esses pacientes eram ligeiramente mais jovens que os RSCcPN, e a idade média encontrada na primeira cirurgia foi de aproximadamente 42 anos. Este resultado é semelhante ao descrito por Moloney (1977), Drake-Lee et al. (1984) e Larsen e Tos (1994). Pilan et al. (2012) avaliaram pacientes por meio de questionário epidemiológico na cidade de São Paulo, e a média de idade dos com RSC foi de 39 anos.

Entre os pacientes com RSCsPN, 70\% foram do sexo feminino. Existem poucos estudos na literatura sobre esse tema, e outros autores também encontraram resultado semelhante (Busaba; Sin; Salman, 2008). No estudo de Pilan et al. (2012) houve maior prevalência do sexo feminino (55\%), entre todos os pacientes com RSC com ou sem PN.

No presente estudo, os pacientes com RSCcPN estiveram igualmente distribuídos entre os sexos. Não existem dados demográficos brasileiros para comparação com os achados desta pesquisa, mas em alguns estudos em outros países é considerada uma doença mais prevalente em homens: estudos europeus (Hosemann; Göde; Wagner, 1994; Hedman et al., 1999; Larsen; Tos, 2002; Busaba; Sin; Salman, 2008; Velosoteles; Cerejeira, 2017); norte-americano (Tan et al., 2011) ou asiático (Akhtar et al., 2010). Já em dois estudos franceses (Settipane; Chafee 1977; Klossek et al., 2005), a RSCcPN foi mais prevalente entre as mulheres. Talvez exista esta diferença pelas distintas metodologias para diagnóstico de RSCcPN e pelas diferentes características demográficas. 
Importante reforçar que este estudo não objetivou avaliar a prevalência da RSC em gêneros ou por idade, o que pode ter sido um viés dos resultados encontrados.

Verificou-se que o número médio de cirurgia dos pacientes seguidos nesse período médio de 12 anos foi significativamente maior no grupo RSCcPN com asma do que nos outros dois grupos (RSCsPN ou RSCcPN sem asma). A média de tempo entre a primeira e a segunda cirurgia nos pacientes RSCCPN foi de 6,6 anos, e nos RSCsPN foi de 4,7 anos. Em estudo longitudinal de pacientes com RSCcPN submetidos a duas ou mais cirurgias, a média de tempo entre elas foi de $4.87 \pm 3.61$ anos (Wu et al., 2014).

Os pacientes RSCcPN apresentaram OR de 3,03 de risco de nova cirurgia em relação aos RSCsPN; ou seja, quando diagnosticado com RSCcPN, o paciente tem chance em torno de três vezes maior de ser submetido a outra cirurgia do que quando não apresenta PN. Não foram encontrados estudos que tenham abordado especificamente esse aspecto prognóstico na literatura.

Neste estudo, a recidiva da RSCsPN não mostrou associação com a extensão radiológica da doença. Não foram encontrados achados na literatura comparando o prognóstico desses pacientes em relação à extensão da doença, provavelmente por esta possuir extensão tomográfica mais limitada.

Observou-se que no seguimento médio de 12 anos, os pacientes RSCcPN com recidiva cirúrgica tenderam a apresentar pólipos maiores à endoscopia nasal, com maior acometimento à $\mathrm{TC}$ do que aqueles com RSCcPN sem recidiva. Akhtar et al. (2010) relataram que pacientes com RSCcPN que apresentam doença mais extensa à TC correm maior risco de desenvolver recorrências após a ESS, durante o seguimento de 24 meses. DeConde et al. (2017) observaram que, entre 363 pacientes com RSCcPN, seguidos durante 14 meses, os com piores escores tomográficos de PN tiveram maior chance de recorrência (OR: 1,4; IC95\%: 1.1-1.8; $p=0,016)$. Já no estudo de Sil, Mackay e Rowe-Jones (2007), os escores de TC e de pólipos foram preditores de maior necessidade de medicação sistêmica pósoperatória. Em contraste, Velosoteles e Cerejeira (2017) descreveram que nem a graduação dos pólipos e nem o escore tomográfico alteraram a recorrência nos pacientes RSCcPN. Apesar de não ser uniforme em todos os estudos, os pacientes 
com maior extensão da RSCcPN parecem apresentar maior predisposição à recidiva cirúrgica. Cabe aqui ressaltar que o seguimento máximo dos outros estudos foi de apenas dois anos, e o presente estudo, numa coorte de seguimento bem mais longa, reforça essa relação entre extensão da doença e maior predisposição à recorrência de PNs.

Notou-se, ainda, que a maioria dos pacientes do presente estudo (63\%) apresentou positividade a algum alérgeno, sendo $60 \%$ do grupo RSCsPN sem asma, $70 \%$ do grupo RSCsPN com asma, 57\% do grupo RSCcPN sem asma e 70\% RSCcPN com asma, sendo que metade deles (50\%) foi atópica a múltiplos alérgenos. Estudos com pacientes com RSC, também submetidos à ESS, demonstraram a prevalência de prick tests positivos, variando de $30 \%$ a $84 \%$ (Savolainen, 1989; Emanuel; Shah, 2000; Gutman et al., 2004; Wynn; Har-El, 2004; Robinson; Douglas; Wormald, 2006; Houser; Keen 2008; Pearlman et al., 2009; Tan et al., 2011). No estudo de Emanuel e Shah (2000), a maioria dos pacientes com RSC atópicos (60\%) foram sensíveis a múltiplos alérgenos.

Neste estudo, observou-se que a atopia, a inalantes ou fungos, não influenciou a recidiva cirúrgica ao longo do seguimento entre pacientes com RSCsPN. Naqueles com RSCcPN, a atopia a inalantes também não influenciou a recidiva cirúrgica. No entanto, os $\mathrm{RSCCPN}$ com positividade para fungos tiveram quase duas vezes mais chance de recidiva cirúrgica do que os RSCcPN não alérgicos a fungos, durante o seguimento.

Assim como nesta pesquisa, diversos outros autores não encontraram relação entre RSCsPN e atopia. Pearlman et al. (2009) examinaram o efeito da asma e da atopia sobre a gravidade da RSC e sobre a presença de PN. Cento e seis pacientes com RSC foram submetidos ao prick test, dos quais 52 (49\%) eram atópicos e 54 (51\%) não atópicos. No subconjunto dos 66 pacientes com RSCsPN (62\%), os autores observaram atopia mais prevalente naqueles com asma. No entanto, não houve diferença nos escores de Lund-Mackay entre os grupos de RSC atópicos e não-atópicos; concluindo, assim, que a associação entre atopia sistêmica e gravidade da RSC é fraca, e que a RSCsPN é uma doença inflamatória que ocorre independentemente das vias sistêmicas mediadas por lgE. 
Gelincik et al. (2008) avaliaram pacientes com rinite persistente e descobriram que a RSC era igualmente prevalente naqueles com rinite alérgica (43\%) e não alérgica (50\%). Além disso, os PNs estavam igualmente presentes entre os dois grupos. Robinson, Douglas e Wormald (2006) analisaram a relação entre atopia e RSC em 193 pacientes com RSC por meio de testes in vitro, e constataram que o status atópico não foi associado com os escores de sintomas de Lund, e nem com os escores de TC. Concluíram que as características clínicas da RSC não são influenciadas pela atopia.

Tan et al. (2011) examinaram pacientes que falharam na terapia médica para RSCcPN e RSCsPN com sensibilidade a alérgenos e compararam com outros com RA, mas sem RSC, e com a população geral. Evidenciou-se tendência de aumento das taxas de atopia, sendo de $72 \%$ no grupo RA, $79 \%$ no grupo RSCsPN e $86 \%$ no grupo RSCcPN. As taxas gerais de atopia não foram significativamente diferentes entre os três grupos, porém maiores que as da população geral (54,3\%). Dessa forma, os autores concluíram que a atopia não predispõe os pacientes à RSC. Em contrapartida, os estudos que relacionam RSCcPN à atopia foram discordantes.

Erbek et al. (2007) não encontraram relação significativa entre a presença de alergia e o tamanho do $\mathrm{PN}$, pontuação de sintomas ou taxa de recorrência da RSCcPN. Görgulu et al. (2012) não observaram diferença significativa na taxa de sensibilidade aos alérgenos ambientais, por meio de exames de sangue, entre pacientes com RSCcPN submetidos à ESS e o grupo controle. Bonfils, Avan e Malinvaud (2006) e Bonfils e Malinvaud (2008) também não detectaram diferenças em nenhum parâmetro entre pacientes com RSCcPN e alérgicos e os não alérgicos. Pearlman et al. (2009) mencionaram que as taxas de alergia eram praticamente idênticas entre os grupos RSCcPN e RSCsPN.

Alguns autores sugerem que relações podem existir entre RSCcPN e asma, bem como asma e rinite alérgica, mas não relação direta entre RSCcPN e alergia (Voegels et al., 2001; Muñoz del Castillo et al. 2009; Pearlman et al., 2009; Tan et al., 2011). Entretanto, outros relatam que a atopia predispõe ao desenvolvimento de RSC (Kaliner, 1998; Krause, 2003) pela maior prevalência de atopia nos pacientes RSCcPN do que em grupos controle (Pumhirun; Limitlaohapanth; Wasuwat, 1999; Houser; Keen 2008; Muñoz del Castillo et al., 2009); por piores índices radiológicos 
(Berrettini et al., 1999; Kirtsreesakul; Ruttanaphol, 2008); ou por pior prognóstico (Marks; Shamsa, 1997; Wynn; Har-El, 2004). Cabe aqui salientar que todos os autores que relacionaram atopia ao prognóstico da RSC utilizaram análise de contingência em sua estatística; e os aqui citados tiveram tempo de seguimento consideravelmente menor do que o deste estudo.

Um achado particular na presente casuística foi a alta prevalência de atopia a fungos nos pacientes com RSCcPN, e que esses apresentaram chance quase que duas vezes maior de recidiva cirúrgica do que os com RSCcPN não alérgicos a fungos. Não existem estudos prospectivos que tenham realizado essa análise para este grupo de pacientes, em específico. Em duas pesquisas distintas, Asero e Bottazzi (2000, 2001) encontraram maior prevalência de positividade a testes cutâneos para pelo menos uma espécie de fungos e ácaros em pacientes com RSCcPN, quando comparados com controles alérgicos e RSCsPN; entre esses pacientes, a única espécie a atingir significância estatística foi Cândida. Tan et al. (2011), em estudo transversal, não encontraram diferença estatística em relação à positividade de prick test em pacientes com RSCsPN, RSCcPN e RA, e também não verificaram diferença na positividade entre alérgenos perenes ou sazonais (que incluem árvores, gramas, ambrósia e fungos, sem discriminar qual deles).

Em resumo, foi observada fraca evidência do papel da RA na etiologia da $\mathrm{RSC}$, exceto para o dos fungos na RSCcPN. Os resultados contraditórios nos estudos descritos provavelmente refletem as diferenças na metodologia dos estudos, nos critérios de inclusão, entre as populações estudadas e o baixo tempo de seguimento desses pacientes. A conclusão mais razoável parece ser que a RA geralmente deva ser considerada um problema sobreposto, que contribui para a inflamação nasosinusal de forma variada nos pacientes com RSC.

No presente estudo foram incluídos apenas pacientes com RSC sem mucina eosinofílica e sem alterações tomográficas clássicas de RSFA ou RSME. Importante reforçar que todas as fichas operatórias dos pacientes analisados foram verificadas para que não houvesse tal confusão. Já se sabe que a RSFA tem pior prognóstico que a RSC (Philpott et al., 2015), e em estudo recente demonstrou-se que a mucina eosinofílica presente na RSFA e na RSME foi significativamente associada à maior taxa de cirurgia de revisão (Younis; Ahmed, 2017). Evidenciou-se que os pacientes 
com RSCcPN e atopia a fungos (sem mucina eosinofílica) tiveram maior chance de cirurgia. Assim, pode-se concluir que, de fato, a sensibilidade a fungos pode predispor à possibilidade de pior prognóstico nesse grupo de pacientes; entretanto mais estudos serão necessários para se confirmar este achado.

Não se observou influência do tabagismo no prognóstico cirúrgico, tanto nos pacientes RSCsPN quanto nos RSCcPN. É importante salientar que a prevalência de fumantes na população estudada foi relativamente baixa (apenas 21 pacientes), o que pode ter influenciado os resultados. Na literatura, a maioria dos estudos não mostra efeito do tabagismo no prognóstico da ESS (Das et al. 2007, 2009; Rudmik; Mace; Smith, 2011; Naidoo et al. 2012; Juan et al., 2017; Velosoteles; Cerejeira 2017). No entanto, Rudmik, Mace e Smith (2011) indicam que o tabagismo pode contribuir para pior pontuação de endoscopia no pós-operatório. Além disso, autores sugerem que o tabagismo esteja associado à RSCcPN (Houser; Keen 2008; Görgülü et al., 2012), e outros demonstram que o tempo médio para a cirurgia de revisão em pacientes com RSCcPN foi menor nos que fumaram, comparados aos não fumantes (2,82 versus 4,31 anos, respectivamente, $p=0,022)$ (Wu et al., 2014).

Neste estudo, observou-se que 33\% dos pacientes com RSC, com ou sem PN, tinham asma; esta taxa varia na literatura de 20,7\% a 47,7\% (Ragab et al., 2006; Seybt; McMains; Kountakis, 2007; Matsuno et al., 2008; Staikūniene et al., 2008; Pearlman et al. 2009; Lin et al., 2011; Zhang et al., 2011a; Benninger; Holy, 2014; Velosoteles; Cerejeira, 2017). Ainda, Ragab, Clement e Vincken (2004) sugerem que essa prevalência deve ser subestimada, uma vez que identificaram hiperreatividade brônquica à histamina em $36 \%$ dos pacientes com RSC, e que se consideravam assintomáticos para asma. Os autores observaram que $60 \%$ dos pacientes com RSC apresentavam algum grau de alteração em via aérea inferior. Esses valores são consideravelmente maiores do que a prevalência da asma na população geral, entre 5 e 10\% (Bousquet, 2000; Jarvis et al., 2012), ou no Brasil, estimada em 4,4\% (Menezes et al., 2015).

Quando analisado apenas o grupo RSCsPN, pacientes com asma tiveram chance maior de recorrência cirúrgica do que aqueles sem asma, com OR de 5,5. Existem poucos estudos que avaliaram este grupo específico de pacientes, e eles divergem entre si: enquanto alguns autores mostram que a asma é um fator 
determinante para recorrência após ESS em pacientes RSCsPN (Matsuwaki et al. 2008; Zhang et al. 2011a), outros autores não observaram essa relação (Young et al., 2007).

No grupo RSCcPN, pacientes asmáticos apresentaram maior número de pólipos à endoscopia nasal em relação aos RSCcPN sem asma; não havendo, no entanto, diferença significativa entre os grupos. Outros autores reportaram doença mais extensa nos pacientes com RSCcPN com asma, pelo achado endoscópico (Staikūniene et al., 2008) ou pelo escore tomográfico de Lund e Mackay (Kennedy 1992; Pearlman et al., 2009; Lin et al., 2011; Zhang et al., 2011a). Ainda, os pacientes com RSCcPN e asma tiveram risco 3,2 vezes maior para recorrência da doença do que os com RSCcPN sem asma, ao longo do seguimento. Esses resultados corroboram diversos outros estudos (Dinis; Gomes 1997; Marks ;Shamsa, 1997; Deal; Kountakis, 2004; Wynn; Har-El, 2004; Dejima et al., 2005; McMains; Kountakis, 2005; Matsuwaki et al., 2008; Pearlman et al., 2009; Velosoteles; Cerejeira, 2017), que inferem risco maior de recidiva em pacientes com RSCcPN e asma associada. Vale salientar que esses autores utilizaram análise de contingência para avaliar seus dados, não considerando, assim, o tempo para recidiva, e que realizaram seguimento pós-operatório mais curto (no máximo dois anos) do que o presente estudo.

Dessa forma, pode-se concluir que grande percentagem de pacientes com RSC apresenta asma que é um fator prognóstico importante na possibilidade de recidiva da doença em pacientes com e sem $\mathrm{PN}$. Desde o conceito de via aérea unida (Bousquet; Van Cauwenberge; Khaltaev, 2001), diversos autores têm sugerido essa relação, mas esta é a primeira vez em que a asma foi comprovadamente relacionada à maior probabilidade de um novo evento cirúrgico.

Encontrou-se, por fim, relação de aumento de níveis de eosinófilos periféricos à asma nos pacientes com RSC (geral). Este resultado confirma, em um estudo clínico, a importância dos eosinófilos na asma e na RSC pela infiltração histológica eosinofílica na asma e na RSC, que são semelhantes (Ponikau et al., 2003); e que existem eosinófilos na mucosa nasal de pacientes asmáticos, mesmo sem sintomas nasais (Gaga et al., 2000). 
Em se tratando de prognóstico, a eosinofilia periférica não influenciou na recorrência cirúrgica nos pacientes sem PNs. Já naqueles com RSCcPN, a eosinofilia periférica maior que $500 / \mu \mathrm{L}$ está relacionada a 1,93 vezes maior chance de uma segunda intervenção cirúrgica do que em pacientes com as mesmas características, porém sem eosinofilia periférica. Poucos estudos clínicos foram realizados sobre o real papel da eosinofilia sérica no prognóstico da RSCcPN; normalmente eles não são homogêneos e têm como objetivo calcular o papel prognóstico e os valores de corte confiáveis, capazes de identificar pacientes com maior risco de recorrência de RSCcPN após a cirurgia. Assim, alguns autores demonstraram que pacientes com hipereosinofilia sérica foram mais propensos à recorrência de RSC após a cirurgia (Matsuwaki et al., 2008; Brescia et al., 2015, 2017; Ottaviano et al., 2015; Tokunaga et al., 2015), e outros relataram que pacientes com mais eosinófilos nos pólipos estão sujeitos a maior número de cirurgias (Tosun et al., 2010; Ikeda et al., 2013; Vlaminck et al., 2014), sendo que nenhum desses estudos teve seguimento maior que três anos dos pacientes avaliados. Ebbens et al. (2011) referiram que pacientes com RSC com maiores níveis de eosinófilos são menos propensos à recorrência cirúrgica no pós-operatório quando tratados com corticoides nasais. A eosinofilia periférica ainda se relaciona fortemente à extensão radiológica da RSC (Newman et al., 1994; Hoover et al., 1997), e à maior presença de PNs à endoscopia pós-operatória (Drake; Rafaels; Kim, 2016).

Dos 120 pacientes com RSCcPN estudados, 29 (24\%) apresentaram asma e intolerância ao AAS, configurando DREA; esta taxa foi maior do que os $9,7 \%$ descritos em outros estudos (Szczeklik; Stevenson, 2003; Baker; Quinn, 2011; Rajan et al., 2015). Talvez esta diferença tenho ocorrido por terem sido avaliados pacientes de um hospital terciário, que geralmente são mais graves, e por trabalharmos com grande proximidade com o Departamento de Alergologia e Imunologia do HCFMRPUSP.

Finalmente, observou-se que pacientes com DREA apresentam 2,46 vezes mais chance de um novo procedimento cirúrgico do que os com RSCcPN sem DREA; resultado semelhante ao do estudo de Mendelsohn et al. (2011), que encontraram OR de 2,7 (IC95\% = 1,5-3,2; $p<0,01)$ em um seguimento longitudinal. 
Diversos outros estudos transversais também demonstraram que a DREA influencia negativamente o resultado cirúrgico (McFadden et al., 1997; Riechelmann et al., 2002; Kim; Kountakis, 2007; Gosepath; Pogodsky; Mann, 2008).

Neste estudo, foram avaliados, durante longo seguimento, pacientes com RSC, e tentou-se buscar uma associação de prognóstico com atopia, asma, DREA e eosinofilia periférica. Os resultados mostraram que a fenotipagem da RSC no momento do diagnóstico pode predizer como otimizar o tratamento e determinar alguns fatores prognósticos da doença. 
8. Conclusões 
Neste seguimento de aproximadamente 12 anos de pós-operatório de EES nos pacientes com RSC, concluiu-se que:

- Pacientes com RSCcPN têm chance três vezes maior de nova cirurgia do que aqueles com RSCsPN

- Entre os pacientes RSCsPN:

- Os asmáticos tiveram 5,5 vezes maior chance de recidiva cirúrgica.

- A extensão da doença à TC, a atopia, o tabagismo e a eosinofilia periférica não influenciaram no prognóstico.

- Entre os pacientes RSCcPN:

- A extensão da doença esteve relacionada a pior prognóstico.

- A atopia a fungos levou à chance quase duas vezes maior de cirurgia do que os não atópicos a fungos.

- Asmáticos tiveram 3,2 vezes mais chance de recorrência cirúrgica.

- Pacientes com eosinofilia periférica $>500 / \mu \mathrm{L}$ tiveram quase duas vezes mais chance de recorrência cirúrgica.

- A intolerância ao AAS (DREA) representa 2,5 vezes maior chance de um evento cirúrgico.

- O tabagismo e a atopia, no geral, não influenciaram no prognóstico. 


\section{Referências Bibliográficas}

\footnotetext{
${ }^{1}$ Elaboradas de acordo com as Diretrizes para Apresentação de Dissertações e Teses da USP: Documento Eletrônico e Impresso - Parte IV (Vancouver) 3로 ed. São Paulo: SIBi/USP, 2016.
} 
Ahsan SF, Jumans S, Nunez DA. Chronic rhinosinusitis: a comparative study of disease occurrence in North of Scotland and Southern Caribbean otolaryngology outpatient clinics over a two month period. Scott Med J. 2004;49(4):130-3.

Akdis, CA et al. Endotypes and phenotypes of chronic rhinosinusitis: a PRACTALL document of the European Academy of Allergy and Clinical Immunology and the American Academy of Allergy, Asthma \& Immunology. J Allergy Clin Immunol. 2013;131(6):1479-90.

Akhtar $S$ et al. Factors associated with recurrent nasal polyps: a tertiary care experience. J Pak Med Assoc. 2010;60(2):102-4.

Alt JA et al. Sleep quality and disease severity in patients with chronic rhinosinusitis. Laryngoscope. 2013;123(10):2364-70.

Amar YG, Frenkiel S, Sobol SE. Outcome analysis of endoscopic sinus surgery for chronic sinusitis in patients having Samter's triad. J Otolaryngol. 2000;29(1):7-12.

Anselmo-Lima WT et al. Rhinosinusitis: evidence and experience. Braz J Otorhinolaryngol. 2015;81(1 Suppl 1), pp.S1-S49.

Antunes MB, Gudis DA, Cohen NA. Epithelium, cilia, and mucus: their importance in chronic rhinosinusitis. Immunol Allergy Clin North Am. 2009;29(4):631-43.

Asero R, Bottazzi G. Hypersensitivity to molds in patients with nasal polyposis: A clinical study. J Allergy Clin Immunol. 2000;105(1 Pt 1):186-8.

Asero R, Bottazzi G. Nasal polyposis: a study of its association with airborne allergen hypersensitivity. Ann Allergy Asthma Immunol. 2001;86(3):283-5.

Awad OG et al. Asthma outcomes after endoscopic sinus surgery in aspirin-tolerant versus aspirin-induced asthmatic patients. Am J Rhinol. 2008a;22(2):197-203.

Awad OG, et al. Sinonasal outcomes after endoscopic sinus surgery in asthmatic patients with nasal polyps: A difference between aspirin-tolerant and aspirin-induced asthma? Laryngoscope, 2008b;118(7):1282-6.

$\mathrm{Ba} \mathrm{L}$ et al. The association between bacterial colonization and inflammatory pattern in Chinese chronic rhinosinusitis patients with nasal polyps. Allergy. $2011 ; 66(10): 1296-303$.

Bachert $\mathrm{C}$ et al. Total and specific $\lg \mathrm{E}$ in nasal polyps is related to local eosinophilic inflammation. J Allergy Clin Immunol. 2001;107(4):607-14.

Bachert $\mathrm{C}$ et al. Role of staphylococcal superantigens in upper airway disease. Curr Opin Allergy Clin Immunol. 2008;8(1):34-8. 
Bachert C, Zhang L, Gevaert P. Current and future treatment options for adult chronic rhinosinusitis: Focus on nasal polyposis. J Allergy Clin Immunol. 2015;136(6):143140.

Baker TW, Quinn JM. Aspirin therapy in aspirin-exacerbated respiratory disease: a risk-benefit analysis for the practicing allergist. Allergy Asthma Proc. 2011;32(5):33540.

Baradaranfar $\mathrm{MH}$ et al. Comparison of the effect of endoscopic sinus surgery versus medical therapy on olfaction in nasal polyposis. Eur Arch Otorhinolaryngol. 2014;271(2):311-6.

Bassiouni A, Naidoo Y, Wormald PJ. When FESS fails: the inflammatory load hypothesis in refractory chronic rhinosinusitis. Laryngoscope. 2012;122(2):460-6.

Bassiouni A, Chen PG, Wormald PJ. Mucosal remodeling and reversibility in chronic rhinosinusitis. Curr Opin Allergy Clin Immunol. 2013;13(1):4-12.

Batra PS et al. Outcome analysis of endoscopic sinus surgery in patients with nasal polyps and asthma. Laryngoscope, 2003;113(10):1703-6.

Benninger MS, Holy CE. The impact of endoscopic sinus surgery on health care use in patients with respiratory comorbidities. Otolaryngol Head Neck Surg. 2014;151(3):508-15.

Bent JP, Kuhn FA. Diagnosis of allergic fungal sinusitis. Otolaryngol Head Neck Surg. 1994;111(5):580-8.

Berges-Gimeno MP, Simon RA, Stevenson DD. The natural history and clinical characteristics of aspirin-exacerbated respiratory disease. Ann Allergy Asthma Immunol. 2002;89(5), pp.474-8.

Berges-Gimeno MP, Simon RA, Stevenson DD. Long-term treatment with aspirin desensitization in asthmatic patients with aspirin-exacerbated respiratory disease. $J$ Allergy Clin Immunol. 2003;111(1):180-6.

Berrettini $S$ et al. Perennial allergic rhinitis and chronic sinusitis: correlation with rhinologic risk factors. Allergy. 1999;54(3):242-8.

Bhattacharyya N. The economic burden and symptom manifestations of chronic rhinosinusitis. Am J Rhinol. 2003;17(1):27-32.

Bhattacharyya N. Clinical outcomes after revision endoscopic sinus surgery. Arch Otolaryngol Head Neck Surg. 2004;130(8):975-8.

Bhattacharyya N. Contemporary assessment of the disease burden of sinusitis. Allergy Rhinol. 2010;1(1):8-8. 
Bhattacharyya N, Lee LN. Evaluating the diagnosis of chronic rhinosinusitis based on clinical guidelines and endoscopy. Otolaryngol Head Neck Surg. 2010;143(1):147-51.

Bhattacharyya N. Incremental health care utilization and expenditures for chronic rhinosinusitis in the United States. Ann Otol Rhinol Laryngol. 2011a;120(7):423-7.

Bhattacharyya N. Incremental healthcare utilization and expenditures for allergic rhinitis in the United States. Laryngoscope. 2011b;121(9):1830-3.

Bhattacharyya $\mathrm{N}$ et al. Cost burden of chronic rhinosinusitis: a claims-based study. Otolaryngol Head Neck Surg. 2011;144(3):440-5.

Blackwell DL, Collins JG, Coles R. Summary health statistics for U.S. adults: National Health Interview Survey, 1997. Vital Health Stat 10. 2002;(205):1-109.

Boase $S$ et al. The microbiome of chronic rhinosinusitis: culture, molecular diagnostics and biofilm detection. BMC Infect Dis. 2013;13(1):210.

Bonfils P, Avan P, Malinvaud D. Influence of allergy on the symptoms and treatment of nasal polyposis. Acta Otolaryngol. 2006;126(8):839-44.

Bonfils $\mathrm{P}$, Malinvaud D. Influence of allergy in patients with nasal polyposis after endoscopic sinus surgery. Acta Otolaryngol. 2008;128(2):186-92.

Bousquet J. Global initiative for asthma (GINA) and its objectives. Clinical and experimental allergy. Clin Exp Allergy. 2000;30(Suppl 1):2-5.

Bousquet $\mathrm{J}$, Van Cauwenberge $\mathrm{P}$, Khaltaev $\mathrm{N}$. Allergic rhinitis and its impact on asthma. J Allergy Clin Immunol. 2001;108(5 Suppl):S147-334.

Bousquet $\mathrm{J}$ et al. Unmet needs in severe chronic upper airway disease (SCUAD). J Allergy Clin Immunol. 2009;124(3):428-33.

Braun $\mathrm{H}$ et al. Eosinophilic Fungal Rhinosinusitis: A Common Disorder in Europe? Laryngoscope. 2003;113(2):264-9.

Brenner DJ, Hall EJ. Computed tomography--an increasing source of radiation exposure. N Engl J Med. 2007;357(22):2277-84.

Brenner DJ. Should we be concerned about the rapid increase in CT usage? Rev Environ Health. 2010;25(1):63-8.

Brescia $G$ et al. Can a panel of clinical, laboratory, and pathological variables pinpoint patients with sinonasal polyposis at higher risk of recurrence after surgery? Am J Otolaryngol. 2015;36(4):554-8.

Brescia $G$ et al. The prognostic role of serum eosinophil and basophil levels in sinonasal polyposis. Int Forum Allergy Rhinol. 2017;7(3):261-7. 
Bunnag $C$ et al. A study of allergic factor in nasal polyp patients. Ann Allergy. 1983;50(2):126-32.

Busaba NY, Sin HJ, Salman SD. Impact of gender on clinical presentation of chronic rhinosinusitis with and without polyposis. J Laryngol Otol. 2008;122(11):1180-4.

Calus $L$ et al. Local inflammation in chronic upper airway disease. Curr Pharm Des. 2012;18(16):2336-46.

Caplin I, Haynes JT, Spahn J. Are nasal polyps an allergic phenomenon? Ann Allergy. 1971;29(12):631-4.

Centers for Disease Control and Prevention (CDC). Current depression among adults---United States, 2006 and 2008. MMWR Morb Mortal Wkly Rep. 2010;59(38):1229-35.

Chambers DW et al. Long-term outcome analysis of functional endoscopic sinus surgery: correlation of symptoms with endoscopic examination findings and potential prognostic variables. Laryngoscope. 1997;107(4):504-10.

Chen $B$ et al. Reversal of chronic rhinosinusitis-associated sinonasal ciliary dysfunction. Am J Rhinol. 2007;21(3):346-53.

Chen Y, Dales R, Lin M. The epidemiology of chronic rhinosinusitis in Canadians. Laryngoscope. 2003;113(7):1199-205.

Chin D, Harvey RJ. Nasal polyposis: an inflammatory condition requiring effective anti-inflammatory treatment. Curr Opin Otolaryngol Head Neck Surg. 2013;21(1):2330.

Cho DY, Hwang PH. Results of endoscopic maxillary mega-antrostomy in recalcitrant maxillary sinusitis. Am J Rhinol. 2008;22(6):658-62.

Chu CT, Lebowitz RA, Jacobs JB. An analysis of sites of disease in revision endoscopic sinus surgery. Am J Rhinol. 1997;11(4):287-91.

Cimmino $\mathrm{M}$ et al. Clinical characteristics and genotype analysis of patients with cystic fibrosis and nasal polyposis. Clin Otolaryngol Allied Sci. 2003;28(2):125-32.

Cohen NA et al. Cigarette smoke condensate inhibits transepithelial chloride transport and ciliary beat frequency. Laryngoscope. 2009;119(11):2269-74.

Collins JG. Prevalence of selected chronic conditions: United States, 1990-1992. Vital Health Stat 10. 1997;(194):1-89.

Comhai, SA et al. Extracellular glutathione peroxidase induction in asthmatic lungs: evidence for redox regulation of expression in human airway epithelial cells. FASEB J. $2001 ; 15(1): 70-8$. 
Corriveau MN, Zhang N, Bachert C. The presence of Staphylococcus aureus is not equivalent to an immune reaction to it's enterotoxins. Allergy. 2009;64(6):959-60.

Couto LGF et al. Histological aspects of rhinosinusal polyps. Braz J Otorhinolaryngol. 2008;74(2):207-12.

Cutting GR. Modifier genetics: cystic fibrosis. Annu Rev Genomics Hum Genet. 2005;6(1):237-60.

Dahlén $\mathrm{B}$, Zetterström $\mathrm{O}$. Comparison of bronchial and per oral provocation with aspirin in aspirin-sensitive asthmatics. Eur Respir J. 1990;3(5):527-34.

Dall'Igna $\mathrm{C}$ et al. Fungal rhinosinusitis in patients with chronic sinusal disease Braz $\mathrm{J}$ Otorhinolaryngol. 2005;71(6):712-20.

Damm $\mathrm{M}$ et al. Impact of functional endoscopic sinus surgery on symptoms and quality of life in chronic rhinosinusitis. Laryngoscope. 2002;112(2):310-5.

Das $S$ et al. The effects of smoking on short-term quality of life outcomes in sinus surgery. Laryngoscope. 2007;117(12):2229-32.

Das $S$ et al. Effects of smoking on quality of life following sinus surgery: 4-year followup. Laryngoscope, 2009;119(11):2284-7.

Dautremont JF, Rudmik L. When are we operating for chronic rhinosinusitis? A systematic review of maximal medical therapy protocols prior to endoscopic sinus surgery. Int Forum Allergy Rhinol. 2015;5(12):1095-103.

Deal RT, Kountakis SE. Significance of nasal polyps in chronic rhinosinusitis: symptoms and surgical outcomes. Laryngoscope, 2004;114(11):1932-5.

DeConde AS et al. Investigation of change in cardinal symptoms of chronic rhinosinusitis after surgical or ongoing medical management. Int Forum Allergy Rhinol. 2015;5(1):36-45.

DeConde AS, Soler ZM. Chronic rhinosinusitis: Epidemiology and burden of disease. Am J Rhinol Allergy. 2016;30(2):134-9.

DeConde AS et al. Prevalence of polyp recurrence after endoscopic sinus surgery for chronic rhinosinusitis with nasal polyposis. Laryngoscope. 2017;127(3):550-5.

Dejima $\mathrm{K}$ et al. A clinical study of endoscopic sinus surgery for sinusitis in patients with bronchial asthma. Int Arch Allergy Immunol. 2005;138(2):97-104.

DeMarcantonio MA, Han JK. Nasal polyps: pathogenesis and treatment implications. Otolaryngol Clin North Am. 2011;44(3):685-95. 
Den Beste KA et al. Epithelial permeability alterations in an in vitro air-liquid interface model of allergic fungal rhinosinusitis. Int Forum Allergy Rhinol. 2013;3(1):19-25.

Dhong $\mathrm{HJ}$ et al. Effect of endoscopic sinus surgery on asthmatic patients with chronic rhinosinusitis. Otolaryngol Head Neck Surg. 2001;124(1):99-104.

Dinis PB, Gomes A. Sinusitis and asthma: how do they interrelate in sinus surgery? Am J Rhinol. 1997;11(6):421-8.

Drake VE, Rafaels N, Kim J. Peripheral blood eosinophilia correlates with hyperplastic nasal polyp growth. Int Forum Allergy Rhinol. 2016;6(9):926-34.

Drake-Lee $A B$ et al. Clinical profile and recurrence of nasal polyps. J Laryngol Otol. 1984;98(8):783-93.

Drake-Lee AB, McLoughlan P. The release of histamine from nasal polyp tissue and peripheral blood when challenged with antihuman $\lg \mathrm{E}$, house dust mite extract and mixed grass pollen extract and compared with positive skin tests. J Laryngol Otol. 1988;102(10):886-9.

Dubin MG et al. American Rhinologic Society member survey on "maximal medical therapy" for chronic rhinosinusitis. Am J Rhinol. 2007;21(4):483-8.

Durr DG, Desrosiers MY, Dassa C. Impact of rhinosinusitis in health care delivery: the Quebec experience. J Otolaryngol. 2001;30(2):93-7.

Ebbens FA et al. Predictors of post-operative response to treatment: a double blind placebo controlled study in chronic rhinosinusitis patients. Rhinology. $2011 ; 49(4): 413-9$.

Ehnhage A et al. Functional endoscopic sinus surgery improved asthma symptoms as well as PEFR and olfaction in patients with nasal polyposis. Allergy. 2009; 64(5):762-9.

Emanuel IA, Shah SB. Chronic rhinosinusitis: allergy and sinus computed tomography relationships. Otolaryngol Head Neck Surg. 2000;123(6):687-91.

English GM. Nasal polypectomy and sinus surgery in patients with asthma and aspirin idiosyncrasy. Laryngoscope. 1986;96(4):374-80.

Erbek SS et al. The role of allergy in the severity of nasal polyposis. Am J Rhinol. 2007;21(6):686-90.

Erskine $S$ et al. A cross sectional analysis of a case-control study about quality of life in CRS in the UK; a comparison between CRS subtypes. Rhinology. 2016;54(4):3115. 
Fandiño $M$ et al. The use of postoperative topical corticosteroids in chronic rhinosinusitis with nasal polyps: a systematic review and meta-analysis. Am J Rhinol Allergy. 2013;27(5):e146-57.

Ferguson BJ. Eosinophilic mucin rhinosinusitis: a distinct clinicopathological entity. Laryngoscope. 2000;110(5 Pt 1):799-813.

Figueiredo CR, Silva IDCG, Weckx LLM. Inflammatory genes in nasal polyposis. Curr Opin Otolaryngol Head Neck Surg. 2008;16(1):18-21.

Fischer AR et al. Direct evidence for a role of the mast cell in the nasal response to aspirin in aspirin-sensitive asthma. J Allergy Clin Immunol. 1994;94(6 Pt 1):1046-56.

Fleming-Dutra KE et al. Prevalence of inappropriate antibiotic prescriptions among us ambulatory care visits, 2010-2011. JAMA. 2016;315(17):1864-73.

Fokkens W et al. European position paper on rhinosinusitis and nasal polyps 2007. Rhinol Suppl. 2007;20:1-136.

Fokkens WJ, Lund V, Mullol J. European Position Paper on Rhinosinusitis and Nasal Polyps 2012. Rhinology. 2012;50(Suppl. 23):1-298.

Forer B et al. Aspirin desensitization for ASA triad patients--prospective study of the rhinologist`s perspective. Rhinology. 2011;49(1):95-9.

Furukido $\mathrm{K}$ et al. Cytokine profile in paranasal effusions in patients with chronic sinusitis using the YAMIK sinus catheter with and without betamethasone. Eur Arch Otorhinolaryngol. 2005;262(1):50-4.

Gaga $\mathrm{M}$ et al. Eosinophils are a feature of upper and lower airway pathology in nonatopic asthma, irrespective of the presence of rhinitis. Clin Exp Allergy. 2000;30(5):663-9.

Gelincik A et al. Allergic vs nonallergic rhinitis: which is more predisposing to chronic rhinosinusitis? Ann Allergy Asthma Immunol. 2008;101(1):18-22.

Georgalas $\mathrm{C}$ et al. Evidence-based surgery for chronic rhinosinusitis with and without nasal polyps. Curr Allergy Asthma Rep. 2014;14(4):427.

Gillett S et al. A pilot study of the SNOT 22 score in adults with no sinonasal disease. Clin Otolaryngol. 2009;34(5):467-9.

Gliklich RE, Metson R. The health impact of chronic sinusitis in patients seeking otolaryngologic care. Otolaryngol Head Neck Surg. 1995;113(1):104-9.

Goetzel RZ et al. The health and productivity cost burden of the "top 10" physical and mental health conditions affecting six large U.S. employers in 1999. J Occup Environ Med. 2003;45(1):5-14. 
Goldstein-Daruech $\mathrm{N}$ et al. Tobacco smoke mediated induction of sinonasal microbial biofilms. PloS one, 2011;6(1):e15700.

Gordts F, Clement PA, Buisseret T. Prevalence of sinusitis signs in a non-ENT population. ORL J Otorhinolaryngol Relat Spec. 1996;58(6):315-9.

Görgülü $O$ et al. Analysis of the roles of smoking and allergy in nasal polyposis. Ann Otol Rhinol Laryngol. 2012;121(9):615-9.

Gosepath J, Pogodsky T, Mann WJ. Characteristics of recurrent chronic rhinosinusitis after previous surgical therapy. Acta Otolaryngol. 2008;128(7):778-84.

Gungor AA. On chronic rhinosinusitis and the prevalence of fungal sinus disease: problems of diagnostic accuracy and a proposed classification of chronic rhinosinusitis. Am J Otolaryngol. 2012;33(5):543-8.

Gutman $M$ et al. Prevalence of allergy in patients with chronic rhinosinusitis. Otolaryngol Head Neck Surg. 2004;130(5):545-52.

Habib ARR, Javer AR, Buxton JA. A population-based study investigating chronic rhinosinusitis and the incidence of asthma. Laryngoscope, 2016;126(6):1296-302.

Håkansson $\mathrm{K}$ et al. Airway inflammation in chronic rhinosinusitis with nasal polyps and asthma: The united airways concept further supported. PLoS One. 2015;10(7):111.

Haruna $S$ et al. A study of poor responders for long-term, low-dose macrolide administration for chronic sinusitis. Rhinology, 2009;47(1):66-71.

Hastan D et al. Chronic rhinosinusitis in Europe--an underestimated disease. A GA2LEN study. Allergy, 2011;66(9):1216-23.

Hedman $\mathrm{J}$ et al. Prevalence of asthma, aspirin intolerance, nasal polyposis and chronic obstructive pulmonary disease in a population-based study. Int $\mathrm{J}$ Epidemiol. 1999;28(4):717-22.

Hermann I et al. Staphylococcus aureus hemolysin A disrupts cell-matrix adhesions in human airway epithelial cells. Am J Respir Cell Mol Biol. 2015;52(1):14-24.

Heymans $F$ et al. Screening for staphylococcal superantigen genes shows no correlation with the presence or the severity of chronic rhinosinusitis and nasal polyposis. PloS One. 2010;5(3):e9525.

Hoover GE et al. Chronic sinusitis: risk factors for extensive disease. J Allergy Clin Immunol. 1997;100(2):185-91. 
Hopkins $\mathrm{C}$ et al. Complications of surgery for nasal polyposis and chronic rhinosinusitis: the results of a national audit in England and Wales. Laryngoscope. 2006;116(8):1494-9.

Hopkins $\mathrm{C}$ et al. Long-term outcomes from the English national comparative audit of surgery for nasal polyposis and chronic rhinosinusitis. Laryngoscope. 2009;119(12):2459-65.

Hosemann W, Göde U, Wagner W. Epidemiology, pathophysiology of nasal polyposis, and spectrum of endonasal sinus surgery. Am $\mathrm{J}$ Otolaryngol. $1994 ; 15(2): 85-98$.

Houser SM, Keen KJ. The Role of Allergy and Smoking in Chronic Rhinosinusitis and Polyposis. Laryngoscope. 2008;118(9):1521-7.

Hull J, Thomson AH. Contribution of genetic factors other than CFTR to disease severity in cystic fibrosis. Thorax. 1998;53(12):1018-21.

Huvenne $W$ et al. Chronic rhinosinusitis with and without nasal polyps: what is the difference? Curr Allergy Asthma Rep. 2009;9(3):213-20.

Hwang $\mathrm{PH}$. Staph aureus has long been recognized as being more prevalent in cultures from patients with chronic rhinosinusitis(CRS) compared to those with acute rhinosinusitis. Int Forum Allergy Rhinol. 2013;3(2):81-2.

Ichimura $\mathrm{K}$ et al. Effect of new macrolide roxithromycin upon nasal polyps associated with chronic sinusitis. Auris Nasus Larynx. 1996;23:48-56.

Ikeda $\mathrm{K}$ et al. Subclassification of chronic rhinosinusitis with nasal polyp based on eosinophil and neutrophil. Laryngoscope, 2013;123(11):E1-9.

Jarvis $D$ et al. Asthma in adults and its association with chronic rhinosinusitis: the GA2LEN survey in Europe. Allergy. 2012;67(1):91-8.

Johansson $L$ et al. Prevalence of nasal polyps in adults: the Skövde populationbased study. Ann Otol Rhinol Laryngol. 2003;112(7):625-9.

Jorissen M, Bachert C. Effect of corticosteroids on wound healing after endoscopic sinus surgery. Rhinology. 2009;47(3):280-6.

Juan $\mathrm{F}$ et al. Risk Factors of Chronic Rhinosinusitis After Functional Endoscopic Sinus Surgery. Med Sci Monit. 2017;23:1064-8.

Kaliner M. Treatment of sinusitis in the next millennium. Allergy Asthma Proc. 1998;19(4):181-4.

Kalish $\mathrm{L}$ et al. Topical steroids for nasal polyps. Cochrane Database Syst Rev. 2012;12:CD006549. 
Katotomichelakis $\mathrm{M}$ et al. Allergic rhinitis and aspirin-exacerbated respiratory disease as predictors of the olfactory outcome after endoscopic sinus surgery. Am J Rhinol Allergy. 2009;23(3):348-53.

Katzenstein AL, Sale SR, Greenberger PA. Allergic Aspergillus sinusitis: a newly recognized form of sinusitis. J Allergy Clin Immunol. 1983;72(1):89-93.

Kennedy DW. Prognostic factors, outcomes and staging in ethmoid sinus surgery. Laryngoscope. 1992;102(12 Pt 2 Suppl 57):1-18.

Kern RC et al. Perspectives on the etiology of chronic rhinosinusitis: an immune barrier hypothesis. Am J Rhinol. 2008;22(6):549-59.

Kim CS et al. Effects of beta-toxin of Staphylococcus aureus on ciliary activity of nasal epithelial cells. Laryngoscope. 2000;110(12):2085-8.

Kim JE, Kountakis SE. The prevalence of Samter's triad in patients undergoing functional endoscopic sinus surgery. Ear Nose Throat J. 2007;86(7):396-9.

Kim RJT et al. The interaction between bacteria and mucosal immunity in chronic rhinosinusitis: A prospective cross-sectional analysis. Am J Rhinol Allergy. 2013;27(6):183-189.

Kim ST et al. Comparison between polymerase chain reaction and fungal culture for the detection of fungi in patients with chronic sinusitis and normal controls. Acta Otolaryngol. 2005;125(1):72-5.

Kim YS et al. Prevalence and risk factors of chronic rhinosinusitis in Korea. Am J Rhinol Allergy. 2011;25(3):117-21.

Kirtsreesakul V, Ruttanaphol S. The relationship between allergy and rhinosinusitis. Rhinology. 2008;46(3):204-8.

Klossek JM et al. Prevalence of nasal polyposis in France: a cross-sectional, casecontrol study. Allergy. 2005;60(2):233-7.

Kountakis SE, Bradley DT. Effect of asthma on sinus computed tomography grade and symptom scores in patients undergoing revision functional endoscopic sinus surgery. Am J Rhinol. 2003;17(4):215-9.

Kowalski ML et al. Hypersensitivity to nonsteroidal anti-inflammatory drugs (NSAIDs) - classification, diagnosis and management: review of the EAACI/ENDA(\#) and GA2LEN/HANNA*. Allergy. 2011;66(7):818-29.

Kowalski ML. Aspirin-sensitive rhinosinusitis and asthma. Clin Allergy Immunol. 2007;19:147-75. 
Krause HF. Allergy and chronic rhinosinusitis. Otolaryngol Head Neck Surg. 2003;128(1):14-6.

Krouse $\mathrm{JH}$ et al. Asthma and the unified airway. Otolaryngol Head Neck Surg. 2007;136(5 Suppl):S75-106.

Krzeski A et al. Influence of cigarette smoking on endoscopic sinus surgery long-term outcomes. Rhinology. 2011;49(5):577-82.

Lal D, Hwang $\mathrm{PH}$. Oral corticosteroid therapy in chronic rhinosinusitis without polyposis: a systematic review. Int Forum Allergy Rhinol. 2011;1(2):136-43.

Larsen K, Tos M. Clinical course of patients with primary nasal polyps. Acta Otolaryngol. 1994;114(5):556-9.

Larsen $\mathrm{K}$, Tos $\mathrm{M}$. The estimated incidence of symptomatic nasal polyps. Acta Otolaryngol. 2002;122(2):179-82.

Larsen PL, Tos M. Origin of nasal polyps. Laryngoscope. 1991;101(3):305-12.

Larsen PL, Tos M, Baer S. En bloc removal of the ethmoid and ostiomeatal complex in cadavers, with a practical application. Rhinology. 1994;32(2):62-4.

Larson DA, Han JK. Microbiology of sinusitis: does allergy or endoscopic sinus surgery affect the microbiologic flora? Curr Opin Otolaryngol Head Neck Surg. $2011 ; 19(3): 199-203$.

Lavigne $\mathrm{F}$ et al. Intrasinus administration of topical budesonide to allergic patients with chronic rhinosinusitis following surgery. Laryngoscope. 2002;112(5):858-64.

Lee JM, Chiu AG. Role of maximal endoscopic sinus surgery techniques in chronic rhinosinusitis. Otolaryngol Clin North Am. 2010;43(3):579-89.

Lee RU, Stevenson DD. Aspirin-exacerbated respiratory disease: evaluation and management. Allergy Asthma Immunol Res. 2011;3(1):3-10.

Leung RM et al. Osteomeatal complex obstruction is not associated with adjacent sinus disease in chronic rhinosinusitis with polyps. Am $J$ Rhinol Allergy. $2011 ; 25(6): 401-3$.

Li C et al. Gene expression signatures: a new approach to understanding the pathophysiology of chronic rhinosinusitis. Curr Allergy Asthma Rep. 2013;13(2):20917.

Lieu JE, Feinstein AR. Confirmations and surprises in the association of tobacco use with sinusitis. Arch Otolaryngol Head Neck Surg. 2000;126(8):940-6. 
Lim M, Citardi MJ, Leong JL. Topical antimicrobials in the management of chronic rhinosinusitis: a systematic review. Am J Rhinol. 2008;22(4):381-9.

Lin DC et al. Association between severity of asthma and degree of chronic rhinosinusitis. Am J Rhinol Allergy. 2011;25(4):205-8.

Litvack JR, Mace J, Smith TL. Role of depression in outcomes of endoscopic sinus surgery. Otolaryngol Head Neck Surg. 2011;144(3):446-51.

Liu CM, Shun CT, Hsu MM. Lymphocyte subsets and antigen-specific IgE antibody in nasal polyps. Ann Allergy. 1994;72(1):19-24.

Lund VJ, Kennedy DW. Quantification for staging sinusitis. The Staging and Therapy Group. Ann Otol Rhinol Laryngol Suppl. 1995;167:17-21.

Lund VJ et al. Efficacy and tolerability of budesonide aqueous nasal spray in chronic rhinosinusitis patients. Rhinology. 2004;42(2):57-62.

Lupa M, DelGaudio JM. Evidence-Based Practice. Otolaryngol Clin North Am. 2012;45(5):983-92.

Mace $\mathrm{J}$ et al. Effects of depression on quality of life improvement after endoscopic sinus surgery. Laryngoscope. 2008;118(3):528-34.

Malik Z et al. Staphylococcus aureus impairs the airway epithelial barrier in vitro. Int Forum Allergy Rhinol. 2015;5(6):551-6.

Marks SC, Shamsa F. Evaluation of prognostic factors in endoscopic sinus surgery. Am J Rhinol. 1997;11(3):187-91.

Marple BF et al. Diagnosis and management of chronic rhinosinusitis in adults. Postgrad Med. 2009;121(6):121-39.

Martino DJ, Prescott SL. Silent mysteries: epigenetic paradigms could hold the key to conquering the epidemic of allergy and immune disease. Allergy. 2010;65(1):7-15.

Matsuno $O$ et al. Asthma and sinusitis: association and implication. Int Arch Allergy Immunol. 2008;147(1):52-8.

Matsuwaki $Y$ et al. Chronic rhinosinusitis: risk factors for the recurrence of chronic rhinosinusitis based on 5-year follow-up after endoscopic sinus surgery. Int Arch Allergy Immunol. 2008;146(Suppl):77-81.

May $\mathrm{M}$ et al. Complications of endoscopic sinus surgery: analysis of 2108 patients-incidence and prevention. Laryngoscope. 1994;104(9):1080-3.

McDonald JR, Mathison DA, Stevenson DD. Aspirin intolerance in asthma. Detection by oral challenge. J Allergy Clin Immunol. 1972;50(4):198-207. 
McFadden EA et al. Surgical treatment of aspirin triad sinusitis. Am J Rhinol. 1997;11(4):263-70.

McMains KC, Kountakis SE. Revision functional endoscopic sinus surgery: objective and subjective surgical outcomes. Am J Rhinol. 2005;19(4):344-7.

Mehanna $\mathrm{H}$ et al. Benefit from endoscopic sinus surgery. Clin Otolaryngol Allied Sci. 2002;27(6):464-71.

Meltzer EO, Hamilos DL. Rhinosinusitis diagnosis and management for the clinician: a synopsis of recent consensus guidelines. Mayo Clin Proc. 2011;86(5):427-43.

Mendelsohn $\mathrm{D}$ et al. Revision rates after endoscopic sinus surgery: a recurrence analysis. Ann Otol Rhinol Laryngol. 2011;120(3):162-6.

Menezes AM et al. Prevalência de diagnóstico médico de asma em adultos brasileiros: Pesquisa Nacional de Saúde, 2013. Rev. Bras. Epidemiol. 2015;18(Supl. 2):204-13.

Min YG et al. Prevalence and risk factors of chronic sinusitis in Korea: results of a nationwide survey. Eur Arch Otorhinolaryngol. 1996;253(7):435-9.

Misso NLA, Thompson PJ. Oxidative stress and antioxidant deficiencies in asthma: potential modification by diet. Redox Rep. 2005;10(5):247-55.

Moloney JR. Nasal polyps, nasal polypectomy, asthma, and aspirin sensitivity. Their association in 445 cases of nasal polyps. J Laryngol Otol. 1977;91(10):837-46.

Mullol $\mathrm{J}$ et al. Comparative study of the effects of different glucocorticosteroids on eosinophil survival primed by cultured epithelial cell supernatants obtained from nasal mucosa and nasal polyps. Thorax. 1995a;50(3):270-4.

Mullol $\mathrm{J}$ et al. Cytokine gene expression and release from epithelial cells. A comparison study between healthy nasal mucosa and nasal polyps. Clin Exp Allergy. 1995b;25(7):607-15.

Mullol $\mathrm{J}$ et al. Eosinophil activation by epithelial cells of the respiratory mucosa. Comparative study of normal mucosa and inflammatory mucosa. Med Clin. 1997a;109(1):6-11.

Mullol $\mathrm{J}$ et al. Effects of topical anti-inflammatory drugs on eosinophil survival primed by epithelial cells. Additive effect of glucocorticoids and nedocromil sodium. Clin Exp Allergy. 1997b;27(12):1432-41.

Mullol $J$ et al. Inhibition of GM-CSF secretion by topical corticosteroids and nedocromil sodium. A comparison study using nasal polyp epithelial cells. Respir Med. 2000;94(5):428-31. 
Muñoz del Castillo $\mathrm{F}$ et al. Allergenic profile of nasal polyposis. J Investig Allergol Clin Immunol. 2009;19(2):110-6.

Murphy MP et al. Health care utilization and cost among adults with chronic rhinosinusitis enrolled in a health maintenance organization. Otolaryngol Head Neck Surg. 2002;127(5):367-76.

Murr AH, Goldberg AN, Vesper S. Fungal speciation using quantitative polymerase chain reaction (QPCR) in patients with and without chronic rhinosinusitis. Laryngoscope. 2006;116(8):1342-8.

Naidoo $Y$ et al. Long-term results after primary frontal sinus surgery. Int Forum Allergy Rhinol. 2012;2(3):185-90.

Nanayakkara JP et al. The impact of mental health on chronic rhinosinusitis symptom scores. Eur Arch Otorhinolaryngol. 2013;270(4):1361-4.

Nasser $S$ et al. Effect of endobronchial aspirin challenge on inflammatory cells in bronchial biopsy samples from aspirin-sensitive asthmatic subjects. Thorax. 1996;51(1):64-70.

Newman LJ et al. Chronic sinusitis. Relationship of computed tomographic findings to allergy, asthma, and eosinophilia. JAMA. 1994;271(5):363-7.

Nishioka GJ et al. Functional endoscopic sinus surgery in patients with chronic sinusitis and asthma. Otolaryngol Head Neck Surg. 1994;110(6):494-500.

Nizankowska-Mogilnicka E et al. EAACI/GA2LEN guideline: aspirin provocation tests for diagnosis of aspirin hypersensitivity. Allergy. 2007;62(10):1111-8.

Nomura $\mathrm{K}$ et al. Pseudomonas aeruginosa elastase causes transient disruption of tight junctions and downregulation of PAR-2 in human nasal epithelial cells. Respir Res. 2014;15(1):21.

Ooi EH et al. Innate immunity. Otolaryngol Clin North Am. 2010;43(3):473-87.

Orlandi RR et al. Immunologic response to fungus is not universally associated with rhinosinusitis. Otolaryngol Head Neck Surg. 2009;141(6):750-6.e1-2.

Orlandi RR et al. International Consensus Statement on Allergy and Rhinology: Rhinosinusitis. Int Forum Allergy Rhinol. 2016;6(Suppl 1):S22-S209.

Ottaviano $G$ et al. Endoglin (CD105) expression in sinonasal polyposis. Eur Arch Otorhinolaryngol. 2015;272(11):3367-73.

Otto BA, Wenzel SE. The role of cytokines in chronic rhinosinusitis with nasal polyps. Curr Opin Otolaryngol Head Neck Surg. 2008;16(3):270-4. 
$\mathrm{Ou} \mathrm{J}$ et al. Association of intracellular Staphylococcus aureus with prognosis in chronic rhinosinusitis. Int Forum Allergy Rhinol. 2016;6(8):792-9.

Pandak $\mathrm{N}$ et al. Bacterial colonization or infection in chronic sinusitis. Wien Klin Wochenschr. 2011;123(23-24):710-3.

Parikh A et al. Topical corticosteroids in chronic rhinosinusitis: a randomized, doubleblind, placebo-controlled trial using fluticasone propionate aqueous nasal spray. Rhinology.;39(2):75-9.

Patel VS et al. Equivalence in outcomes between Draf 2B vs Draf 3 frontal sinusotomy for refractory chronic frontal rhinosinusitis. Int Forum Allergy Rhinol. 2018;8(1):25-31.

Pawankar R. Nasal polyposis: an update: editorial review. Curr Opin Allergy Clin Immunol. 2003;3(1):1-6.

Pearlman AN et al. Relationships between severity of chronic rhinosinusitis and nasal polyposis, asthma, and atopy. Am J Rhinol Allergy. 2009;23(2):145-8.

Pepys J, Duveen GW. Negative skin tests in allergic rhinitis and nasal polyposis. Int Arch Allergy Appl Immunol. 1951;2(2):147-60.

Pezato $\mathrm{R}$ et al. Role of imbalance of eicosanoid pathways and staphylococcal superantigens in chronic rhinosinusitis. Allergy. 2012;67(11):1347-56.

Philpott $C$ et al. The burden of revision sinonasal surgery in the UK-data from the Chronic Rhinosinusitis Epidemiology Study (CRES): a cross-sectional study. BMJ Open. 2015;5(4):e006680.

Pilan RR et al. Prevalence of chronic rhinosinusitis in Sao Paulo. Rhinology. 2012;50(2):129-38.

Pleskow WW et al. Aspirin desensitization in aspirin-sensitive asthmatic patients: clinical manifestations and characterization of the refractory period. J Allergy Clin Immunol. 1982;69(1 Pt 1):11-9.

Poetker DM, Mendolia-Loffredo S, Smith TL. Outcomes of endoscopic sinus surgery for chronic rhinosinusitis associated with sinonasal polyposis. Am J Rhinol. 2007;21(1):84-8.

Poetker DM et al. Oral corticosteroids in the management of adult chronic rhinosinusitis with and without nasal polyps: an evidence-based review with recommendations. Int Forum Allergy Rhinol. 2013;3(2):104-20.

Ponikau JU et al. The diagnosis and incidence of allergic fungal sinusitis. Mayo Clin Proc. 1999;74(9):877-84. 
Ponikau JU et al. Features of airway remodeling and eosinophilic inflammation in chronic rhinosinusitis: is the histopathology similar to asthma? J Allergy Clin Immunol. 2003;112(5):877-82.

Proimos $\mathrm{E}$ et al. The effect of functional endoscopic sinus surgery on patients with asthma and CRS with nasal polyps. Rhinology. 2010;48(3):331-8.

Pumhirun $\mathrm{P}$, Limitlaohapanth $\mathrm{C}$, Wasuwat $\mathrm{P}$. Role of allergy in nasal polyps of Thai patients. Asian Pac J Allergy Immunol. 1999;17(1):13-5.

Ragab A, Clement P, Vincken W. Objective assessment of lower airway involvement in chronic rhinosinusitis. Am J Rhinol. 2004;18(1):15-21.

Ragab $S$ et al. Treatment of chronic rhinosinusitis and its effects on asthma. Eur Respir J. 2006;28(1):68-74.

Ragab SM, Hassanin MZ. Optimizing the surgical field in pediatric functional endoscopic sinus surgery: a new evidence-based approach. Otolaryngol Head Neck Surg. 2010;142(1):48-54.

Rajan JP et al. Prevalence of aspirin-exacerbated respiratory disease among asthmatic patients: A meta-analysis of the literature. $J$ Allergy Clin Immunol. 2015;135(3):676-681.e1.

Ramadan $\mathrm{HH}$. Surgical causes of failure in endoscopic sinus surgery. Laryngoscope. 1999;109(1):27-9.

Ray NF et al. Healthcare expenditures for sinusitis in 1996: contributions of asthma, rhinitis, and other airway disorders. J Allergy Clin Immunol. 1999;103(3 Pt 1):408-14.

Riechelmann $\mathrm{H}$ et al. Nasal allergen provocation with Dermatophagoides pteronyssinus in patients with chronic rhinitis referred to a rhinologic surgical center. Ann Allergy Asthma Immunol. 2002;88(6):624-31.

Robinson S, Douglas R, Wormald PJ. The relationship between atopy and chronic rhinosinusitis. Am J Rhinol. 2006;20(6):625-8.

Roca-Ferrer $\mathrm{J}$ et al. Effect of topical anti-inflammatory drugs on epithelial cell-induced eosinophil survival and GM-CSF secretion. Eur Respir J. 1997;10(7):1489-95.

Rogers GA et al. Epithelial tight junction alterations in nasal polyposis. Int Forum Allergy Rhinol. 2011;1(1):50-4.

Rosenfeld RM et al. Clinical practice guideline (Update): Adult sinusitis. Otolaryngol Head Neck Surg. 2015;152(Suppl 2):S1-S39. 
Rudmik L, Mace JC, Smith TL. Smoking and endoscopic sinus surgery: does smoking volume contribute to clinical outcome. Int Forum Allergy Rhinol. 2011;1(3):145-52.

Rudmik L et al. Early postoperative care following endoscopic sinus surgery: an evidence-based review with recommendations. Int Forum Allergy Rhinol. 2011;1(6):417-30.

Rudmik L et al. Impact of topical nasal steroid therapy on symptoms of nasal polyposis: a meta-analysis. Laryngoscope. 2012;122(7):1431-7.

Rudmik $L$ et al. Long-term utility outcomes in patients undergoing endoscopic sinus surgery. Laryngoscope. 2014;124(1):19-23.

Saleh AM et al. Prophylactic perioperative antibiotic use in endoscopic sinus surgery: a systematic review and meta-analysis. Otolaryngol Head Neck Surg. 2012;146(4):533-8.

Samter M, Beers RF. Intolerance to aspirin. Clinical studies and consideration of its pathogenesis. Ann Intern Med. 1968;68(5):975-83.

Savolainen S. Allergy in patients with acute maxillary sinusitis. Allergy. 1989;44(2):116-22.

Scadding GK, Lund VJ, Darby YC. The effect of long-term antibiotic therapy upon ciliary beat frequency in chronic rhinosinusitis. J Laryngol Otol. 1995;109(1):24-6.

Scadding $G$ et al. Diagnostic tools in Rhinology EAACl position paper. Clin Transl Allergy. 2011;1(1):2.

Schiller JS, Lucas JW, Peregoy JA. Summary health statistics for U.S. Adults: national health interview survey, 2011. Vital Health Stat 10. 2012;(256):1-218.

Senior BA et al. Long-term impact of functional endoscopic sinus surgery on asthma. Otolaryngol Head Neck Surg. 1999;121(1):66-8.

Settipane GA, Chafee FH. Nasal polyps in asthma and rhinitis. A review of 6,037 patients. J Allergy Clin Immunol. 1977;59(1):17-21.

Settipane GA. Epidemiology of nasal polyps. Allergy Asthma Proc. 1996;17(5):231-6.

Seybt MW, McMains KC, Kountakis SE. The prevalence and effect of asthma on adults with chronic rhinosinusitis. Ear Nose Throat J. 2007;86(7):409-11.

Shi JB et al. Epidemiology of chronic rhinosinusitis: results from a cross-sectional survey in seven Chinese cities. Allergy. 2015;70(5):533-9. 
Sil A, Mackay I, Rowe-Jones J. Assessment of predictive prognostic factors for functional endoscopic sinus surgery in a 5-year prospective outcome study. Am J Rhinol. 2007;21(3):289-96.

Singhal D et al. Staphylococcus aureus biofilms: Nemesis of endoscopic sinus surgery. Laryngoscope, 2011;121(7):1578-83.

Smith TL et al. Predictive factors and outcomes in endoscopic sinus surgery for chronic rhinosinusitis. Laryngoscope, 2005;115(12):2199-205.

Smith TL et al. Determinants of outcomes of sinus surgery: a multi-institutional prospective cohort study. Otolaryngol Head Neck Surg. 2010;142(1):55-63.

Snidvongs $\mathrm{K}$ et al. Sinus surgery and delivery method influence the effectiveness of topical corticosteroids for chronic rhinosinusitis: systematic review and meta-analysis. Am J Rhinol Allergy. 2013;27(3):221-33.

Soler ZM, Mace J, Smith TL. Symptom-based presentation of chronic rhinosinusitis and symptom-specific outcomes after endoscopic sinus surgery. Am J Rhinol. 2008;22(3):297-301.

Soyka MB et al. Defective epithelial barrier in chronic rhinosinusitis: the regulation of tight junctions by IFN-y and IL-4. J Allergy Clin Immunol. 2012;130(5):10871096.e10.

Spies JW et al. The role of aspirin desensitization in patients with aspirin-exacerbated respiratory disease (AERD). Braz J Otorhinolaryngol. 2016;82(3):263-8.

Staikūniene $\mathrm{J}$ et al. Association of chronic rhinosinusitis with nasal polyps and asthma: clinical and radiological features, allergy and inflammation markers. Medicina (Kaunas, Lithuania), 2008;44(4):257-65.

Stevenson DD et al. Aspirin desensitization treatment of aspirin-sensitive patients with rhinosinusitis-asthma: long-term outcomes. J Allergy Clin Immunol. 1996;98(4):751-8.

Stevenson DD. Approach to the patient with a history of adverse reactions to aspirin or NSAIDs: diagnosis and treatment. Allergy Asthma Proc. 2000;21(1):25-31.

Stevenson DD, Szczeklik A. Clinical and pathologic perspectives on aspirin sensitivity and asthma. J Allergy Clin Immunol. 2006;118(4):773-86; quiz 787-8.

Stevenson DD. Aspirin sensitivity and desensitization for asthma and sinusitis. Curr Allergy Asthma Rep. 2009;9(2):155-63.

Suzuki $\mathrm{H}$ et al. Effects of long-term low-dose macrolide administration on neutrophil recruitment and IL-8 in the nasal discharge of chronic sinusitis patients. Tohoku $\mathrm{J}$ Exp Med. 1997;182(2):115-24. 
Szczeklik A, Gryglewski RJ, Czerniawska-Mysik G. Relationship of inhibition of prostaglandin biosynthesis by analgesics to asthma attacks in aspirin-sensitive patients. Br Med J. 1975;1(5949):67-9.

Szczeklik A, Stevenson DD. Aspirin-induced asthma: advances in pathogenesis, diagnosis, and management. J Allergy Clin Immunol. 2003;111(5):913-21; quiz 922.

Tamashiro $\mathrm{E}$ et al. Implications of bacterial biofilms in chronic rhinosinusitis. Braz $\mathrm{J}$ Infect Dis. 2009;13(3):232-5.

Tan BK et al. Atopic profile of patients failing medical therapy for chronic rhinosinusitis. Int Forum Allergy Rhinol. 2011;1(2):88-94.

Tan BK et al. Incidence and associated premorbid diagnoses of patients with chronic rhinosinusitis. J Allergy Clin Immunol. 2013;131(5):1350-60.

Tan NC et al. Identifying intracellular Staphylococcus aureus in chronic rhinosinusitis: a direct comparison of techniques. Am J Rhinol Allergy. 2012a;26(6):444-9.

Tan NC et al. The multiplicity of Staphylococcus aureus in chronic rhinosinusitis: correlating surface biofilm and intracellular residence. Laryngoscope. 2012b;122(8):1655-60.

Tan NC et al. Intracellular Staphylococcus aureus: the Trojan horse of recalcitrant chronic rhinosinusitis? Int Forum Allergy Rhinol. 2013;3(4):261-6.

Tan NC et al. Small-colony variants and phenotype switching of intracellular Staphylococcus aureus in chronic rhinosinusitis. Allergy. 2014;69(10):1364-71.

ten Brinke $A$ et al. Chronic sinusitis in severe asthma is related to sputum eosinophilia. J Allergy Clin Immunol. 2002;109(4):621-6.

Thanasumpun T, Batra PS. Endoscopically-derived bacterial cultures in chronic rhinosinusitis: A systematic review. Am J Otolaryngol. 2015;36(5):686-91.

Tieu DD, Kern RC, Schleimer RP. Alterations in epithelial barrier function and host defense responses in chronic rhinosinusitis. J Allergy Clin Immunol. 2009;124(1):3742.

Tokunaga $T$ et al. Novel scoring system and algorithm for classifying chronic rhinosinusitis: the JESREC Study. Allergy. 2015;70(8):995-1003.

Tomassen P et al. Reliability of EP3OS symptom criteria and nasal endoscopy in the assessment of chronic rhinosinusitis--a GA² LEN study. Allergy. 2011b;66(4):556-61.

Tosun $\mathrm{F}$ et al. Relationship between postoperative recurrence rate and eosinophil density of nasal polyps. Ann Otol Rhinol Laryngol. 2010;119(7):455-9. 
Trinh NTN et al. Deleterious impact of Pseudomonas aeruginosa on cystic fibrosis transmembrane conductance regulator function and rescue in airway epithelial cells. Eur Respir J. 2015;45(6):1590-602.

Uri $\mathrm{N}$ et al. Functional endoscopic sinus surgery in the treatment of massive polyposis in asthmatic patients. J Laryngol Otol. 2002;116(3):185-9.

van Agthoven $\mathrm{M}$ et al. Cost analysis of regular and filgrastim treatment in patients with refractory chronic rhinosinusitis. Rhinology. 2002;40(2):69-74.

van Bruaene $\mathrm{N}$, Bachert $\mathrm{C}$. Tissue remodeling in chronic rhinosinusitis. Curr Opin Allergy Clin Immunol. 2011;11(1):8-11.

van Crombruggen $\mathrm{K}$ et al. Pathogenesis of chronic rhinosinusitis: inflammation. J Allergy Clin Immunol. 2011;128(4):728-32.

van Drunen $\mathrm{CM}$ et al. Inflammation in chronic rhinosinusitis and nasal polyposis. Immunol Allergy Clin North Am. 2009;29(4):621-9.

Van Zele $T$ et al. Differences in initial immunoprofiles between recurrent and nonrecurrent chronic rhinosinusitis with nasal polyps. Am $J$ Rhinol Allergy. 2014;28(3):192-8.

Vashishta $\mathrm{R}$ et al. A systematic review and meta-analysis of asthma outcomes following endoscopic sinus surgery for chronic rhinosinusitis. Int Forum Allergy Rhinol. 2013;3(10):788-94.

Velosoteles R, Cerejeira R. Endoscopic sinus surgery for Chronic rhinosinusitis with nasal polyps: Clinical outcome and predictive factors of recurrence. Am J Rhinol Allergy. 2017;31(1):56-62.

Vento SI et al. Nasal polyposis: clinical course during 20 years. Ann Allergy Asthma Immunol. 2000;85(3):209-14.

Vercelli D. Genetics, epigenetics, and the environment: switching, buffering, releasing. J Allergy Clin Immunol. 2004;113(3):381-6; quiz 387.

Vlaminck $S$ et al. The importance of local eosinophilia in the surgical outcome of chronic rhinosinusitis: A 3-year prospective observational study. Am J Rhinol Allergy. 2014;28(3):260-4.

Voegels RL et al. Nasal polyposis and allergy: is there a correlation? Am J Rhinol. $2001 ; 15(1): 9-14$.

Voegels RL, de Melo Pádua FG. Expression of interleukins in patients with nasal polyposis. Otolaryngol Head Neck Surg. 2005;132(4):613-9. 
Vuillermin PJ et al. Microbial exposure, interferon gamma gene demethylation in naïve T-cells, and the risk of allergic disease. Allergy. 2009;64(3):348-53.

Wallwork $B$ et al. A double-blind, randomized, placebo-controlled trial of macrolide in the treatment of chronic rhinosinusitis. Laryngoscope. 2006;116(2):189-93.

Ware JE, Sherbourne CD. The MOS 36-item short-form health survey (SF-36). I. Conceptual framework and item selection. Med Care. 1992;30(6):473-83.

Wei CC, Adappa ND, Cohen NA. Use of topical nasal therapies in the management of chronic rhinosinusitis. Laryngoscope. 2013;123(10):2347-59.

Wilson KF, McMains KC, Orlandi RR. The association between allergy and chronic rhinosinusitis with and without nasal polyps: an evidence-based review with recommendations. Int Forum Allergy Rhinol. 2014;4(2):93-103.

Winstead W, Barnett SN. Impact of endoscopic sinus surgery on global health perception: an outcomes study. Otolaryngol Head Neck Surg. 1998;119(5):486-91.

Wise SK et al. Interleukin-4 and interleukin-13 compromise the sinonasal epithelial barrier and perturb intercellular junction protein expression. Int Forum Allergy Rhinol. 2014;4(5):361-70.

Wood AJ et al. Intramucosal bacterial microcolonies exist in chronic rhinosinusitis without inducing a local immune response. Am J Rhinol Allergy. 2012;26(4):265-70.

Wu AW et al. Factors affecting time to revision sinus surgery for nasal polyps: a 25year experience. Laryngoscope. 2014;124(1):29-33.

Wynn R, Har-El G. Recurrence rates after endoscopic sinus surgery for massive sinus polyposis. Laryngoscope. 2004;114(5):811-3.

Xaubet $A$ et al. Effect of budesonide and nedocromil sodium on IL- 6 and IL-8 release from human nasal mucosa and polyp epithelial cells. Respir Med. 2001;95(5):408-14.

Xiao $\mathrm{C}$ et al. Defective epithelial barrier function in asthma. J Allergy Clin Immunol. 2011;128(3):549-56.e1-12.

Yamin $\mathrm{M}$ et al. Cigarette smoke combined with Toll-like receptor 3 signaling triggers exaggerated epithelial regulated upon activation, normal T-cell expressed and secreted/CCL5 expression in chronic rhinosinusitis. J Allergy Clin Immunol. 2008;122(6):1145-53.e3.

Young $\mathrm{J}$ et al. Long-term outcome analysis of endoscopic sinus surgery for chronic sinusitis. Am J Rhinol. 2007;21(6):743-7.

Younis RT, Ahmed J. Predicting revision sinus surgery in allergic fungal and eosinophilic mucin chronic rhinosinusitis. Laryngoscope. 2017;127(1):59-63. 
Zhang $Z$ et al. Asthma and biofilm-forming bacteria are independently associated with revision sinus surgeries for chronic rhinosinusitis. J Allergy Clin Immunol. 2011a;128(1):221-3.e1.

Zhang Z et al. Clinical factors associated with bacterial biofilm formation in chronic rhinosinusitis. Otolaryngol Head Neck Surg. 2011b;144(3), pp.457-62.

Zhang Z et al. Different clinical factors associated with Staphylococcus aureus and Pseudomonas aeruginosa in chronic rhinosinusitis. Int Forum Allergy Rhinol. 2015;5(8):724-33.

Zuckerman JD et al. Pathophysiology of nasal polyposis: the role of desmosomal junctions. Am J Rhinol. 2008;22(6):589-97. 


\section{COMPROVANTE DE APROVAÇÃO DO COMITÊ DE ÉTICA}

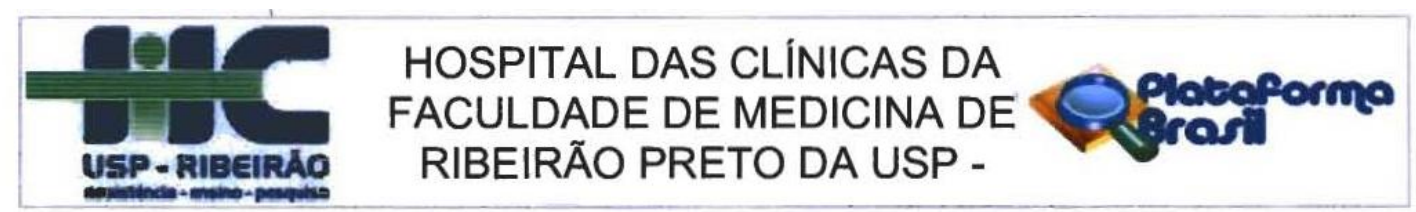

\section{PARECER CONSUBSTANCIADO DO CEP}

\section{DADOS DO PROJETO DE PESQUISA}

Título da Pesquisa: Estudo comparando o Prick Test ao sucesso no tratamento de Rinossinusite Crônica

Pesquisador: Guilherme Constante Preis Sella

Área Temática:

Versão: 1

CAAE: 13091313.7 .0000 .5440

Instituição Proponente: Hospital das Clínicas da Faculdade de Medicina de Ribeirão Preto da USP -

Patrocinador Principal: Financiamento Próprio

\section{DADOS DO PARECER}

Número do Parecer: 286.290

Data da Relatoria: $25 / 04 / 2013$

\section{Apresentação do Projeto:}

O projeto trata-se de um estudo a respeito do tema Rinossinusite Crônica, podendo estar associada ou não a Polipose Nasossinusal. Alguns fatores, como a asma, estão sabidamente associados com a doença, influenciando inclusive no prognóstico da mesma. No entanto, muito pouco se sabe sobre o real papel da atopia na evoluçăo da RSC. O documento apresența um breve resumo, justificativa, objetivo, metodologia, casuística (descrição dos dados a serem anotados do prontuário médico), análise critica dos riscos e beneficios, orçamento, cronograma e oito referência bibliográficas.

Objetivo da Pesquisa:

Objetivo principal é avaliar pacientes com RSC operados no Hospital das Clínicas de 2002 a 2010, e correlacionar a recidiva ou não da RSC com o resultado do Prick Test, por meio da análise de prontuário do paciente.

\section{Avaliação dos Riscos e Benefícios:}

O pesquisador responsável descreve que se tratando de pesquisa de prontuários, não há riscos para os pacientes. $O$ benefício não será direto ao paciente, mas aos pacientes hoje seguidos no nosso ambulatório, com melhores recomendações de tratamento no pós-operatório para serem

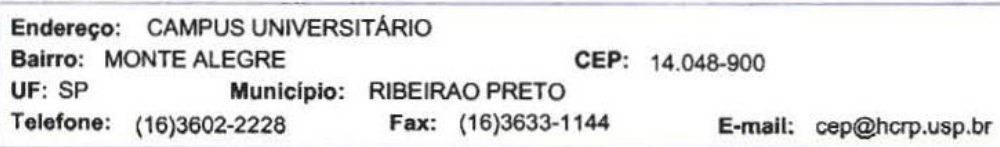




\section{HOSPITAL DAS CLINICAS DA
FACULDADE DE MEDICINA DE
RIBEIRÃO PRETO DA USP -}

Continuaçăo do Parecer: 286.290

submetidos cada vez a um menor número de procedimentos cirúrgicos.

\section{Comentários e Consideraçōes sobre a Pesquisa:}

Prever que o procedimentos assegurem a confiabilidade e a privacidade, a proteção da imagem e a nãoestigmatização dos participantes,garantindo a não utilização das informações, a serem analisados nos prontuários, em prejuízo das pessoas e lou comunidades.

Considerações sobre os Termos de apresentação obrigatória:

O projeto é retrospectivo e busca a analise de prontuários de pacientes submetidos à cirurgia há muitos anos atrás, muitos dos pacientes não acompanham mais neste hospital. Desta forma, solicitamos que o TCLE seja dispensado, em vista da dificuldade de se conseguir a autorização pelo paciente, podendo inviabilizar o projeto, e do fato de estarmos fazendo levantamento de dados restrospectivamente.

\section{Recomendações:}

Conclusões ou Pendências e Lista de Inadequações:

Diante do exposto e a luz da Resolução CNS 196/96 e suas complementares, o meu parecer é que o projeto de pesquisa deve ser enquadrado na categoria "APROVADO", bem como a dispensa do Termo de Consentimento Livre e Esclarecido.

\section{Situação do Parecer:}

Aprovado

Necessita Apreciação da CONEP:

Não

\section{Consideraçōes Finais a critério do CEP:}

Projeto Aprovado: Tendo em vista a legislação vigente, devem ser encaminhados ao CEP, relatórios parciais anuais referentes ao andamento da pesquisa e relatório final ao término do trabalho. Qualquer modificação do projeto original deve ser apresentada a este CEP em nova versão, de forma objetiva e com justificativas, para nova apreciação.

Endereço: CAMPUS UNIVERSITARIO

Bairro: MONTE ALEGRE CEP: $14.048-900$

UF: SP Município: RIBEIRAO PRETO

Telefone: (16)3602-2228 Fax: (16)3633-1144 E-mail: cep@hcrp.usp.br 